\title{
A Multiple-Objective Framework for Sustainable Forest Management under Uncertainty in the U.S. Central Hardwood Region
}

Wu Ma

Follow this and additional works at: https://researchrepository.wvu.edu/etd

\section{Recommended Citation}

$\mathrm{Ma}, \mathrm{Wu}$, "A Multiple-Objective Framework for Sustainable Forest Management under Uncertainty in the U.S. Central Hardwood Region" (2016). Graduate Theses, Dissertations, and Problem Reports. 6128. https://researchrepository.wvu.edu/etd/6128

This Dissertation is protected by copyright and/or related rights. It has been brought to you by the The Research Repository @ WVU with permission from the rights-holder(s). You are free to use this Dissertation in any way that is permitted by the copyright and related rights legislation that applies to your use. For other uses you must obtain permission from the rights-holder(s) directly, unless additional rights are indicated by a Creative Commons license in the record and/ or on the work itself. This Dissertation has been accepted for inclusion in WVU Graduate Theses, Dissertations, and Problem Reports collection by an authorized administrator of The Research Repository @ WVU.

For more information, please contact researchrepository@mail.wvu.edu. 


\title{
A Multiple-Objective Framework for Sustainable Forest Management under Uncertainty in the U.S. Central Hardwood Region
}

\author{
Wu Ma
}

\author{
Dissertation submitted \\ to the Davis College of Agriculture, Natural Resources and Design at \\ West Virginia University \\ in partial fulfillment of the requirements for the degree of \\ Doctor of Philosophy in \\ Forest Resources Science
}

Mo Zhou, Ph.D., Chair

Jonathan Cumming, Ph.D.

Jingxin Wang, Ph.D.

Alan Collins, Ph.D.

Jingjing Liang, Ph.D.

Division of Forestry and Natural Resources

\author{
Morgantown, West Virginia \\ 2016
}

Keywords: Climate change, Climate-sensitive matrix model, Monte Carlo simulations, Fire disturbance, Carbon dynamics, Soil carbon, Ecosystem process, Multi-stage optimization model, Adaptive measures.

Copyright 2016 Wu Ma 


\section{ABSTRACT}

\section{A Multiple-Objective Framework for Sustainable Forest Management under Uncertainty in the U.S. Central Hardwood Region}

\section{Wu Ma}

Despite the economic and ecological significance of oak-hickory forests in the Central Hardwood Region (CHR), major challenges are faced by both private and public landowners and policymakers due to the lack of reliable growth and yield models as well as the absence of useful tools for multi-criteria management. Moreover, the effects of climate change and fire disturbance on these forests and their management are largely unknown.

The second chapter of the dissertation is directed towards the study of the community and population structure of CHR forests under climate change and associated changes of fire regimes. The Central Hardwood Region of the United States constitutes one of the most diverse ecoregions in North America and the most extensive temperate deciduous forest in the world. Despite the economic and ecological significance of the CHR, the long term effects of changes in climate and fire regime on forest structures remain largely unknown. In this study, we developed an integrated climate sensitive matrix framework to synchronously couple (1) forest dynamics, (2) mean fire interval, (3) population density, and (4) future climate scenarios to study the community and population structure of CHR forests under climate change and associated changes of fire regimes. Using Monte Carlo simulations and coupled forest dynamics-disturbance models, we projected that the CHR would undergo a major shift in population structure from the present to year 2100 . The fundamental changes 
would consist of a transition of dominant species from oak and hickory to maple species, reduced species diversity $(9.6-11.5 \%)$, and substantial declines in stand basal area (55.1 $62.0 \%)$ and stand volume $(56.3-62.4 \%)$ compared to year 2010 . These projected changes may have profound ecological and economic implications. Ecologically, changes in tree species diversity favoring maples would alter ecosystem processing of nutrients and subsequent nutrient flows to drainage waters within the region. Habitat change would alter the broad spectrum of organisms relying on the forest, leading to a redistribution of wildlife species, further heightening the risks for endangered species. Economically, the total stumpage value throughout the CHR would be reduced by $54.5-59.8 \%$ from approximately $\$ 1,317$ billion to $\$ 529-599$ billion. On the brink of these fundamental shifts, our study calls for ecologically and economically informed conservation and mitigation strategies to better prepare society for the associated changes in ecosystem services and economic benefits derivable from the CHR forests.

The third chapter further addresses assessments of management impacts on central hardwood forests under climate and fire uncertainty. Central hardwood forests, in the absence of management, are predicted to undergo a species shift and decline in stocks due to climate change and increased fire frequencies. Here I quantified how various management intensities would influence these forests in terms of the net present value (NPV) of harvests, tree species and size diversity, and carbon stocks in four pools: above-ground biomass, fine roots, dead organic matters, and soil. Predictions were based on simulations of forest growth under uncertain fire and subject to low (20\%), medium (50\%), and high (80\%) management intensities in four IPCC future climate scenarios RCP2.6, 4.5, 6.0 and 8.5 from 2010 to 2100. 
Partial, diameter-limit, and diameter-cap harvesting practices were assessed with harvesting cycles of 10 and 20 years, respectively. The major findings are: low intensity (20\%) management would cause the highest carbon stock and size diversity, but the lowest NPV and species diversity; medium intensity (50\%) management would lead to a lower carbon stock but produce satisfactory levels of species diversity, size diversity, and NPV; high intensity $(80 \%)$ management would result in the lowest carbon stock and size diversity but the highest NPV and species diversity. The NPV of harvests with a 10-year harvesting cycle was more than twice of that with 20 years, yet the total carbon stock was only $1.3 \%-5.0 \%$ lower. An uncertainty analysis with fuzzy sets shows that when considering uncertain climate and fire, the NPV, size diversity, and total carbon stock would be distinctively different in climate scenarios RCP2.6 and RCP8.5 with high certainty. However, for species diversity, similar climatic effects on species diversity may exist across most management regimes.

The fourth chapter focused on modeling multi-stage scenario-based optimization under uncertainty in climate-induced fire disturbance. I developed multi-stage scenario-based optimization models for managing central hardwood forests under uncertainty in climate change and associated fire regimes. Based on a climate-sensitive matrix growth model and a mean fire interval model, four future climate scenarios and attendant fire intervals combined with two fire severity regimes were transformed into 36 and 20 tree growth scenarios for harvesting cycles of 10 and 20 years, respectively. Three alternatives of optimization formulations were proposed: 1) optimize for the maximum objective value under each individual scenario independently; 2) based on results from (1), find the compromise management plan that's feasible for all scenarios while minimizing the weighted sum of 
deviations between the realized and maximum objective values; and 3) derive the optimal management plan over the entire scenario tree. Four objectives were considered: the net present value (NPV) of harvests, total carbon stock, tree species diversity, and tree size diversity. Finally I determined the trade-off between economic and ecological benefits by quantifying the opportunity cost of increasing ecological benefits in terms of NPV. Without considering any constraints for the optimization approach, the maximum NPV varied from $\$ 30,396$ to $\$ 35,378 \mathrm{ha}^{-1}$ for 36 scenarios with harvesting every 10 years, and $\$ 17,838$ to $\$ 18,992 \mathrm{ha}^{-1}(53.7 \%-58.7 \%$ of 10 years $)$ for 20 scenarios with doubled harvesting cycle. The optimization approach produced $9.7 \%-22.4 \%$ (10 years) and $29.7 \%-38.1 \%$ (20 years) more NPV than the deterministic approach. Among the values of the same criterion derived with all three methods, as expected, the one from optimizing the individual scenario was the highest. With harvesting cycles of 10 and 20 years, the feasible NPV declined \$123-\$944 $\mathrm{ha}^{-1}, \$ 435-\$ 1,270 \mathrm{ha}^{-1}, \$ 376-\$ 2,011 \mathrm{ha}^{-1}$, and \$ $73-\$ 483 \mathrm{ha}^{-1}, \$ 229-\$ 646 \mathrm{ha}^{-1}, \$ 204$ $-\$ 1,022 \mathrm{ha}^{-1}$ when each unit of species diversity, size diversity, and carbon weights increased from 1 to 10 , respectively, while the other criterions were held fixed. 


\section{Acknowledgements}

I would first like to express the deepest appreciation to my advisor, Dr. Mo Zhou, for the continuous support of my Ph.D. study and research, for her patience, motivation, excellent guidance, enthusiasm, immense knowledge, tolerance. Without her guidance and persistent help this dissertation would not have been possible. I could not have imagined having a better advisor and mentor for my Ph.D. study.

I would like to thank my co-advisor Dr. Jingjing Liang, who opened me the gate to Ph.D. study and provided me valuable suggestions to pursue the $\mathrm{PhD}$ degree in the United States. I would like to thank the rest of my dissertation committee members: Dr. Jonathan Cumming, Dr. Jingxin Wang, and Dr. Alan Collins, for their encouragement, insightful comments, and hard questions.

I would like to thank my funding support from the Davis College of Agriculture, Natural Resources \& Design, West Virginia University, under the US Department of Agriculture (USDA) McIntire-Stennis Funds WVA00105.

I would like to thank my friends, James Watson, Zhen Yu, Weiguo Liu, Xinfeng Xie, Changle Jiang, Yuxi Wang, Nan Nan, Zane Mikesell for all the fun we have had together and the stimulating discussions. In particular, I am grateful to Master advisor Dr. Xiangdong Lei for enlightening me the first glance of research.

Last but not the least, I would like to thank my family: my parents Guoxin Ma and Qingzhi Huang, my wife Jiaojiao Chen and my daughter Catherine Ma. They were always supporting me and encouraging me with their best wishes. 


\section{Table of Contents}

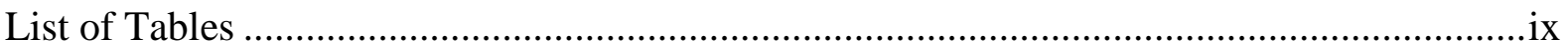

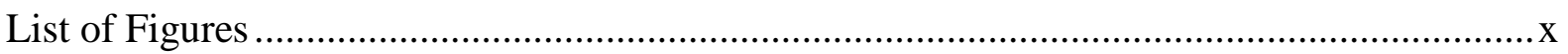

1. Introduction

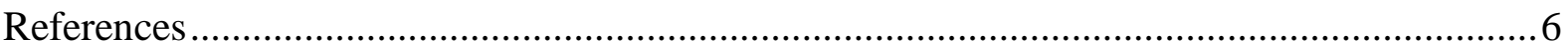

2. Fundamental shifts of central hardwood forests under climate change ..............................

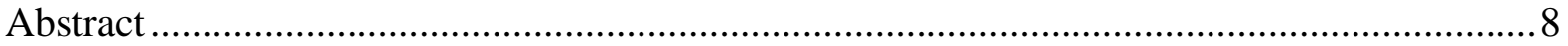

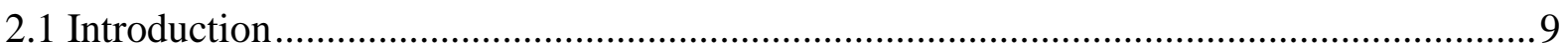

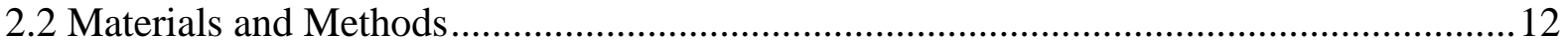

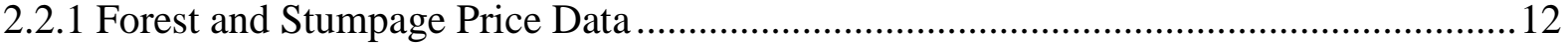

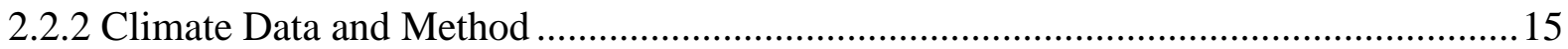

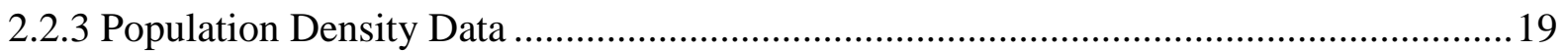

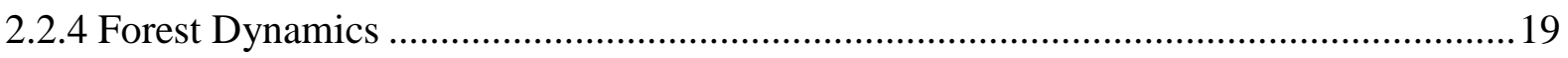

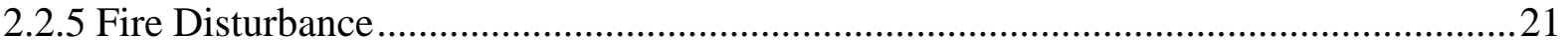

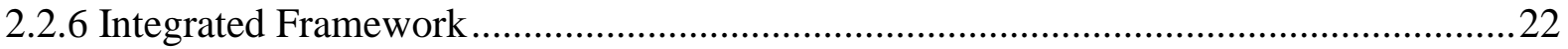




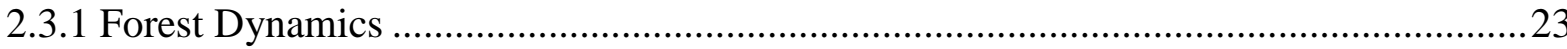

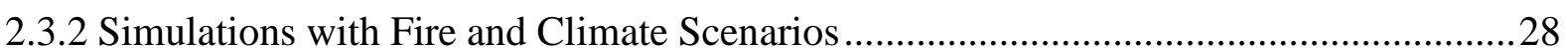

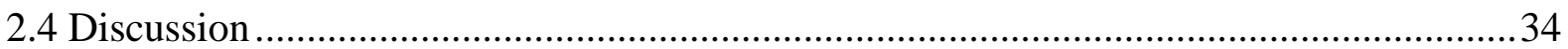

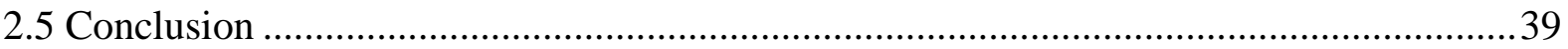

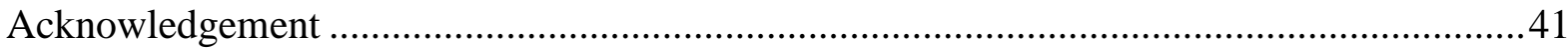

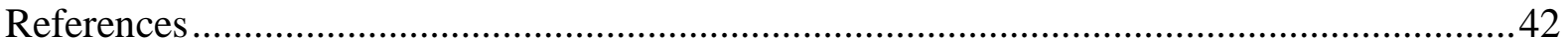

3. Assessments of management impacts on central hardwood forests under climate and fire

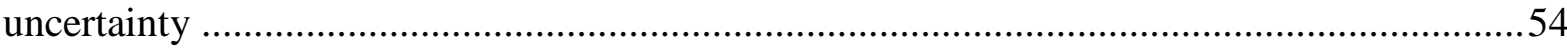

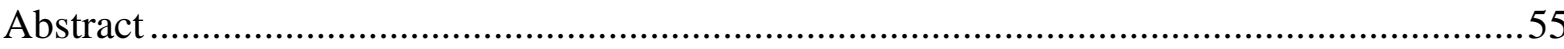

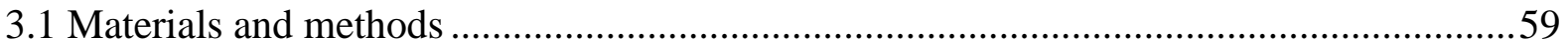

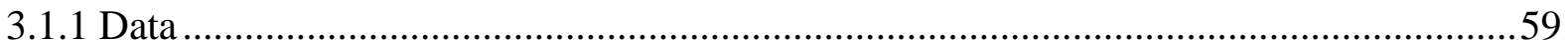

3.1.2 Predicting Forest Dynamics under Climate Change .................................................. 61

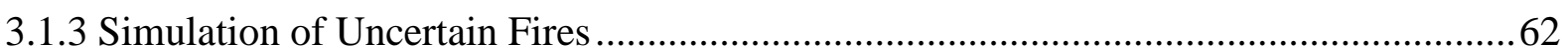

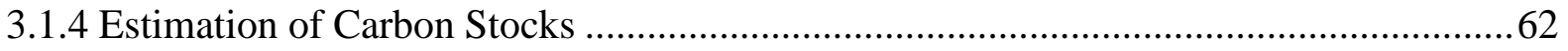

3.1.5 Evaluation of Forest Management of Various Intensities...........................................63

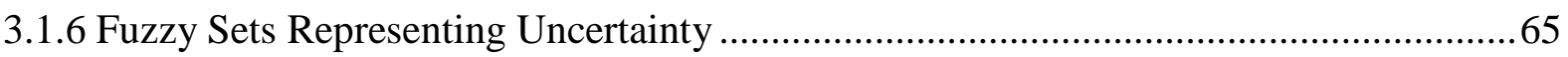

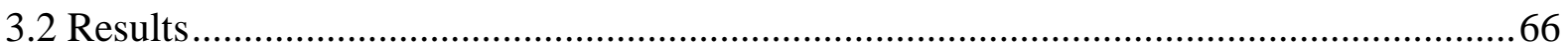

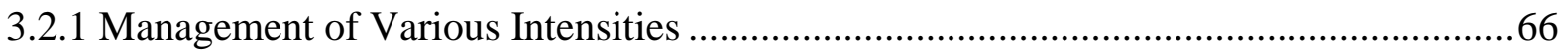

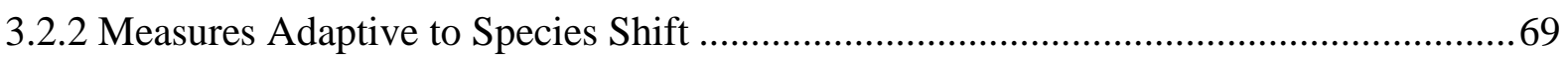

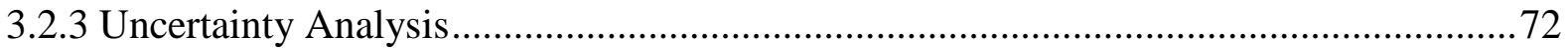

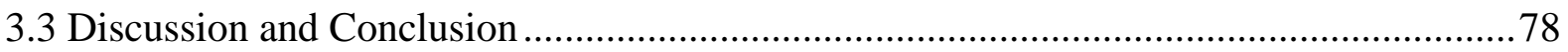

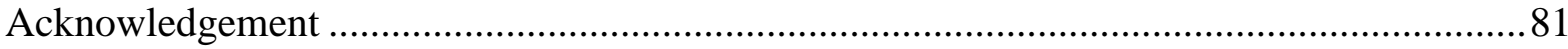

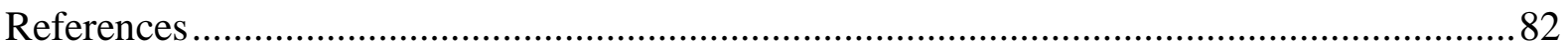

4. Multi-criteria management of central hardwood forest under climate and fire uncertainty with scenario-based models

Abstract 


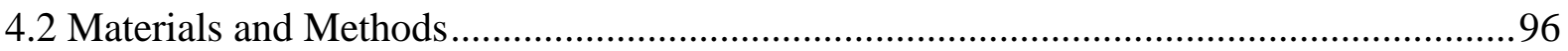

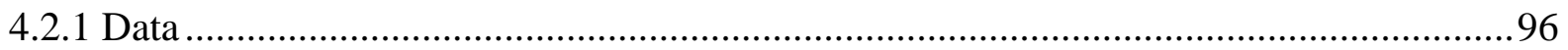

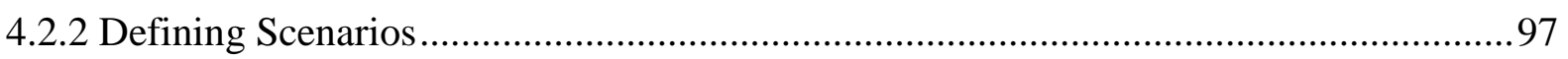

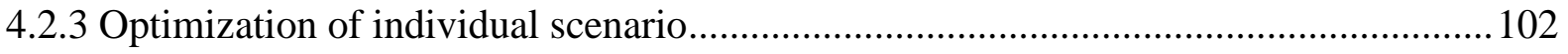

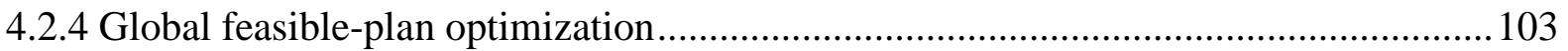

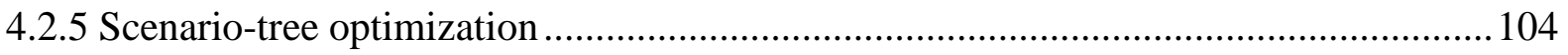

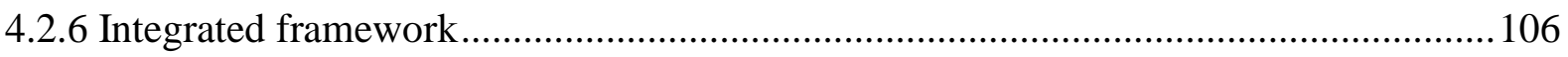

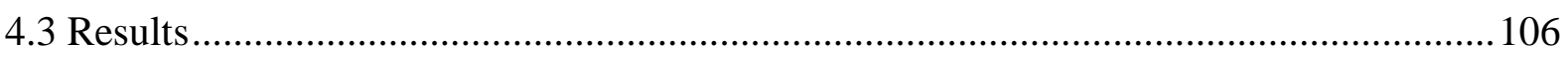

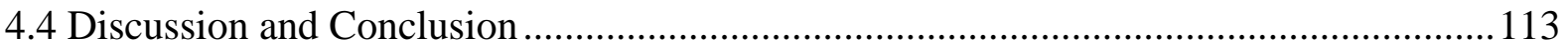

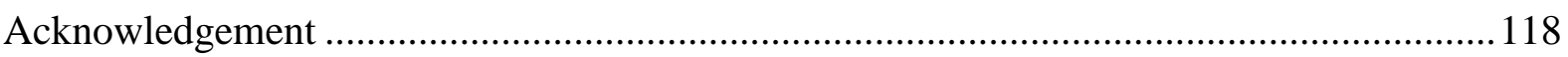

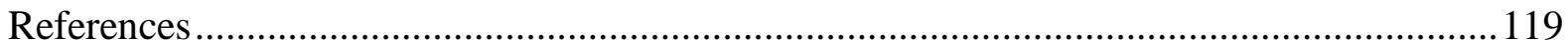

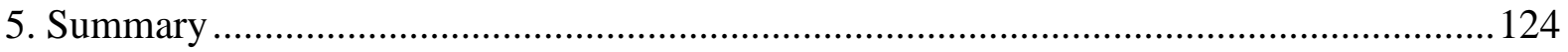

Appendix A. Supplemental Information for Chapter 2 .................................................. 127

Appendix B. Supplemental Information for Chapter 3 ........................................................ 148 


\section{List of Tables}

Table 2-1 Definitions and units of variables used in the CSMatrix model for CHR forests... 15

Table 2-2 Estimated parameters of the CSMatrix model for CHR forests. .25

Table 2-3 Total average volume $\left(\mathrm{m}^{3} \mathrm{ha}^{-1}\right)$ for climate scenarios RCP2.6, RCP4.5, RCP6.0, RCP8.5 from year 2010-2100.

Table 3-1 Adjusted real average stumpage prices $\left(\$ \mathrm{~m}^{-3}\right)$ (base year=2015) for three commercial sizes and seven species groups

Table 4-1 Adjusted real average stumpage prices $\left(\$ \mathrm{~m}^{-3}\right)$ (base year=2015) for three commercial sizes and four commercial species groups.

Table 4-2 The maximum, feasible and adaptive maximum average net present values (NPV) $\left(\$ \mathrm{ha}^{-1}\right)$, average species diversity (Hs), average size diversity (Hd), and average total carbon stocks (ton ha ${ }^{-1}$ ) in 2100 in each scenario, with harvesting cycle of 10 years, respectively.. 108 Table 4-3 The maximum, feasible and adaptive maximum average net present values (NPV) $\left(\$ h^{-1}\right)$, average species diversity (Hs), average size diversity (Hd), and average total carbon stocks (ton ha ${ }^{-1}$ ) in 2100 in each scenario, with harvesting cycle of 20 years, respectively.. 109 


\section{List of Figures}

Figure 1-1 Integrated sustainable management framework .5

Figure 2-1 Geographic distribution of the calibration (dots) and validation (+) plots, in the Central Hardwood Region (CHR). Inset shows the relative location of CHR in the contiguous United States. The box indicates the CHR region where the future relative changes of temperature and precipitation (trend ratio) were extracted for four future climate scenarios. 13 Figure 2-2 Temporal changes of mean annual temperature $\left({ }^{\circ} \mathrm{C}\right)$, annual average of monthly mean precipitation $\left(100 \mathrm{~mm} \mathrm{month}^{-1}\right)$ and mean fire interval (year) across the 1107 sample plots estimated under four climate scenarios of RCP2.6, RCP4.5, RCP6.0, and RCP8.5, and the climate constant at year 2010 .

Figure 2-3 Conceptual diagram showing how the CSMatrix framework integrated forest dynamics, climate data, and the Mean Fire Interval Model to project the population dynamics of CHR forests under future climate change scenarios. .23

Figure 2-4 Average predicted and observed stand states at the second inventory for the conventional matrix model (CON), climate-sensitive matrix model (CS), and LANDIS PRO 7.0 on the 1107 post-sample validation plots, with the $95 \%$ confidence interval of the observed mean.

Figure 2-5 Stand basal area under wildfire disturbance under four climate scenarios RCP2.6, RCP4.5, RCP6.0, and RCP8.5 from year 2010-2100.

Figure 2-6 Species composition in terms of basal area in year 2010 (a) and year 2100 under wildfire disturbance with four climate scenarios RCP2.6, RCP4.5, RCP6.0, and RCP8.5 (b). Vertical bars represent one standard error of the average predicted values from Monte Carlo simulations. The pie charts to the right show the corresponding percentage of basal area by species and climate scenario.

Figure 2-7 Tree species (a-d) and size diversity (e-h) under wildfire disturbance with 4 climate scenarios RCP2.6, RCP4.5, RCP6.0, and RCP8.5 from year 2010-2100.

Figure 3-1 Percentages of above-ground biomass in seven species groups under management regimes Adaptive1 and Adaptive2, and with harvesting cycles of 10 and 20 years, respectively. QQ: Quercus-Quercus (white oak species), QL: Quercus-Lobatae (red oak 
species), JD: Juglandaceae (hickory), SD: Sapindaceae (maple family), GS: Gymnosperms (softwoods), FG: Fagus (American beech), OA: Other Angiosperms (other species).

Figure 4-1 Scenario tree of with harvesting cycle of 10 years under 4 climate scenarios and 2 fire severity levels. C1: RCP2.6; C2: RCP4.5; C3: RCP6.0; C4: RCP8.5; S1: Fire severity 1, S2: Fire severity 2; t: Harvesting stage; A: Scenario. 100 Figure 4-2 Scenario tree of with harvesting cycle of 20 years under 4 climate scenarios and 2 fire severity levels. C1: RCP2.6; C2: RCP4.5; C3: RCP6.0; C4: RCP8.5; S1: Fire severity 1, S2: Fire severity 2; t: Harvesting stage; B: Scenario. 102 Figure 4-3 The integrated multi-stage scenario-based optimization framework. 106 Figure 4-4 Changes of feasible net present value (NPV) over altering the weights of carbon when other criterions fixed under global feasible-plan optimization. 
1. Introduction 
The Central Hardwood Region (CHR) of the United States, covered by approximately 58 million ha of forests stretching from the upper Southeast to Indiana and from Oklahoma to Pennsylvania, constitutes the most extensive temperate deciduous forest in the world (Box \& Fujiwara, 2015). This region is well known for its variety of oak-hickory forest resources that provide significant economic and ecological benefits to local, regional, and national communities. It is home to a wide array of flora and fauna species (Schmidt \& McWilliams, 2003) and is one of the most diverse ecoregions in North America (Mueller, 1996). Ninety percent of hardwoods in the continental United States is located in the CHR, accounting for one third of the total forest growing stock (Hicks, 1998). The high quality hardwood timber resources play a vital role in regional employment by wood related industries. The CHR forms the headwaters for many major U.S. rivers and plays critical roles in improving and protecting soil and water resources as well as in mitigating flooding (Bernhardt \& Palmer, 2011).

In the CHR, the ownership distribution has remained relatively static over time (Schmidt $\&$ McWilliams, 2003), with more than 80 percent of the timberland area in private ownership, including nonindustrial private (over $80 \%$ ) and industrial private, and the rest publicly held by Federal, State and local governments (Hicks, 1998). While timber production is still one primary management goal, especially for private landowners, and is expected to remain so in future, the provisioning of nontimber ecosystem services has been likewise deemed as a critical component of sustainable forestry for both private and public ownerships. Among those services, carbon sequestration is of particular importance in a world undergoing global climate change.

Major challenges are faced by both private and public landowners and natural resources policy makers in the region. First of all, reliable models predicting structured forest populations are lacking for the CHR forests. Secondly, forest composition and dynamics in this region have 
been shaped historically by natural disturbances especially by stand-replacing fires, so they must be accounted for in future management. In addition, climate change is expected to alter both forest growth and disturbance regimes in this region. Thus a quantitative framework of sustainable forest management is much needed. It must be based on a dependable growth and yield model and take into account uncertainty of climate change and natural disturbances. The framework requires the capacity of evaluating the consequences of various management practices under climate change. To further assist in decision making, it is essential to address multiple economic and ecological benefits that CHR forests provide and derive their trade-offs. Of particular interest is it to estimate the opportunity cost of conservation, for example, for carbon sequestration, in terms of foregone timber income, which will likely facilitate the making of conservation and climate change policies.

This study aims at building a multiple-objective framework for sustainable management under uncertainty in the U.S. Central Hardwood Region. The specific objectives of this proposed study are:

(1) to develop an empirical model of forest growth and yield that predicts the dynamics and composition of CHR forests with climatic variables;

(2) to estimate future fire regimes under climate change with a mean fire interval model and future human population density;

(3) to integrate the models from objectives (1) and (2) and use Monte Carlo simulations in an effort to project future forest states under four future climate scenarios: RCP2.6, RCP4.5, RCP6.0, and RCP8.5 and associated fire regime changes;

(4) to quantify the influences of forest management of various intensities and explorative adaptive measures on forest states and carbon in four pools: above-ground biomass, soil, 
fine roots, and dead organic matters, based on the aforementioned integrated models and a soil carbon model (Yasso07);

(5) to evaluate economic and ecological performance of these management practices in terms of the net present value of harvests, structural and species diversity, and other appropriate ecological metrics;

(6) to develop a stochastic multi-stage optimization model of multiple objectives that accounts for uncertainty in climate change and fire disturbance and derive optimal decision guidelines for different ownership types;

(7) to determine the trade-off between various objectives, especially between economic and ecological benefits, with the stochastic optimization model. 


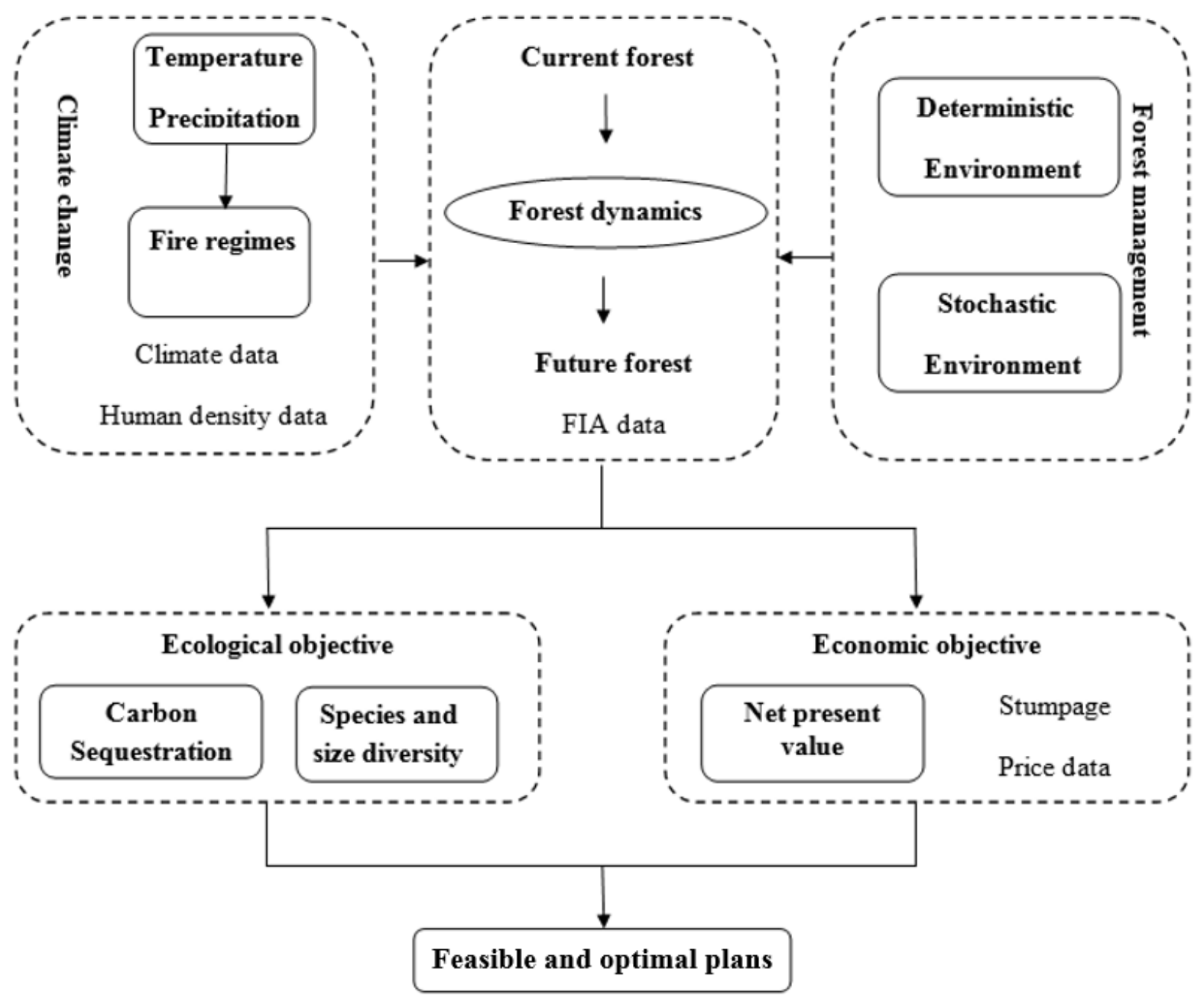

Figure 1-1 Integrated sustainable management framework

Figure 1-1 illustrates the conceptual multiple-objective framework for sustainable forest management under uncertainty. In this framework, I will couple (1) the model of forest dynamics, (2) mean fire interval model, (3) human population density model, (4) future climate scenarios, (5) soil carbon model (YASSO07), (6) forest management regimes, and (7) multi-stage scenariobased optimization model. 


\section{References}

Box EO, Fujiwara K (2015) Warm-Temperate Deciduous Forests around the Northern Hemisphere, Springer.

Bernhardt ES, Palmer MA (2011) The environmental costs of mountaintop mining valley fill operations for aquatic ecosystems of the Central Appalachians. Annals of the New York Academy of Sciences, 1223, 39-57.

Hicks RR (1998) Ecology and management of central hardwood forests, John Wiley and Sons.

Mueller RF (1996) Biodiversity: central Appalachian plant distributions and forest types. Wild Earth, 6, 37-43.

Schmidt TL, Mcwilliams WH (2003) Shifts and future trends in the forest resources of the central hardwood region. North Central Research Station, Forest Service, U.S. Department of Agriculture. 


\section{Fundamental shifts of central hardwood forests under climate change*}

\footnotetext{
* This chapter was published in Ecological Modelling. (Ma, W., Liang, J., Cumming, J. R., Lee, E., Welsh, A. B., Watson, J. V., \& Zhou, M. (2016). Fundamental shifts of central hardwood forests under climate change. Ecological Modelling, 332, 28-41.)
} 


\section{Abstract}

The Central Hardwood Region (CHR) of the United States constitutes one of the most diverse ecoregions in North America and the most extensive temperate deciduous forest in the world. Despite the economic and ecological significance of the CHR, the long-term effects of changes in climate and fire regime on forest structure remain largely unknown. In this study, we developed an integrated climate-sensitive matrix framework to synchronously couple (1) forest dynamics, (2) mean fire interval, (3) population density, and (4) future climate scenarios to study the community and population structure of CHR forests under climate change and associated changes of fire regimes. Using Monte Carlo simulations and coupled forest dynamicsdisturbance models, we projected that the CHR would undergo a major shift in forest community structure from the present to year 2100. The fundamental changes would consist of a transition of dominant species from oak and hickory to maple species, reduced species diversity $(9.6 \%-$ $11.5 \%)$, and substantial declines in stand basal area $(55.1 \%-62.0 \%)$ and stand volume $(56.3 \%-$ 62.4\%). These projected changes will have profound ecological and economic implications. Ecologically, changes in tree species diversity favoring maples would alter ecosystem processing of nutrients and subsequent nutrient flows to drainage waters within the region. Habitat change would alter the broad spectrum of organisms relying on the forest, leading to a redistribution of wildlife species, further heightening the risks for endangered species. Economically, the total stumpage value throughout the CHR would be reduced by $54.5 \%-59.8 \%$ from approximately $\$$ 1,317 billion to $\$ 529-599$ billion. On the brink of these fundamental shifts, our study calls for ecologically- and economically-informed conservation and mitigation strategies to better prepare society for the associated changes in ecosystem services and economic benefits derived from CHR forests. 


\subsection{Introduction}

A growing body of evidence suggests that global climate change will have significant impacts on forest ecosystems by affecting the distribution and variation of key environmental factors, such as $\mathrm{CO}_{2}$, humidity, and incoming solar radiation (e.g., Aber et al., 2001, Allen et al., 2010, Boisvenue \& Running, 2006, Latta et al., 2010, Lindner et al., 2010, Schoene \& Bernier, 2012) . These changes will affect species composition and the productivity of forest ecosystems in this region (Aber et al., 2001, Boisvenue \& Running, 2006, Latta et al., 2010, Shugart et al., 2003, Smith et al., 1995) as well as forest ecosystem processes through alterations in resource acquisition and resource utilization efficiency (Hansen \& Dale, 2001, Hansen et al., 2001, Helmick et al., 2014, Juday et al., 2005). Precipitation and temperature, and their seasonality and extremes, may change species' ranges, inter-species relationships, fire frequency, and other ecosystem processes in the CHR that will have broad ecological and economic implications across the region and beyond (Alexander \& Arthur, 2010, Lafon et al., 2005, Parisen \& Moritz, 2009). In addition, recent theoretical advances and empirical evidence (Cardinale et al., 2012, Liang et al., 2015, Naeem et al., 2012, Tilman et al., 1997) have revealed substantial impact of the loss of biodiversity on the functioning of ecosystems. The impact of climate change and biodiversity loss on CHR forests, however, has yet to be quantified.

Natural disturbances are a major factor affecting forest dynamics and composition (Fischer et al., 2013), and influence the development of effective ecosystem restoration and management practices (Foster, 2000, Zhou \& Buongiorno, 2006). Throughout the CHR, forest dynamics have been driven historically by high intensity stand-replacing fires necessary for the successful regeneration of shade intolerant species (Albrecht \& Mccarthy, 2006, Brose et al., 2013, McEwan et al., 2011, McEwan et al., 2007, Schuler et al., 2012, Signell et al., 2005). 
However, human intervention has reduced both the intensity and area of CHR forests burned since 1940, which has led to a widespread transition in dominant species from oak (Quercus spp.) and hickory (Carya spp.) to other early successional maple species (Acer spp.). This transition is termed the mesophication of the eastern hardwood forests (Fralish \& McArdle, 2009, Nowacki \& Abrams 2008). Accompanying this transition has been a reduction in area of bottomland hardwood forests and original oak savannas (Schmidt \& McWilliams, 2003). In modeling fire impacts, fire regimes are typically based on the vegetation associations (Hann et al., 2004, Keane et al., 2002). Recent modeling efforts consider climate variables as predictors (Jiang et al., 2012, Parisen \& Moritz, 2009, Westerling et al., 2006), and synthesize existing fire history information and mean fire intervals (MFI) based on physical mechanisms associated with dry climatic conditions (Guyette et al., 2010). Temperature, precipitation, and their interaction prove to be the most significant factors controlling fire frequencies and intensity in forest ecosystems (Morgan $e t$ $a l ., 2001)$, and these environmental factors are predicted to change in the future.

Reliable forest growth models are lacking for the CHR. One of the first forest growth models for the region was established by Perkey (1985). This whole-stand model simulated stand-level attributes, but did not specify population structure. Later, the distance-independent individual tree growth and yield system OAKSIM (Hilt, 1985) was developed for even-aged upland oak stands in southern Ohio and southeastern Kentucky, but this model has rarely been used due to limited applicability and a lack of stability (Brooks \& Miller, 2011). Three more recent models for the region, namely SILVAH (Marquis \& Ernst, 1992), the Forest Vegetation Simulator (FVS, Bush, 1995), and the Stand Damage Model (Colbert \& Racin, 1995), have substantial prediction bias ranging from 20 to $140 \%$ of actual trees per acre (Brooks \& Miller, 2011). Another whole-stand growth and yield model (Brooks, 2012) demonstrates better 
accuracy, but a lack of recruitment module renders this model inappropriate for long-term projections. More recently, LANDIS PRO has been developed to project forest successional trajectories and stand development patterns (Wang et al., 2014). However, data are missing for several key tree species including yellow poplar, white ash, and black gum (He et al., 2012); consequently, this model is susceptible to errors in terms of structured forest populations.

The primary objective of this study was to develop an empirical model of forest dynamics to study the successional patterns of CHR forests under future climate change. I then extended this modeling framework to account for climate-induced changes of fire regimes. I further employed Monte Carlo simulations in projecting future forest states and stumpage values under four future climate scenarios: RCP2.6, RCP4.5, RCP6.0 and RCP8.5. Ecological and economic implications of the simulation results are discussed in relation to known ecosystem services provided by CHR forests. 


\subsection{Materials and Methods}

\subsubsection{Forest and Stumpage Price Data}

The CHR encompasses three ecoregions, namely the Blue Ridge Mountains, the historic Great Valley, and the ridges and valleys of the Allegheny Mountains (see Bailey, 2004 and references therein). Additionally, the CHR covers a wide range of stand states, community species composition, and climatic conditions (Fig. 2-1). Data used for model calibration consisted of 5,196 re-measured permanent sample plots (PSP's) from the Forest Inventory and Analysis (FIA) database (Sharon et al., 2011) following three criteria. First, stand characteristics of the sample plots were closely monitored and re-measured. Second, stands had at least one live tree at the time of both measurements. Finally, plots were located in forests without any evidence of silvicultural treatments or any other forms of human interference, such as harvesting and artificial regeneration. For validation purposes, we acquired an additional 1,107 plots randomly located throughout the region to test model accuracy. 


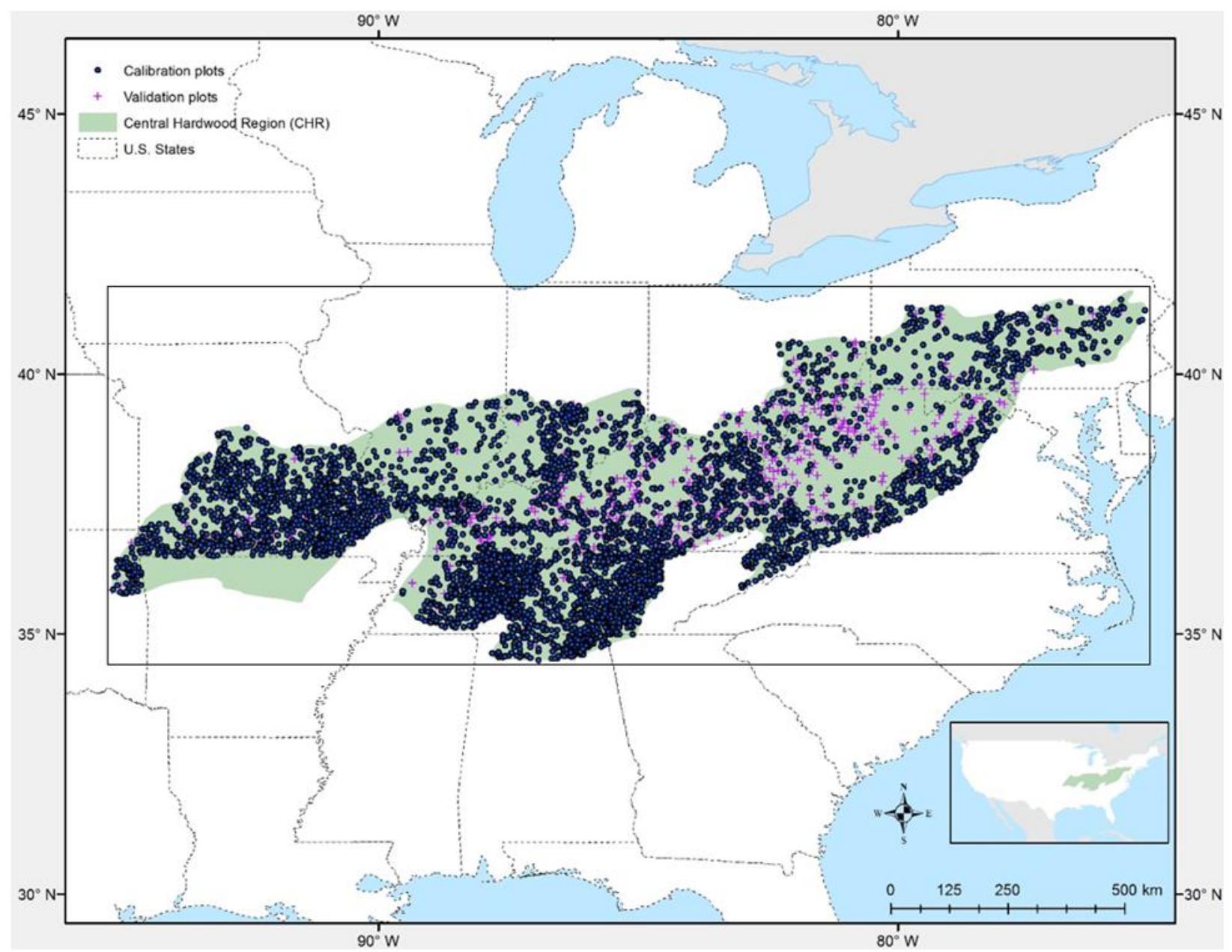

Figure 2-1 Geographic distribution of the calibration (dots) and validation (+) plots, in the

Central Hardwood Region (CHR). Inset shows the relative location of CHR in the contiguous

United States. The box indicates the CHR region where the future relative changes of

temperature and precipitation (trend ratio) were extracted for four future climate scenarios.

For each sample plot, physical site attributes included geographic coordinates, slope, aspect, and elevation. Tree data, including species, diameter, and status (recruitment, live, or dead), were also collected on site. The research area is largely dominated by seven major species: Quercus alba (white oak), Quercus velutina (black oak), Quercus rubra (northern red oak), Carya glabra (pignut hickory), Acer saccharum (sugar maple), Acer rubrum (red maple), and Liriodendron tulipifera (yellow-poplar). White oak had the highest basal area of all the species 
(13.9\%), followed by black oak (10.9\%), northern red oak (5.8\%), pignut hickory (4.7\%), sugar maple (4.5\%), red maple (4.4\%), and yellow-poplar (3.9\%) (see Supplemental Information, Table A1). Due to the high diversity in this region, there also exist over 100 other tree species. For simplicity and due to computational constraints, we classified all tree species into seven species groups according to their taxonomic features: white oak species (Quercus - Quercus, QQ), red oak species (Quercus - Lobatae, QL), Juglandaceae (JD), Sapindaceae (SD), Gymnosperms (GS), Fagus (FG), and Other Angiosperms (OA) (see Supplemental Information, Table A1). Within each species group, trees were further categorized into seventeen diameter at breast height (DBH) classes of 5-cm increments, except for the first class $(2.54-7 \mathrm{~cm})$ and the last ( $82 \mathrm{~cm}$ and above) class.

Among all the variables studied (Table 2-1), the average recruitment $(R)$ and total stem density $(N)$ were the highest for Sapindaceae (SD) and lowest for Fagus (FG, see Supplemental Information, Table A2). The average interval between two inventories was roughly 6 years. At the individual tree level (see Supplemental Information, Table A3), the Quercus - Lobatae (QL) had the largest diameter at breast height $(D)$ and the highest average annual diameter growth $(g)$. Juglandaceae (JD) had the lowest mortality rate $(m)$, and Gymnosperms (GS) had the highest. 
Table 2-1 Definitions and units of variables used in the CSMatrix model for CHR forests.

\begin{tabular}{lll}
\hline Variable & Unit & Definition/explanation \\
\hline$B$ & $\mathrm{~m}^{2} \mathrm{ha}^{-1}$ & Total stand basal area \\
$C$ & $\mathrm{~m}^{3} \mathrm{ha}^{-1} \mathrm{yr}^{-1}$ & Site productivity \\
$D$ & $\mathrm{~cm}^{\mathrm{cm} \mathrm{yr}}$ & Diameter at breast height \\
$g$ & $\mathrm{~km}$ & Annual diameter growth \\
$E$ & degrees & Plot elevation \\
$S$ & & Plot slope \\
$H_{d}$ & & Tree size diversity in Shannon's index \\
$H_{S}$ & ${ }^{\circ}$ & Tree species diversity in Shannon's index \\
$T$ & $100 \mathrm{~mm} \mathrm{month}^{-1}$ & Mean annual temperature \\
$P$ & Annual average of monthly mean precipitation \\
$m$ & $\mathrm{yr}^{-1}$ & Annual tree mortality \\
$N$ & trees ha $^{-1}$ & Number of trees per hectare \\
$R$ & trees ha $^{-1} \mathrm{yr}^{-1}$ & Recruitment, the number of trees per hectare growing into the \\
$V$ & & smallest diameter class $(2.54-7 \mathrm{~cm})$ in a year \\
$M F I$ & $\mathrm{~m}^{3} \mathrm{ha}^{-1}$ & Stem volume \\
\hline
\end{tabular}

For the analysis of stumpage values, we used the stumpage price data for the CHR in 2015 from the West Virginia Timber Market Report (http://ahc.caf.wvu.edu/ahc-resourcesmainmenu-45/timber-market-report-mainmenu-62, accessed July 3, 2015) and assumed constant real prices in 2015 dollars in the region until 2100 to provide a current value estimate to understand implications in today's dollars.

\subsubsection{Climate Data and Method}

We assembled the historical records (30-year mean for 1981-2010) of the average annual temperature $\left({ }^{\circ} \mathrm{C}\right)$ and annual average of monthly mean precipitation $\left(100 \mathrm{~mm} \mathrm{month}^{-1}\right)$ from the downscaled 4-km resolution Parameter-Elevation Regression on Independent Slopes Model (PRISM) datasets (Daly et al., 2008). PRISM calculates a climate-elevation regression for each digital elevation model grid cell, so the climate variables from PRISM, especially precipitation, are applicable for interpolation over mountain ranges (Daly et al., 2008). The PRISM data set was shown to be a more accurate representation of spatial climatic patterns in the United States 
than the WorldClim and Daymet datasets (Daly et al., 2008). For the prediction of future climatic changes in the CHR, we extracted the future relative changes (trend ratio) over the region $\left(75^{\circ} \mathrm{W}-95^{\circ} \mathrm{W}\right.$ and $34.5^{\circ} \mathrm{N}-42^{\circ} \mathrm{N}$; shown as the box in Figure 1) for the four scenarios of the IPCC AR5 report (Blyth et al., 2007). The trend ratios of temperature and precipitation were obtained from the KNMI Climate Change Atlas (http://climexp.knmi.nl/, last accessed 10-August-2015). The four future climate scenarios of Representative Concentration Pathways (RCPs) were chosen to span a wide range of possible future conditions: RCP8.5 is a business-as-usual scenario with increasing greenhouse gas emissions over time, leading to high greenhouse gas concentration levels; RCP6.0 is a stabilization scenario in which emissions rise quickly until 2060 and then decrease; RCP4.5 assumes quicker action to limit greenhouse gas emissions with emissions peaking in 2040 and declining strongly until 2080; and RCP2.6 describes an all-out effort to limit global warming to below $2{ }^{\circ} \mathrm{C}$, with emissions decreasing sharply after 2020 and to zero emissions from 2080 onward (IPCC, 2013).

We estimated future temperature and precipitation changes in the study area in three steps. First, we extracted the 30-year (1981-2010) average annual temperature and annual average of monthly mean precipitation at all the plots $(5,196$ for calibration and 1,107 for validation plots) using the PRISM data. Second, the trend ratios of temperature and precipitation over the CHR were obtained under the four RCP scenarios of future climate change (2010-2100) from the KNMI Climate Change Atlas. Third, we multiplied the extracted historical normal (30-year mean) temperature and precipitation by the future trend ratios to estimate the future temperature and precipitation changes, respectively, at the validation plot sites in the CHR during 2010-2100. Over the area represented by the validation plots, future annual temperature showed an increasing trend under all four RCP scenarios, and the annual average of monthly mean 
precipitation did not change significantly over time under any scenario, compared to 2010 climate (Figure 2-2). Average annual temperature and annual average of monthly mean precipitation were predicted to have the greatest changes of $+3.6{ }^{\circ} \mathrm{C}$ under RCP8.5 and +14.3 mm month ${ }^{-1}$ under RCP6.0, respectively, over the next 90 years. RCP2.6 has the smallest increase of temperature, $+0.8^{\circ} \mathrm{C}$, and decline of precipitation, $-0.6 \mathrm{~mm}$ month $^{-1}$ (Fig. 2-2a, b). For the study area, the future climate in general would be the warmest in RCP8.5, whereas precipitation on average would be the highest in RCP 6.0 (Fig. 2-2a, b). The precipitation in RCP4.5 had a similar trend as that in RCP6.0, but the temperature was lower in the second half of the century. In RCP2.6, the temperature appeared relatively stationary and stayed the lowest beyond 2050 . 

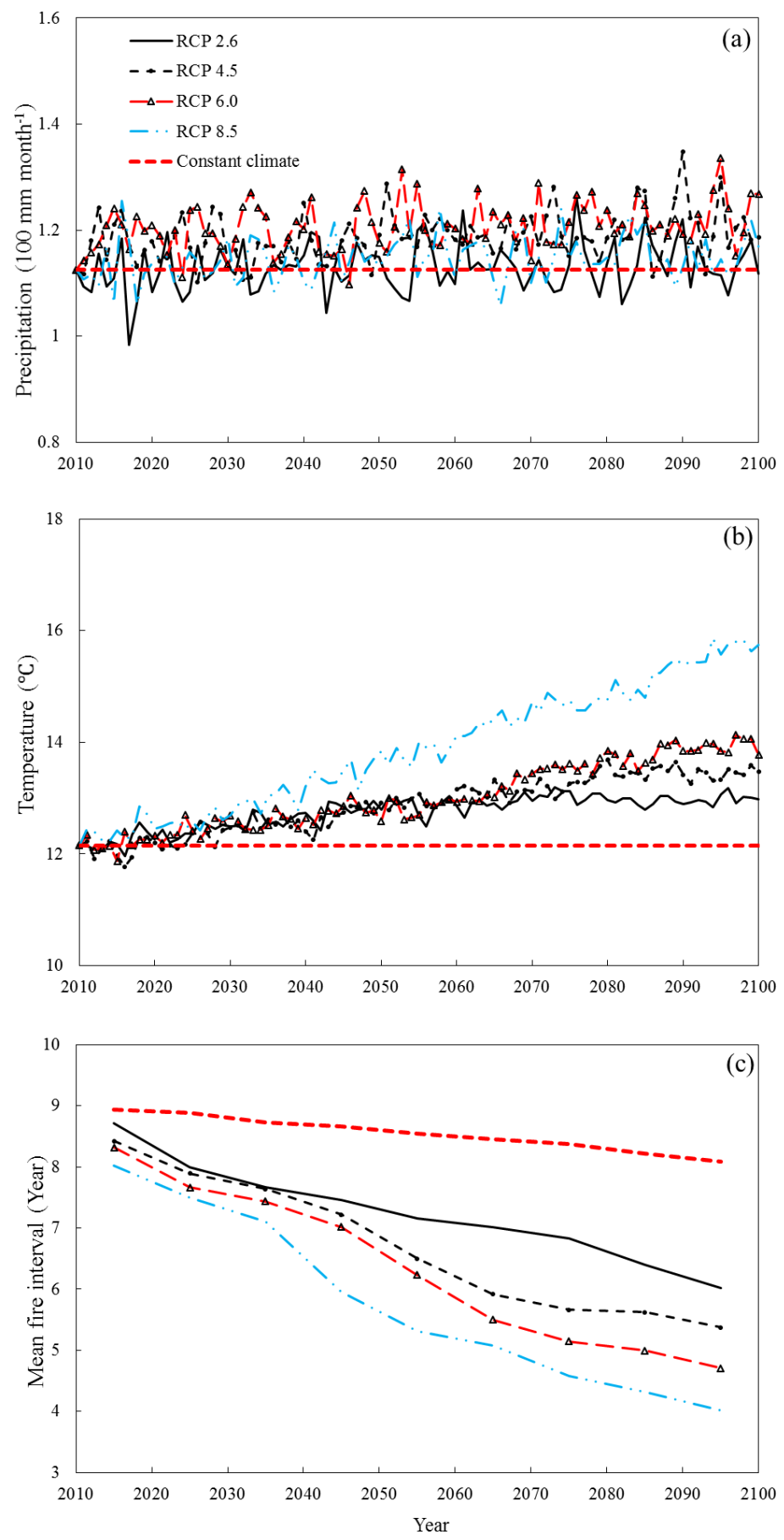

Figure 2-2 Temporal changes of mean annual temperature $\left({ }^{\circ} \mathrm{C}\right)$, annual average of monthly mean precipitation (100 $\left.\mathrm{mm} \mathrm{month}^{-1}\right)$ and mean fire interval (year) across the 1107 sample plots estimated under four climate scenarios of RCP2.6, RCP4.5, RCP6.0, and RCP8.5, and the climate constant at year 2010. 


\subsubsection{Population Density Data}

We collected the historical records of mean human population density in 2000 from Gridded Population of the World (GPW), v3 database

(http://sedac.ciesin.columbia.edu/data/collection/gpw-v3, last accessed 09-June-2015). The range of population density over the entire CHR was from 0 to $1023 \mathrm{~km}^{-2}$ and the mean population density is $28.2 \mathrm{~km}^{-2}$. Spatially specific future population density across the CHR was estimated based on the current CHR population density and the overall population trend in the United States in year 2000 for 2025, 2050, 2075 and 2100 (see Supplemental Information, Fig. A1) (Bos et al., 1994), assuming a constant CHR-nationwide population ratio.

\subsubsection{Forest Dynamics}

We studied forest dynamics and successional patterns using the matrix model, a type of ecological population model that uses transition matrices to estimate the dynamics of structured populations (e.g., Caswell, 2001, Fieberg \& Ellner, 2001, Liang \& Picard, 2013). Developed from ecological studies that date back to the 1940's (Leslie, 1945, Lewis, 1942), matrix models have been widely employed to study the dynamics of forest ecosystems all over the world due to their accuracy and robustness in depicting structured forest populations (see Liang \& Picard, 2013 and references therein).

A conventional matrix model predicts the structured population dynamics of forest stands from time $t$ to $t+1$ :

$\mathbf{y}_{t+1}=\mathbf{G} \cdot \mathbf{y}_{t}+\mathbf{R}+\varepsilon$ 
where $\boldsymbol{y}_{t}=\left[y_{i j t}\right]$ is a column vector representing the number of live trees per hectare of species $i$ $(i=1,2, \ldots, m)$ and diameter class $j(j=1,2, \ldots, n)$ at time $t$ and $\varepsilon$ is a random error. $\mathbf{G}$ is a stateand time-dependent transition matrix describing how trees grow or die between $t$ and $t+1$.

In a Climate-Sensitive Matrix (CSMatrix) model, an extension of the conventional matrix model to control for the climate variability (Liang et al., 2011), $\mathbf{G}$ and $\mathbf{R}$ are revised to be functions of mean annual temperature $(T)$ and annual average of monthly mean precipitation $(P)$. Thus, Eq. (2-1) was extended to control for climate-sensitivity by recognizing effects of temperature and precipitation on tree growth, mortality, and recruitment as follows:

$\mathbf{y}_{t+1}=\mathbf{G}_{t}(T, P) \cdot \mathbf{y}_{t}+\mathbf{R}_{t}(T, P)+\varepsilon$

For the CSMatrix model, the time increment unit-the interval in year between $t$ and $t+1$ of Eq. (2-2) — was one year. The detailed matrix growth model is described in the Supplemental Information.

The dependent variables, i.e., the rates of upgrowth, mortality, and recruitment (see Supplemental Information for definitions), were estimated from tree and stand attributes for 17 size classes and seven species groups using repeated measurements of 5,196 FIA permanent sample plots. For parsimony and accuracy, we only retained variables that met three rigorous criteria: statistical significance, expected biological responses, and contribution to the model goodness-of-fit. To avoid compromised type-I error rates and severe artifacts commonly associated with model selection procedures (Mac Nally, 2000), explanatory variables were selected using hierarchical partitioning (HP) by the average independent contribution of each variable to the overall goodness-of-fit (Chevan \& Sutherland, 1991). The HP analysis was conducted with the hier.part package of the R program (Mac Nally \& Walsh, 2004). 
Accuracy of the resulting model was evaluated through short-term prediction errors of the validation plots, defined as the difference between the observed and the predicted stand state variables at the second inventory. Predicted stand state variables were obtained by setting the first inventory as the initial condition and applying Eq. 2-2 iteratively over the elapsed period between the two inventories.

We further compared the stand state variables predicted by the present model with those predicted with the conventional matrix model and LANDIS PRO. For a fair comparison, an independent post-sample validation dataset (Fig. 2-1) was used for the simulations. For each model, the root mean squared errors (RMSE) (Wooldridge, 2012) were calculated based on the difference between the predicted and observed basal area by species and diameter class as a comparable measure of accuracy.

\subsubsection{Fire Disturbance}

To take into account impacts of altered wildfire regimes induced by climate change, I adopted a mean fire interval (MFI) model by Guyette et al. (2010) specifically designed for the fire management plans in the eastern and southern United States. The historical MFI model is parameterized using mean maximum temperature, precipitation, their interaction, and estimated population density to account for climate change as a main driver of fire regimes. The detailed MFI model structure and definition of fire severity classes are explained in the Supplemental Information.

We followed the conventional assumption that fire occurrence had an exponential distribution with its probability at time $t$,

$p(t)=1-e^{-t / M F I}$

In our simulations, $p(t)$ was drawn as a uniformly distributed random variable ranging from 0 to 
1. Thus the year of fire occurrence, $t$, is calculated by $-\ln (1-p(t))$ MFI. MFI was updated every decade based on the projected climate data and every 25 years based on projected population density data from 2010 to 2100 for all four climate scenarios, respectively. The following probabilities were assigned to fire severity classes $\mathbf{1}$ to $\mathbf{5}$ (see Supplemental Information, Table A6), respectively, based on the rationale that lower severity fires tended to happen more frequently: $40,25,20,10$, and $5 \%$.

\subsubsection{Integrated Framework}

It is important to represent interactions among the components to comprehensively assess how landscapes in this region may respond to climate change. Such an integrated model has the potential to provide resource managers the ability to better visualize potential future landscapes resulting from the interaction of biological and physical processes. In this study, we developed an integrated CSMatrix framework to couple (1) the model of forest dynamics, (2) the mean fire interval model, (3) the population density model, and (4) future climate scenarios. We synchronously coupled the three models and future climate data to evaluate the long-term effects of changes in climate and fire regime on forest structure in the $\mathrm{CHR}$, represented as the average predicted values from Monte Carlo simulations (Fig. 2-3). The simulated changes in landscape structure have important implications for the management of natural resources in eastern United States. 


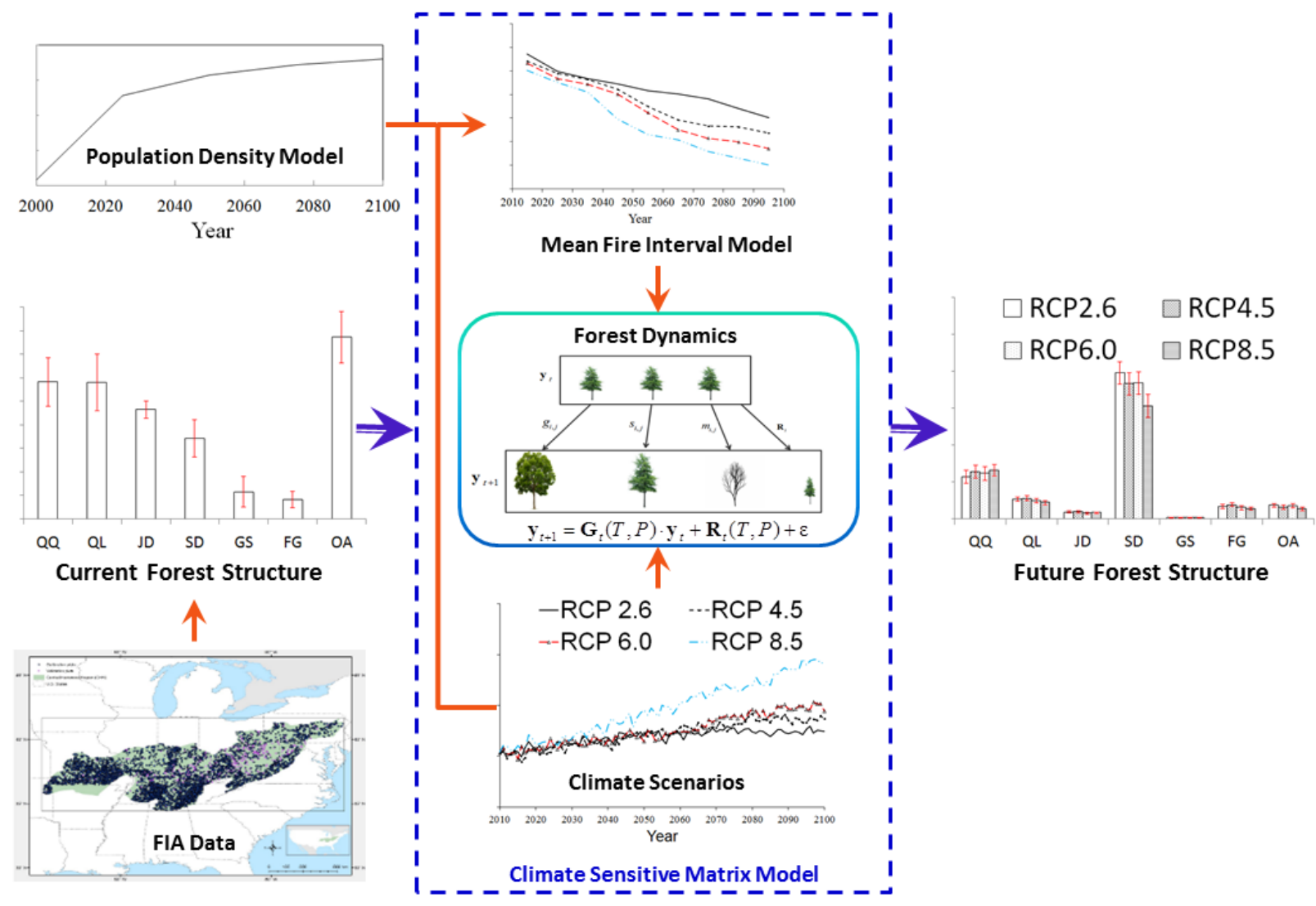

Figure 2-3 Conceptual diagram showing how the CSMatrix framework integrated forest dynamics, climate data, and the Mean Fire Interval Model to project the population dynamics of CHR forests under future climate change scenarios.

\subsection{Results}

\subsubsection{Forest Dynamics}

Starting from a large amount of explanatory variables (see Supplemental Information, Equations S4-S7), we selected a subset to be in the final model (Table 2-2) based on statistical and biological significance and contribution to the goodness-of-fit. The primary control variables for the final matrix model, DBH $(D)$, stand basal area $(B)$, and stem density $(N)$, were significant at the $\alpha \leq 0.05$ level and contributed highly to the overall goodness-of-fit (see Supplemental 
Information, Table A4). All other selected variables had independent contributions greater than the average and most were significant and had consistent signs over different species groups. 
Table 2-2 Estimated parameters of the CSMatrix model for CHR forests.

\begin{tabular}{|c|c|c|c|c|c|c|c|c|c|c|c|c|c|c|}
\hline & QQ & & QL & & JD & & SD & & GS & & FG & & $\mathrm{OA}$ & \\
\hline \multicolumn{15}{|c|}{ Diameter growth } \\
\hline Const & 0.066 & $* * *$ & 0.202 & **** & 0.051 & $* * *$ & 0.077 & *** & 0.181 & **** & 0.492 & **** & 0.0619 & **** \\
\hline$D$ & 0.006 & $* * *$ & 0.007 & **** & 0.009 & $* * *$ & 0.004 & * & -0.001 & ${ }^{*}$ & 0.004 & * & 0.0194 & *** \\
\hline$D^{2}$ & -0.0001 & $* * *$ & -0.0001 & $* * *$ & -0.0001 & **** & & & -0.0001 & $*$ & -0.0001 & *** & -0.0004 & *** \\
\hline$H_{d}$ & & & & & & & & & & & -0.167 & $\begin{array}{r}* * * \\
*\end{array}$ & & $* *$ \\
\hline $\begin{array}{l}P^{*} D \\
P^{*} D^{2}\end{array}$ & 0.003 & 策 & 0.001 & * & 0.001 & * & $\begin{array}{r}0.002 \\
-0.0001\end{array}$ & * & $\begin{array}{c}-0.003 \\
0.0001\end{array}$ & ${ }^{*}$ & 0.001 & 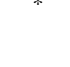 & $\begin{array}{r}0.0026 \\
-0.0001\end{array}$ & $*$ \\
\hline$P * B$ & & & 0.018 & & -0.016 & * & & & & & & & & \\
\hline$T * D$ & 0.0002 & $* * *$ & 0.0001 & & 0.00004 & & 0.001 & $* * *$ & 0.001 & **** & 0.0003 & * & -0.0006 & **** \\
\hline$T * D^{2}$ & & & & & & & -0.0001 & ${ }^{*}$ & -0.0001 & * & & & 0.00002 & **** \\
\hline$T^{*} B$ & & & -0.002 & * & 0.001 & & & & & & & & & \\
\hline Adjusted-R ${ }^{2}$ & 0.32 & & 0.20 & & 0.33 & & 0.31 & & 0.21 & & 0.19 & & 0.34 & \\
\hline $\operatorname{Prob}(\mathrm{F})$ & $<0.001$ & & $<0.001$ & & $<0.001$ & & $<0.001$ & & $<0.001$ & & $<0.001$ & & $<0.001$ & \\
\hline \multicolumn{15}{|c|}{ Mortality } \\
\hline Const & -0.418 & $* * *$ & -0.723 & **** & -0.570 & $* * *$ & -1.200 & $* * *$ & 0.066 & * & -1.465 & **** & -0.5454 & **** \\
\hline$D$ & -0.007 & & 0.044 & $* * *$ & -0.051 & *** & & & & & & & & \\
\hline$D^{2}$ & 0.001 & **** & & & 0.001 & **** & & & & & & & & \\
\hline$B$ & -1.372 & $* * *$ & -1.631 & **** & -1.494 & **** & -0.953 & $* * *$ & & & & & -0.9055 & *** \\
\hline$H_{s}$ & & & & & & & & & -0.665 & $* * *$ & & & & \\
\hline$H_{d}$ & & & & & & & & & & & -0.285 & & & \\
\hline$S$ & & & & & & & & & & & 0.018 & * & & \\
\hline$C$ & & & & & & & & & & & 0.035 & * & & \\
\hline$P * D$ & -0.021 & **** & -0.039 & **** & & & & & & & & & & \\
\hline$P^{*} B$ & 0.567 & $* * *$ & 0.899 & **** & 0.459 & $* * *$ & 0.290 & $* *$ & & & & & 0.1885 & *** \\
\hline$P * H s$ & & & & & & & & & 0.079 & * & & & & \\
\hline$P * S$ & & & & & & & & & & & -0.002 & & & \\
\hline$P * C$ & & & & & & & & & & & & & & \\
\hline$T^{*} D$ & -0.002 & ** & & & & & & & & & & & & \\
\hline$T^{*} B$ & 0.036 & $*$ & 0.025 & ** & 0.030 & ** & 0.029 & * & & & & & 0.0098 & \\
\hline$T^{*} H s$ & & & & & & & & & -0.004 & * & & & & \\
\hline$T * S$ & & & & & & & & & & & -0.001 & * & & \\
\hline AIC & 18578 & & 19852 & & 1092 & & 14563 & & 10350 & & 9167 & & 19850 & \\
\hline BIC & 18645 & & 19902 & & 1132 & & 14620 & & 10436 & & 9210 & & 19948 & \\
\hline \multicolumn{15}{|c|}{ Recruitment } \\
\hline Const & 32.102 & & -79.636 & **** & -36.633 & $* * *$ & -80.766 & $* * *$ & -0.010 & $* * *$ & -0.012 & $* * *$ & 0.1220 & \\
\hline$N$ & 0.186 & $* * *$ & 0.313 & $* * *$ & 0.121 & **** & 0.166 & $* * *$ & 0.189 & $* *$ & 0.212 & & 0.1020 & *** \\
\hline$N^{2}$ & -0.046 & $* * *$ & -0.004 & & -0.022 & $* * *$ & -0.041 & $* * *$ & & & -0.463 & * & 0.0008 & \\
\hline$H_{d}$ & -18.360 & $* * *$ & & & & & & & & & & & & \\
\hline$H_{s}$ & -20.975 & & & & 3.572 & & & & & & & & & \\
\hline$P$ & -65.815 & * & & & & & & & & & & - & 0.5110 & * \\
\hline$P^{2}$ & 6.071 & & & & & & & & & & & & 0.0001 & * \\
\hline$P * N$ & -0.035 & $*$ & -0.131 & **** & 0.010 & * & -0.021 & * & -0.028 & * & -0.011 & * & -0.0114 & \\
\hline$P * H_{s}$ & 15.286 & & & & & & & & & & & & & \\
\hline$P^{*} H_{d}$ & & & & & -25.734 & $* * *$ & & & & & & & & \\
\hline$T^{*} N$ & -0.004 & $*$ & -0.004 & $*$ & -0.004 & * & -0.002 & & -0.005 & & 0.008 & & -0.0053 & ** \\
\hline$T^{*} N^{2}$ & & & -0.004 & & & & & & & & 0.023 & * & & \\
\hline$T^{* P} P$ & & & & & & & & & & & & & -0.8770 & \\
\hline Chi-Sq & 257.37 & & 289.58 & & 262.83 & & 210.43 & & 317.18 & & 247.31 & & 182.47 & \\
\hline P-Value & $<0.001$ & & $<0.001$ & & $<0.001$ & & $<0.001$ & & $<0.001$ & & $<0.001$ & & $<0.001$ & \\
\hline
\end{tabular}

Note: Significance levels: ${ }^{*} \leq 0.05 ;{ }^{* *} \leq 0.01 ;{ }^{* * *} \leq 0.001$. 
Trees grew significantly faster when they were larger for all species groups, except for Gymnosperms (GS). Fitted mortality equations indicated that the probability of dying declined with tree diameter for most species, consistent with previous results (Lin et al., 1998, Schulte \& Buongiorno, 2004, Zenner, 2005). Mortality rate decreased significantly with stand basal area. The parameters in the recruitment equations from maximum-likelihood estimation showed that the recruitment of a species increased strongly with the density of that species in the stand. Total number of trees $(N)$ was the most significant predictor of recruitment and its effect was consistent over most species groups.

For the 1,107 validation plots, the basal area by species and diameter class predicted by the final model fell within the $95 \%$ confidence interval of the observed values in all the 119 species-diameter classes, demonstrating a high accuracy of the CSMatrix model (Fig. 2-4). Compared with the conventional matrix model and LANDIS PRO, our final model had $9.2-$ 16.3\% lower RMSE than the conventional matrix model, and LANDIS PRO had the worst shortterm accuracy, with 49.1 - 266\% higher RMSE than the CSMatrix model across all the species (Fig. 2-4). 

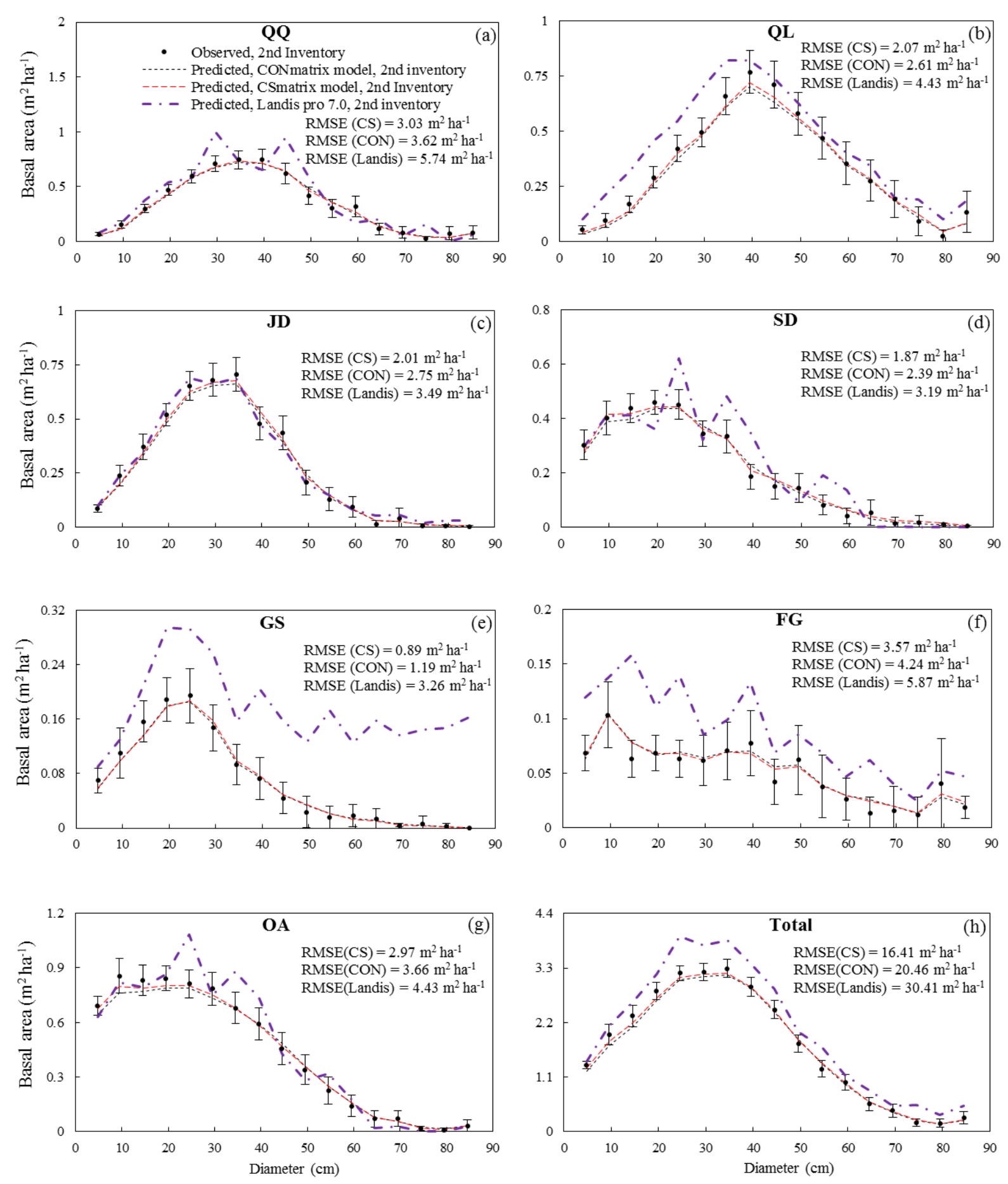

Figure 2-4 Average predicted and observed stand states at the second inventory for the conventional matrix model (CON), climate-sensitive matrix model (CS), and LANDIS PRO 7.0 on the 1107 post-sample validation plots, with the 95\% confidence interval of the observed mean. 
DBH, square DBH, stand basal area, and site productivity were the most significant variables for the volume models (see Supplemental Information, Table A7). The explanatory variables presented here accounted for $93.8-97.0 \%$ of the variability in stem volume across all species.

\subsubsection{Simulations with Fire and Climate Scenarios}

In all four scenarios, mean fire intervals were predicted to decrease considerably in 90 years, relative to the one predicted with 2010 climate (Fig. 2-2c). RCP8.5 had the shortest interval, slightly over 4 years, while RCP2.6 the longest, $\sim 6$ years, as it approached 2100. RCP4.5 and RCP6.0 had the average intervals, $\sim 5$ years, over the next 90 years.

Absent of fire disturbance, climate change increased the total stand basal area but the effect appears to be limited (Fig. 2-5) and mixed for individual species groups (Supplemental Information Figs.A2 - A8). When both climate change and associated fire disturbances were simultaneously accounted for, based on 100, 000 simulations, the projected forest states over the next 90 years displayed completely different patterns. Total stand basal area under the four RCP scenarios declined dramatically over the first 70 years by approximately 50 percent, and converged to around $14.9 \mathrm{~m}^{2} \mathrm{ha}^{-1}$ for RCP2.6, followed by $14.2 \mathrm{~m}^{2} \mathrm{ha}^{-1}$ for RCP4.5, $14.0 \mathrm{~m}^{2} \mathrm{ha}^{-1}$ for RCP6.0, and the lowest $13.0 \mathrm{~m}^{2} \mathrm{ha}^{-1}$ for RCP8.5 (Fig. 2-5). The current average total basal area throughout the CHR is $29.1 \mathrm{~m}^{2} \mathrm{ha}^{-1}$, but would decline by $55.1-62.0 \%$ to $11.1-12.7 \mathrm{~m}^{2}$ $\mathrm{ha}^{-1}$ by 2100 given climate and fire predictions. 

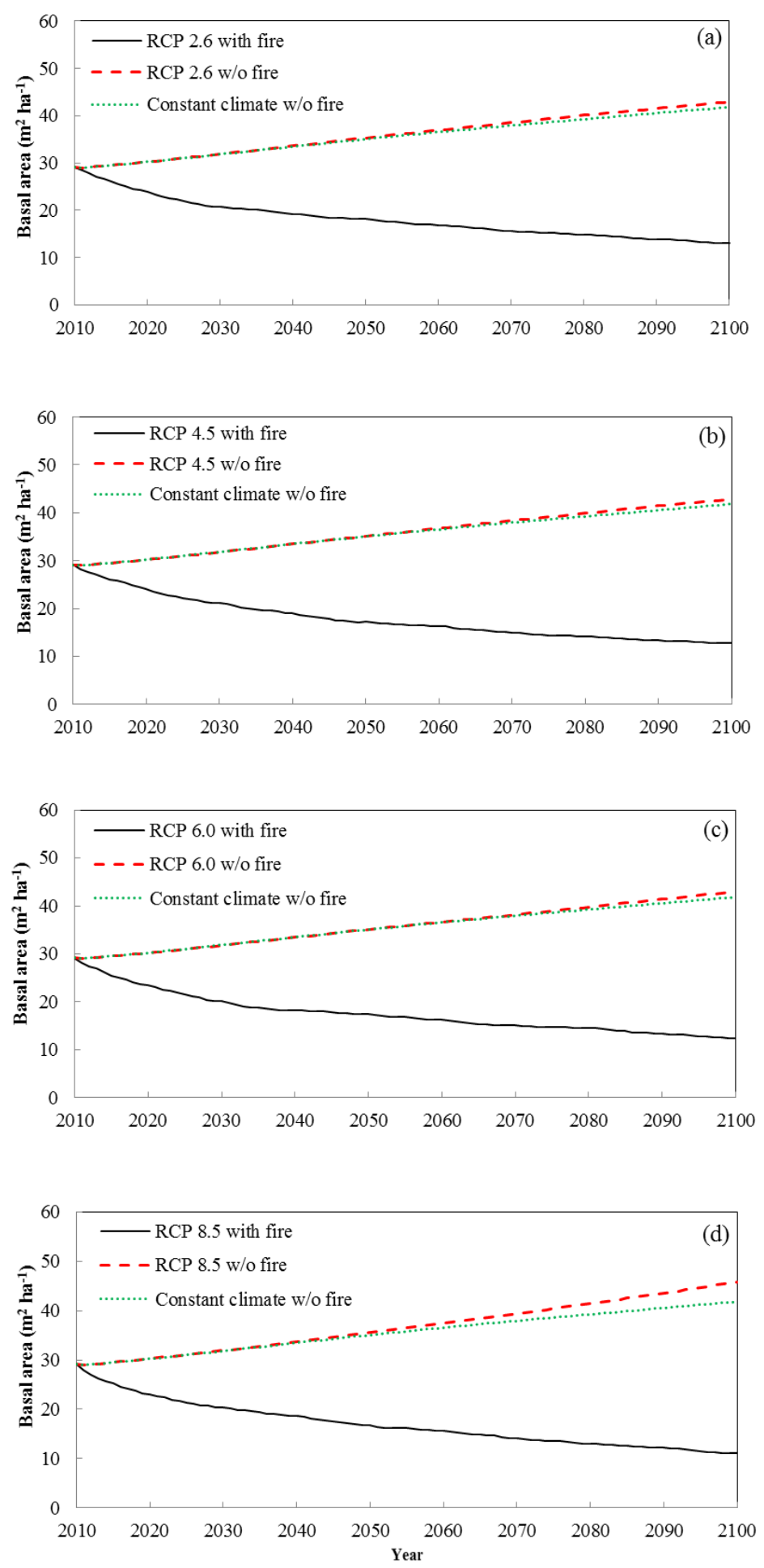

Figure 2-5 Stand basal area under wildfire disturbance under four climate scenarios RCP2.6, RCP4.5, RCP6.0, and RCP8.5 from year 2010-2100. 
In terms of species composition in percentage basal area, current forests in the CHR are dominated by oak (QQ 22.5\%, QL 20.5\%) and hickory (JD 15.4\%) species. Maple species (SD) account for only $8.9 \%$ of the total stocking (Fig. 2-6a). Under climate change and associated alterations of fire regimes, forests in the CHR in year 2100 would be dominated by maple species (SD 55.2-60.4\%), whereas oak species (QQ, QL) would diminish to $25.5-31.5 \%$. GS and JD together would only account for $3.0-3.4 \%$ of the total stand stocking (Fig. 2-6b). These potential changes were consistent across all four climate change scenarios (Fig. 2-6b). Tree size diversity would increase by 27.9 - $30.6 \%$ over the first 20 years, and gradually drop back to a level similar to the present (Fig. 2-7). In contrast, tree species diversity would monotonically decrease by $9.6-11.5 \%$ over the next 90 years (Fig. $2-7$ ). 

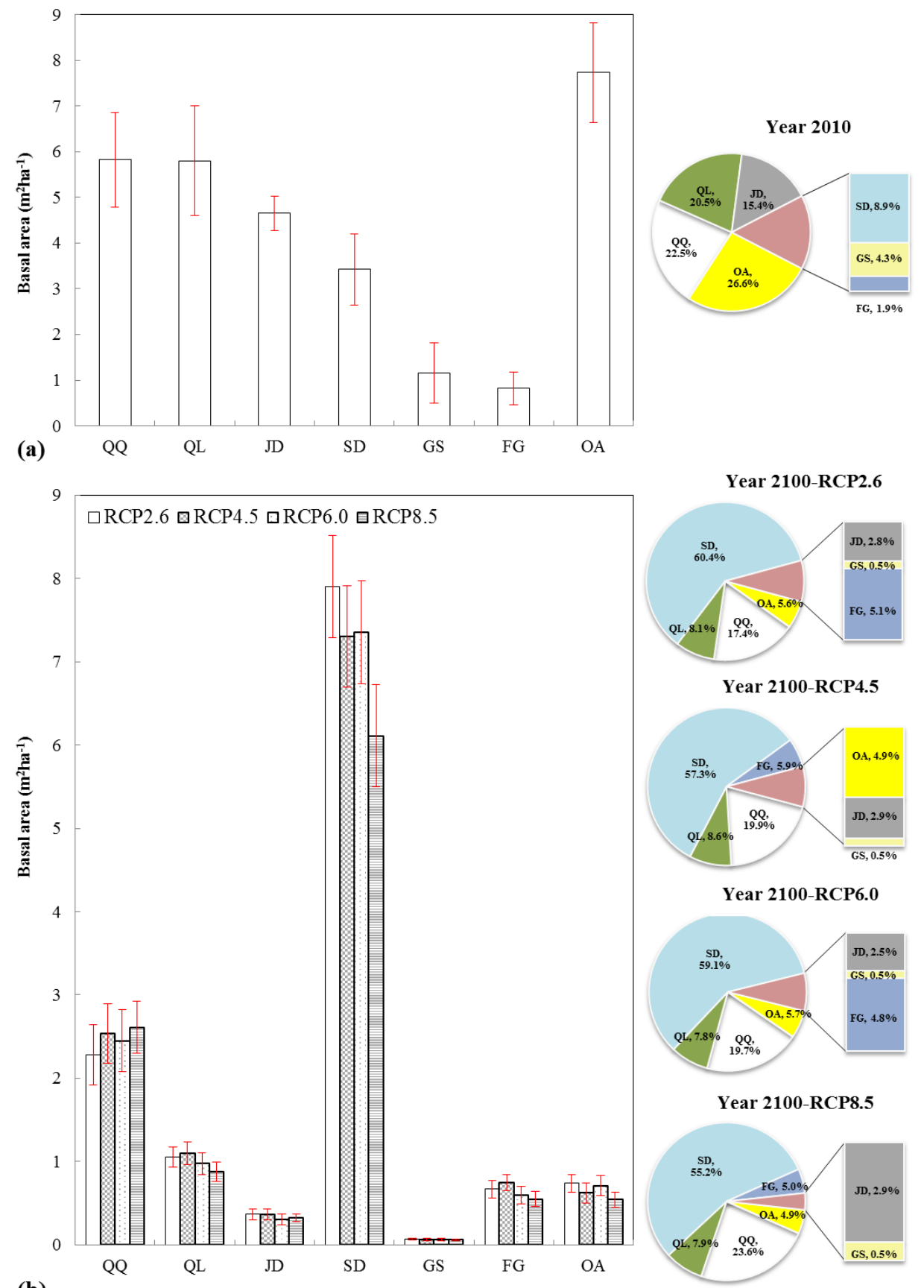

(b)

Figure 2-6 Species composition in terms of basal area in year 2010 (a) and year 2100 under wildfire disturbance with four climate scenarios $\mathrm{RCP} 2.6, \mathrm{RCP} 4.5, \mathrm{RCP6.0}$, and $\mathrm{RCP8.5}(\mathrm{b})$. Vertical bars represent one standard error of the average predicted values from Monte Carlo simulations. The pie charts to the right show the corresponding percentage of basal area by species and climate scenario. 
Species diversity
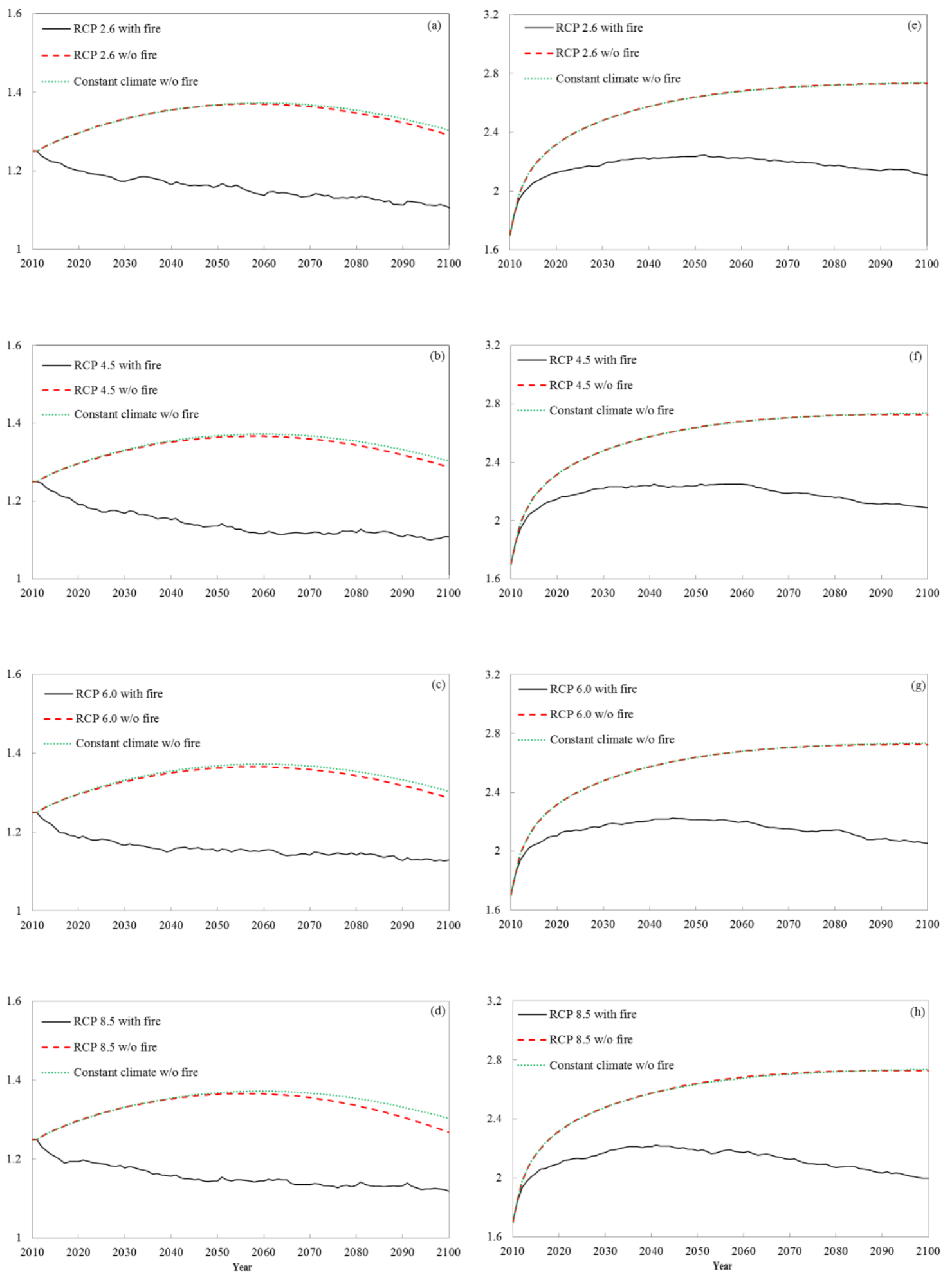

Figure 2-7 Tree species (a-d) and size diversity (e-h) under wildfire disturbance with 4 climate scenarios RCP2.6, RCP4.5, RCP6.0, and RCP8.5 from year 2010-2100. 
Similarly, total stand volume exhibited a steep decline during the first 50 years of the model run and, despite some fluctuations, converged to $330.4 \mathrm{~m}^{3} \mathrm{ha}^{-1}$ for RCP2.6, followed by $313.1 \mathrm{~m}^{3} \mathrm{ha}^{-1}$ for RCP4.5, $310.1 \mathrm{~m}^{3} \mathrm{ha}^{-1}$ for RCP6.0, and $307.5 \mathrm{~m}^{3} \mathrm{ha}^{-1}$ for RCP8.5 (Table 2-3). Total volume stocking would decline by $56.3-62.4 \%$ from $633.5 \mathrm{~m}^{3} \mathrm{ha}^{-1}$ currently to $257.6-$ $276.8 \mathrm{~m}^{3} \mathrm{ha}^{-1}$ throughout the region. OA had the greatest volume stocking decline $(191.6-203.6$ $\left.\mathrm{m}^{3} \mathrm{ha}^{-1}\right)$, followed by JD $\left(51.3-52.5 \mathrm{~m}^{3} \mathrm{ha}^{-1}\right)$, QL $\left(45.6-47.8 \mathrm{~m}^{3} \mathrm{ha}^{-1}\right)$, and QQ $\left(37.6-41.2 \mathrm{~m}^{3}\right.$ $\left.\mathrm{ha}^{-1}\right)$, whereas SD $\left(-11.9-15.3 \mathrm{~m}^{3} \mathrm{ha}^{-1}\right)$ had the least reduction. Assuming constant stumpage prices in 2015 dollars, the total current stumpage value throughout the CHR is approximately $\$ 1,317$ billion. Our projected change of forest population structure would lead to a $54.5-59.8 \%$ reduction in the total value to $\$ 529$ - 599 billion in current dollars over the next 90 years.

Table 2-3 Total average volume $\left(\mathrm{m}^{3} \mathrm{ha}^{-1}\right)$ for climate scenarios $\mathrm{RCP2.6}, \mathrm{RCP} 4.5, \mathrm{RCP6.0}$, RCP8.5 from year 2010-2100.

\begin{tabular}{crrrr}
\hline Year & RCP2.6 & RCP4.5 & RCP6.0 & RCP8.5 \\
\hline $2010-2020$ & 461.1 & 468.7 & 448.5 & 443.6 \\
$2020-2030$ & 394.6 & 392.1 & 367.2 & 380.9 \\
$2030-2040$ & 369.6 & 355.4 & 339.4 & 352.4 \\
$2040-2050$ & 352.2 & 320.2 & 327.4 & 325.0 \\
$2050-2060$ & 330.4 & 313.1 & 316.7 & 307.5 \\
$2060-2070$ & 316.1 & 294.0 & 296.8 & 286.2 \\
$2070-2080$ & 307.0 & 283.6 & 297.8 & 270.5 \\
$2080-2090$ & 292.7 & 270.3 & 269.7 & 257.8 \\
$2090-2100$ & 276.8 & 257.6 & 261.7 & 238.2 \\
\hline
\end{tabular}




\subsection{Discussion}

According to the post-sample validation, the CSMatrix model is the most accurate for gymnosperms ( $\mathrm{RMSE}=0.89)$ and maple species $(\mathrm{RMSE}=1.87)$, and is the least accurate for beech (RMSE=3.57) and white oak species (RMSE=3.03). The results suggested that the growth of beech and white oak species may depend on some factors other than those already controlled for by the CSMatrix model and, upon the emergence of additional data, efforts to improve the current model should focus these two species groups. Nevertheless, the CSMatrix model was accurate over all the species and diameter classes because the predicted means were all within the $95 \%$ confidence interval of the observed means. In terms of RMSE, the CSMatrix model also demonstrated a higher accuracy than its predecessors.

Our study has addressed the direct and indirect effects of climate change on forest dynamics in the CHR. The direct effects refer to the influence of climate change on upgrowth, ingrowth, and mortality of trees. The indirect effects refer to the climate-induced changes in fire disturbance and consequent influences on forest dynamics. Contrary to the prevailing view that climate change will boost forest growth (Boisvenue \& Running, 2006, Pretzsch et al., 2014), we only found slight differences between total stand basal area predicted under constant climate and any of the four climate scenarios. This result seems more in line with research suggesting that warmer temperature and prolonged growing seasons may not have a strong positive effect on forest growth in southeastern U.S. (Melillo et al., 2014) and tropical regions (van der Sleen et al., 2014). The indirect effect of fire was in fact much greater in magnitude and substantially decreased the total stand basal area (Fig. 2-5). This may be attributable to the smaller predicted changes in precipitation (-0.5\% to $12.7 \%$ ) and temperature (6.6\% to $29.6 \%)$ than fire frequency ( $26.1 \%$ to $52.9 \%$ ) relative to the baseline climate. In all, our study suggests that, for the CHR 
study area, climate-induced changes in natural disturbances may have greater impacts on forest dynamics than the direct effects of climate on tree growth. This is consistent with previous findings of the compounding effects of stochastic shocks on ecological processes and the crucial impact of the interaction between stochastic shocks and nonlinearity on shaping the ecosystem dynamics (Zhou \& Buongiorno, 2004, Fortin \& Langevin, 2012).

Contrary to an earlier projection of an increased tree species richness under climate change in the eastern U.S. (Iverson \& Prasad, 2001), our projected 9.6 - 11.5\% decline in tree species diversity in the CHR (Fig. 7) is due to the reduction of oak and hickory species caused by altered fire regimes (see Supplemental Information, Fig. A2 - A8). Historically, shade intolerant oak and hickory species in the region were maintained by high-intensity fires that reduced competition and promoted regeneration (Nowacki \& Abrams, 2008, Ruffner, 2005). Projected shortening of mean fire intervals (Fig. 2-2c) indicates that high-intensity fires will be gradually replaced by more frequent low-intensity fires, diminishing advantages to oak and hickory species and leading to a gradual mesophication of the CHR forests and dominance of shade-tolerant maple species in the long term (Nowacki \& Abrams, 2008). Our projections, consistent with the overall biodiversity trend observed throughout this region (Alexander \& Arthur, 2010, Fralish \& McArdle, 2009, Iverson et al., 1997), present a great challenge from climate change to biological conservation in the region: changes in precipitation, temperature, and associated fire regimes will lead to a decline in tree species richness that may translate to a widespread decline in overall plant and ecosystem diversity.

The projected replacement of dominant oak and hickory species by maple species in the CHR would have profound ecological and economic impacts (Nowacki \& Abrams, 2008). The shift in tree dominance will alter fundamental ecosystem processes, as litter inputs and chemistry, 
throughfall quantity and quality, and soil nutrient cycling change in response to species replacement. Within forest soils, dominant tree species influence soil processes and nutrient cycling through their influence on microbial communities, litter quantity and quality, and direct weathering of soil minerals (Lambers et al., 2009). The different soil symbiotic mycorrhizal fungi that form obligate associations with tree roots control many of these processes. Oaks and hickories form symbioses with ectomycorrhizal (ECM) fungi, whereas maples form arbuscular mycorrhizal (AM) associations. These associations differ extensively in their influences on soil nutrient cycling and scavenging processes (Phillips et al., 2013), and these activities influence leaf litter quality and subsequent decomposition (Cornelissen et al., 2001, Hobbie et al., 2006). In the current case, oaks and their associated ECM fungi produce litter with high $\mathrm{C}: \mathrm{N}$ ratio and low calcium $(\mathrm{Ca})$ availability, which limits decomposition by soil microbes and invertebrates (Fox et al., 2010, Hobbie et al., 2006). In contrast, litter in sugar maple-influenced stands exhibits low $\mathrm{C}: \mathrm{N}$ ratios and elevated $\mathrm{Ca}$ availability in soils relative to many other $\mathrm{CHR}$ species (Dijkstra, 2003, Dijkstra \& Fitzhugh, 2003). This trend in localized N and Ca enrichment may function to enhance decomposition and nitrification, leading to elevated nutrient losses from watersheds draining the CHR (Christ et al., 2002, Piatek et al., 2010).

Fundamental shifts in tree species will alter habitat structure - canopy light, temperature, moisture, and litter and decaying wood - ultimately affecting broader community characteristics (Alexander \& Arthur, 2010, Martin et al., 2011). Soil and arboreal invertebrate communities differ between oak and maple forests (Huebner et al., 2012), and changes from oak to mapledominated communities will affect not only nutrient cycling facilitated by invertebrates but changes in habitat and higher-level trophic interactions within the forest as well, resulting in distribution changes among wildlife dependent on these habitat characteristics (Fox et al., 2010, 
Huebner et al., 2012, Rodewald \& Abrams, 2002, Summerville et al., 2003, Wilhelm, 1991). Oak and hickory are keystone species that provide essential food and habitat for many wildlife species (Fralish, 2004). In the eastern United States, an estimated 44 wildlife species, the majority being birds, are highly dependent on oak and hickory trees, which provide more abundant food resources for wildlife relative to maple due to a higher amount of mast, i.e., nuts, buds, twigs (Fralish, 2004). For most terrestrial species, such as the Southern flying squirrel (Glaucomys volans), projected transition in dominant tree species would lead to declines in habitat availability from the loss of oak/hickory forests. This species' diet consists primarily of nuts and acorns (Helmick et al., 2014, Thomas \& Weigl, 1998), especially in the winter (Saunders, 1998). The transition would also affect avian species, as average abundance of neotropical migrants is higher in oak forests compared to mesic sites (Sierzega \& Eichholz, 2014). However, the response may not be universal, as some species, such as the Kentucky warbler (Oporornis formosus), may instead increase in abundance in more mesic sites. Fire can also influence habitat choices by wildlife. The Indiana bat (Myotis sodalis), a federally-listed endangered species, prefers to roost in hickory trees. However, roosting preferences can change when fire occurs (Johnson et al., 2010). In unburned forests, Indiana bats will roost in hickories, oaks, or maples. When a forest has been burned, however, the Indiana bat prefers to roost in firekilled maples.

In addition to ecological changes accompanying keystone species shifts, climate change and associated changes in tree species composition and productivity will affect the long-term production of timber within the CHR. Such loss of timber production, especially among oak species, would have profound implications for forest management and economic vibrancy in the region. In order to reduce potentially large losses in the future, landowners and managers must 
adapt their management practices to the predicted changes. Alternate harvesting plans or rotation lengths would immediately be called for in response to the emergence of new dominant species (Spittlehouse \& Stewart, 2004). Forest operations must take into account warmer and more variable climates with more frequent fires. Forest industries should prepare for changes in wood quality and size induced by species shifts. The predicted reduction in timber volume could presage a certain degree of transition of employment from traditional timber management and production to the provision of nontimber forest products, especially forest farming that produces high-value specialty crops for culinary and medicinal purposes, such as mushrooms and ginseng (http://nac.unl.edu/practices/forestfarming.htm, accessed September 15, 2015). As a result, the regional economy would likely be impacted significantly. Natural resource policies that promote active adaptation and risk management are thus in urgent need for this region. It remains a subject of debate if fire intervention and suppression is cost-effective and ecologically beneficial (Hand et al., 2015), therefore caution must be used when making policy recommendations regarding wildland fire management.

The success of forest migration, or management plans to mitigate climate change impacts on forested ecosystems, will depend not only on tree species' capacity to move geographically but also on the suitability of soils and soil microbial communities for invasion. In the current study, the large change in MFI frequency within the CHR may potentially be constrained by edaphic factors existing throughout this region. Maples have greater Ca requirement/demand than oaks and soil $\mathrm{Ca}$ is typically higher in soils associated with sugar maple (Christ et al., 2002, Dijkstra \& Fitzhugh, 2003). Soil acidification in the eastern regions of the CHR over the past half century has compromised the capacity of these areas to sustain sugar maple (Elias et al., 2009, Fenn et al., 2006, St. Clair et al., 2008). Areas further west may be less impacted 
(Huntington, 2000), and the capacity of sugar maple to thrive throughout the CHR may depend on the soil base status of potentially invaded sites. Finally, differences in the reproductive systems between the ECM fungi and AM fungi may also limit the migration capacity of maple (Wilkinson 1998). Thus, the health and function of a future forest will depend on soil chemical and microbiological factors needed to support migrating species establishment within these evolving systems.

The CSMatrix model, like all other empirical models, has its inherent limitations, and our results should be interpreted in an appropriate context. In this study, we used the variance of temperature and precipitation across space as a surrogate for the temporal variance in climatic conditions to analyze the effects of climate change on CHR forests. Therefore, there would be an extrapolation bias should future climatic conditions move beyond the range of temperatures and precipitation used herein (see Supplemental Information, Table A2). Because the estimated future climatic conditions over the next 90 years largely match the current range, our 90-year simulation is minimally affected by the extrapolation bias. However, any long-term projection results beyond 90 years using the CSMatrix model should be interpreted with caution. Although the CSMatrix model did not account for other natural disturbances except for wildfire, our results offer a striking illustration of forest population dynamics under climate change and associated change of fire regimes, and may be of unprecedented value to policy making in the United States as well as many ongoing and upcoming ecological studies.

\subsection{Conclusion}

In summary, we developed a Climate-Sensitive Matrix model to estimate forest dynamics as a function of climate, fire disturbance, and shifting forest population structures in diverse ecosystems for the CHR of the U.S. Under four IPCC climate change scenarios and 
accompanying alterations of fire regimes, we projected that the total stand basal area would decline dramatically by approximately $60 \%$ over the first 70 years, and converge to around 14.9 $\mathrm{m}^{2} \mathrm{ha}^{-1}$ for RCP2.6, followed by $14.2 \mathrm{~m}^{2} \mathrm{ha}^{-1}$ for RCP4.5, $14.0 \mathrm{~m}^{2} \mathrm{ha}^{-1}$ for RCP6.0, and the lowest $13.0 \mathrm{~m}^{2} \mathrm{ha}^{-1}$ for RCP8.5. Similarly, total stand volume had a steep decline during the first 50 years and, despite some fluctuations, converged to $330 \mathrm{~m}^{3} \mathrm{ha}^{-1}$ for RCP2.6, followed by 313 $\mathrm{m}^{3} \mathrm{ha}^{-1}$ for RCP4.5, $310 \mathrm{~m}^{3} \mathrm{ha}^{-1}$ for RCP6.0, and $308 \mathrm{~m}^{3} \mathrm{ha}^{-1}$ for RCP8.5. Tree size diversity increased by 27.9 - $30.6 \%$ over the first 20 years, and then decreased to a level similar to the present. In contrast, tree species diversity would gradually decline by $9.6-11.5 \%$ over the next 90 years. These changes in forest structure within the CHR will have regional ecological and economic repercussions. Changes in diversity favoring maples will alter ecosystem processing of nutrients and subsequent nutrient flows to drainage waters within the region. Habitat change will alter the broad spectrum of organisms relying on the forest, with concomitant changes in ecosystem-wide biodiversity. Finally, changes in species composition, stocking, and productivity of CHR forests will reduce the direct and indirect economic benefits generated by timber in the CHR. One uncertainty to these projections is the capacity of soil chemical and microbiological factors needed to support migrating forest tree species establishment within these evolving ecosystems. Such preferences and influences may function to structure communities in new unforeseen ways and may further influence forest ecosystem development under future climate regimes.

The challenge to traditional forestry as well as to the economy brought upon by climate change is by no means unique to the CHR. Globally, changes have been observed or predicted. Response to the expected changes and associated risks summons actions from both private and public sectors. Landowners and managers need to adjust and adapt their practices while public 
policies must promote and facilitate such adjustments and adaptations in order to sustain both the forests and their related ecosystem services in the future.

\section{Acknowledgement}

This study is supported in parts by the Davis College of Agriculture, Natural Resources \&

Design, West Virginia University, under the US Department of Agriculture (USDA) McIntire-

Stennis Funds WVA00105. We thank the USDA Forest Service for providing FIA data, and J.

Shanmugasundaram for assisting with climatic analysis. 


\section{References}

Aber J, Neilson RP, Mcnulty S, Lenihan JM, Bachelet D, Drapek RJ (2001) Forest processes and global environmental change: predicting the effects of individual and multiple stressors. BioScience, 51, 735-751.

Albrecht MA, Mccarthy BC (2006) Effects of prescribed fire and thinning on tree recruitment patterns in central hardwood forests. Forest Ecology and Management, 226, 88-103.

Alexander HD, Arthur MA (2010) Implications of a predicted shift from upland oaks to red maple on forest hydrology and nutrient availability. Canadian Journal of Forest Research, 40, 716-726.

Allen CD, Macalady AK, Chenchouni H et al. (2010) A global overview of drought and heatinduced tree mortality reveals emerging climate change risks for forests. Forest Ecology and Management, 259, 660-684.

Bailey RG (2004) Identifying ecoregion boundaries. Environmental Management, 34, S14-S26.

Bernhardt ES, Palmer MA (2011) The environmental costs of mountaintop mining valley fill operations for aquatic ecosystems of the Central Appalachians. Annals of the New York Academy of Sciences, 1223, 39-57.

Boisvenue C, Running SW (2006) Impacts of climate change on natural forest productivity evidence since the middle of the 20th century. Global Change Biology, 12, 862-882.

Bos E, Vu M, Massiah E, Bulatao R (1994) World population projections 1994-95: estimates and projections with related demographic statistics. New York: Johns Hopkins University Press.

Box EO, Fujiwara K (2015) Warm-temperate deciduous forests around the northern hemisphere, Springer. 
Brooks JR (2012) Central Appalachian hardwood whole stand growth and yield models. Unpublished manuscript, Appalachian Hardwood Forest Research Alliance Technical Report.

Brooks JR, Miller GW (2011) An evaluation of three growth and yield simulators for even-aged hardwood forests of the mid-Appalachian region. In: Proceedings of the 17th Central Hardwood Forest Conference GTR-NRS-P, 78, 23 p.

Brose PH, Dey DC, Phillips RJ, Waldrop TA (2013) A meta-analysis of the fire-oak hypothesis: does prescribed burning promote oak reproduction in eastern North America? Forest Science, 59, 322-334.

Bush RR (1995) Northeast (NE) variant overview: forest vegetation simulator. Washington, DC: U.S. Department of Agriculture, Forest Service, 37 p.

Cardinale BJ, Duffy JE, Gonzalez A et al. (2012) Biodiversity loss and its impact on humanity. Nature, 486, 59-67.

Caswell H (2001) Matrix population models. John Wiley \& Sons, Ltd.

Chevan A, Sutherland M (1991) Hierarchical partitioning. American Statistician, 45, 90-96.

Christ MJ, Peterjohn WT, Cumming JR, Adams MB (2002) Nitrification potentials and landscape, soil and vegetation characteristics in two Central Appalachian watersheds differing in $\mathrm{NO}_{3}{ }^{-}$export. Forest Ecology and Management, 159, 145-158.

Colbert JJ, Racin G (1995) User's guide to the stand damage model: a component of the gypsy moth life system model (Version 1.1). General Technical Report NE-207. Radnor, PA: U.S. Department of Agriculture, Forest Service, Northeastern Forest Experiment Station, $38 \mathrm{p}$. 
Cornelissen J, Aerts R, Cerabolini B, Werger M, Van Der Heijden M (2001) Carbon cycling traits of plant species are linked with mycorrhizal strategy. Oecologia, 129, 611-619.

Daly C, Halbleib M, Smith JI et al. (2008) Physiographically sensitive mapping of climatological temperature and precipitation across the conterminous United States. International Journal of Climatology, 28, 2031-2064.

Dijkstra FA (2003) Calcium mineralization in the forest floor and surface soil beneath different tree species in the northeastern US. Forest Ecology and Management, 175, 185-194.

Dijkstra FA, Fitzhugh RD (2003) Aluminum solubility and mobility in relation to organic carbon in surface soils affected by six tree species of the northeastern United States. Geoderma, 114, 33-47.

Elias PE, Burger J, Adams M (2009) Acid deposition effects on forest composition and growth on the Monongahela National Forest, West Virginia. Forest Ecology and Management, 258, 2175-2182.

Fenn ME, Huntington T, Mclaughlin S, Eagar C, Gomez A, Cook R (2006) Status of soil acidification in North America. Journal of Forest Science, 52, 3-13.

Fieberg J, Ellner SP (2001) Stochastic matrix models for conservation and management: a comparative review of methods. Ecology Letters, 4, 244-266.

Fischer A, Marshall P, Camp A (2013) Disturbances in deciduous temperate forest ecosystems of the northern hemisphere: their effects on both recent and future forest development. Biodiversity and Conservation, 22, 1863-1893.

Foster DR (2000) From bobolinks to bears: interjecting geographical history into ecological studies, environmental interpretation, and conservation planning. Journal of Biogeography, 27, 27-30. 
Fox VL, Buehler CP, Byers CM, Drake SE (2010) Forest composition, leaf litter, and songbird communities in oak-vs. maple-dominated forests in the eastern United States. Forest Ecology and Management, 259, 2426-2432.

Fortin M, Langevin L (2012) Stochastic or deterministic single-tree models: is there any difference in growth predictions?. Annals of Forest Science, 69, 271-282.

Fralish JS (2004) The keystone role of oak and hickory in the central hardwood forest. In: Spetich, M.A. (ed) Upland oak ecology symposium: history, current conditions, and sustainability. General Technical Reports. SRS-73. Asheville, NC pp. 78-87.

Fralish JS, Mcardle TG (2009) Forest dynamics across three century-length disturbance regimes in the Illinois Ozark Hills. The American Midland Naturalist, 162, 418-449.

Guyette RP, Stambaugh MC, Dey DC (2010) Developing and using fire scar histories in the southern and eastern United States. Joint Fire Science Program Final Report, web site: www.firescience.gov.

Hann W, Shlisky A, Havlina D et al. (2004) Interagency fire regime condition class guidebook. Last update October 2007: Version 1.3. [Homepage of the Interagency and The Nature Conservancy fire regime condition class website, USDA Forest Service, U.S. Department of the Interior, The Nature Conservancy, and Systems for Environmental Management]. [Online]. Available: www.frcc.gov.

Hansen A, Dale V (2001) Biodiversity in US forests under global climate change. Ecosystems, 4, 161-163.

Hansen AJ, Neilson RP, Dale VH, Flather C, Iverson L, Currie DJ, Bartlein P (2001) Global change in forests: responses of species, communities, and biomes. BioScience, 51, 765779. 
Hand MS, Wibbenmeyer MJ, Calkin DE, Thompson MP (2015) Risk preferences, probability weighting, and strategy tradeoffs in wildfire management. Risk Analysis, 35, 1876-1891.

He HS, Wang WJ, Fraser JS, Shifley SR, Larsen DR (2012) LANDIS: a spatially explicit model of forest landscape disturbance, management, and succession. LANDIS PRO 7.0 USERS GUIDE.

Helmick KR, Barrett TL, Barrett GW (2014) Dietary resource preference of the Southern flying squirrel (Glaucomys volans). The American Midland Naturalist, 171, 371-374.

Hicks RR (1998) Ecology and management of central hardwood forests, John Wiley \& Sons.

Hilt DE (1985) OAKSIM: an individual-tree growth and yield simulator for managed, even-aged, upland oak stands. Reserch Paper. NE-562. Broomall, PA: U.S. Department of Agriculture, Forest Service, Northeastern Forest Experiment Station, 21 p.

Hobbie SE, Reich PB, Oleksyn J, Ogdahl M, Zytkowiak R, Hale C, Karolewski P (2006) Tree species effects on decomposition and forest floor dynamics in a common garden. Ecology, 87, 2288-2297.

Huebner K, Lindo Z, Lechowicz M (2012) Post-fire succession of collembolan communities in a northern hardwood forest. European Journal of Soil Biology, 48, 59-65.

Huntington TG (2000) The potential for calcium depletion in forest ecosystems of southeastern United States: review and analysis. Global Biogeochemical Cycles, 14, 623-638.

Blyth W, Yang M, Bradley R (2007) Climate policy uncertainty and investment risk. OECD Publishing.

IPCC (2013) Summary for policymakers. In: climate change 2013: the physical science basis. Contribution of Working Group I to the Fifth Assessment Report of the Intergovernmental 
Panel on Climate Change Cambridge University Press, Cambridge, United Kingdom and New York, NY, USA.

Iverson LR, Dale ME, Scott CT, Prasad A (1997) A GIS-derived integrated moisture index to predict forest composition and productivity of Ohio forests (USA). Landscape Ecology, 12, 331-348.

Iverson LR, Prasad AM (2001) Potential changes in tree species richness and forest community types following climate change. Ecosystems, 4, 186-199.

Johnson JB, Ford WM, Rodrigue JL, Edwards JW, Johnson CM (2010) Roost selection by male Indiana myotis following forest fires in central Appalachian hardwoods forests. Journal of Fish and Wildife Management, 1, 111-121.

Juday GP, Barber VA, Duffy P et al. (2005) Forests, land management, and agriculture. In: Arctic Climate Impact Assessment. (eds Symon C, Arris L, Heal B) pp. 781-862. New York, NY, Cambridge University Press.

Jiang Y, Zhuang Q, Mandallaz D (2012) Modeling large fire frequency and burned area in Canadian terrestrial ecosystems with Poisson models. Environmental Modeling \& Assessment, 17, 483-493.

Keane RE, Parsons R, Hessburg P (2002) Estimating historical range and variation of landscape patch dynamics: limitations of the simulation approach. Ecological Modeling, 151, 29-49.

Lafon CW, Hoss JA, Grissino-Mayer HD (2005) The contemporary fire regime of the central Appalachian Mountains and its relation to climate. Physical Geography, 26, 126-146.

Lambers H, Mougel C, Jaillard B, Hinsinger P (2009) Plant-microbe-soil interactions in the rhizosphere: an evolutionary perspective. Plant and Soil, 321, 83-115. 
Latta G, Temesgen H, Adams D, Barrett T (2010) Analysis of potential impacts of climate change on forests of the United States Pacific Northwest. Forest Ecology and Management, 259, 720-729.

Leslie PH (1945) The use of matrices in certain population mathematics. Biometrika, 33, 183212.

Lewis EG (1942) On the generation and growth of a population. Sankhya, 6, 93-96.

Liang J, Picard N (2013) Matrix model of forest dynamics: an overview and outlook. Forest Science, 59, 359-378.

Liang J, Zhou M, Tobin PC, Mcguire AD, Reich PB (2015) Biodiversity influences plant productivity through niche-efficiency. Proceedings of the National Academy of Sciences, 112, 5738-5743.

Liang J, Zhou M, Verbyla D, Zhang L, Springsteen AL, Malone T (2011) Mapping forest dynamics under climate change: a matrix model. Forest Ecology and Management, 262, 2250-2262.

Lin CR, Buongiorno J, Prestemon J, Skog K (1998) Growth model for uneven-aged loblolly pine stands. USDA. Forest Service Reserch Paper. FPL-RP-569. Madison.

Lindner M, Maroschek M, Netherer S et al. (2010) Climate change impacts, adaptive capacity, and vulnerability of European forest ecosystems. Forest Ecology and Management, 259, 698-709.

Mac Nally R (2000) Regression and model-building in conservation biology, biogeography and ecology: the distinction between-and reconciliation of-'predictive' and 'explanatory' models. Biodiversity and Conservation, 9, 655-671. 
Mac Nally R, Walsh C (2004) Hierarchical partitioning public-domain software. Biodiversity Conservation, 13, 659-660.

Marquis DA, Ernst RL (1992) User's guide to SILVAH: stand analysis, prescription, and management simulator program for hardwood stands of the Alleghenies. General Technical Report. NE-162. Radnor, PA: U.S. Department of Agriculture, Forest Service, Northeastern Forest Experiment Station, 124 p.

Martin KL, Hix DM, Goebel PC (2011) Coupling of vegetation layers and environmental influences in a mature, second-growth central hardwood forest landscape. Forest Ecology and Management, 261, 720-729.

Mcewan RW, Dyer JM, Pederson N (2011) Multiple interacting ecosystem drivers: toward an encompassing hypothesis of oak forest dynamics across eastern North America. Ecography, 34, 244-256.

Mcewan RW, Hutchinson TF, Long RP, Ford DR, Mccarthy BC (2007) Temporal and spatial patterns in fire occurrence during the establishment of mixed-oak forests in eastern North America. Journal of Vegetation Science, 18, 655-664.

Melillo JM, Richmond TC, Yohe GW (2014) Climate change impacts in the United States: the third national climate assessment. US Global Change Research Program, 841.

Morgan P, Hardy CC, Swetnam TW, Rollins MG, Long DG (2001) Mapping fire regimes across time and space: understanding coarse and fine-scale fire patterns. International Journal of Wildland Fire, 10, 329-342.

Mueller RF (1996) Biodiversity: central Appalachian plant distributions and forest types. Wild Earth, 6, 37-43. 
Naeem S, Duffy JE, Zavaleta E (2012) The functions of biological diversity in an age of extinction. Science, 336, 1401-1406.

Nowacki GJ, Abrams MD (2008) The demise of fire and "mesophication" of forests in the eastern United States. Bioscience, 58, 123-138.

Parisen MA, Moritz MA (2009) Environmental controls on the distribution of wildfire at multiple spatial scales. Ecological Monographs, 79, 127-154.

Perkey AW (1985) GROAK (Grow OAK) on a computer. Northern Journal of Applied Forestry, 2, 99-100.

Phillips RP, Brzostek E, Midgley MG (2013) The mycorrhizal-associated nutrient economy: a new framework for predicting carbon-nutrient couplings in temperate forests. New Phytologist, 199, 41-51.

Piatek KB, Munasinghe P, Peterjohn WT, Adams MB, Cumming JR (2010) A decrease in oak litter mass changes nutrient dynamics in the litter layer of a Central Hardwood Forest. Northern Journal of Applied Forestry, 27, 97-104.

Pretzsch H, Biber P, Schütze G, Uhl E, Rötzer T (2014) Forest stand growth dynamics in Central Europe have accelerated since 1870. Nature Communications, 5.

Rodewald AD, Abrams MD (2002) Floristics and avian community structure: implications for regional changes in eastern forest composition. Forest Science, 48, 267-272.

Ruffner CM (2005) Understanding the evidence for historical fire across eastern forests. Fire in Eastern Oak Forests: Delivering Science to Land Managers. Proceedings of a Conference. GTR-NRS-P-1.

Saunders DA (1998) Adirondack mountains. State University of New York, College of Environmental Science and Forestry, $216 \mathrm{p}$. 
Schmidt TL, Mcwilliams WH (2003) Shifts and future trends in the forest resources of the Central Hardwood region.United Sates Department of Agriculture Forest Service General Technical Report NC, pp 21-31.

Schoene DHF, Bernier PY (2012) Adapting forestry and forests to climate change: A challenge to change the paradigm. Forest Policy and Economics, 24, 12-19.

Schuler TM, Thomas-Van Gundy M, Adams MB, Ford WM (2012) Analysis of two preshelterwood prescribed fires in a mesic mixed-oak forest in West Virginia. In: Proceedings of the 18th Central Hardwood Forest Conference. pp 26-28.

Schulte BJ, Buongiorno J (2004) A growth and yield model for naturally-regenerated mixed shortleaf pine forests in the southern United States of America. International Forestry Review, 6, 19-29.

Sharon W, Barbara L, Barbara M et al. (2011) The forest inventory and analysis database: database description and users manual version 5.1 for phase 2 .

Shugart H, Sedjo R, Sohngen B (2003) Forests and global climate change: potential impacts on U.S. forest resources. Pew Center on Global Climate Change, Arlington, Virginia. 52 p.

Sierzega KP, Kevin P, Eichholz MW (2014) Factors influencing avian habitat selection between oak-hickory and mesic forests in southern Illinois. In: Proceedings of the 19th Central Hardwood Forest Conference, Groninger, John W., Holzmueller, Eric J, Nielsen, Clayton K., Dey, Daniel C., eds. pp 102-103.

Signell SA, Abrams MD, Hovis JC, Henry SW (2005) Impact of multiple fires on stand structure and tree regeneration in central Appalachian oak forests. Forest Ecology and Management, 218, 146-158. 
Smith TM, Halpin PN, Shugart HH, Secrett CM (1995) 6 Global forests. In: As climate changes: international impacts and implications. (eds Strzepek KM, Smith JB) 146 p. Cambridge, UK, Cambridge University Press.

Spittlehouse DL, Stewart RB (2004) Adaptation to climate change in forest management. Journal of Ecosystems and Management, 4, 1-11.

St. Clair SB, Sharpe WE, Lynch JP (2008) Key interactions between nutrient limitation and climatic factors in temperate forests: a synthesis of the sugar maple literature. Canadian Journal of Forest Research, 38, 401-414.

Summerville KS, Crist TO, Kahn JK, Gering JC (2003) Community structure of arboreal caterpillars within and among four tree species of the eastern deciduous forest. Ecological Entomology, 28, 747-757.

Thomas RB, Weigl PD (1998) Dynamic foraging behavior in the southern flying squirrel (Glaucomys volans): test of a model. The American Midland Naturalist, 140, 264-270.

Tilman D, Lehman CL, Thomson KT (1997) Plant diversity and ecosystem productivity: theoretical considerations. Proceedings of the National Academy of Sciences, 94, 18571861.

Van der Sleen P, Groenendijk P, Vlam M, Anten NP, Boom A, Bongers F, Pons TL, Terburg G, Zuidema PA (2014) No growth stimulation of tropical trees by 150 years of CO2 fertilization but water-use efficiency increased. Nature Geoscience, 8, 24-28.

Wang WJ, He HS, Fraser JS, Iii FRT, Shifley SR, Spetich MA (2014) LANDIS PRO: a landscape model that predicts forest composition and structure changes at regional scales. Ecography, 37, 226-230 
Westerling AL, Hidalgo HG, Cayan DR, Swetnam TW (2006) Warming and earlier spring increase western U.S forest wildfire activity. Science, 313, 940-943.

Wilhelm GS (1991) Implications of changes in floristic composition of the Morton Arboretum's East Woods. In: Proceedings of the Oak Woods Management Workshop. Eastern Illinois University, Charleston. pp 31-54.

Wooldridge JM (2012) Introductory econometrics: a modern approach. Cengage Learning.

Zenner EK (2005) Development of tree size distributions in Douglas-fir forests under differing disturbance regimes. Ecological Applications, 15, 701-714.

Zhou M, Buongiorno J (2004) Nonlinearity and noise interaction in a model of forest growth. Ecological Modelling, 180, 291-304.

Zhou M, Buongiorno J (2006) Forest landscape management in a stochastic environment, with an application to mixed loblolly pine-hardwood forests. Forest Ecology and Management, 223, 170-182. 


\section{Assessments of management impacts on central hardwood forests under climate and fire uncertainty *}

\footnotetext{
${ }^{*}$ This chapter is under review in Forest Science with coauthor M. Zhou.
} 


\section{Abstract}

Central hardwood forests, in the absence of management, are predicted to undergo a species shift and decline in stocks due to climate change and increased fire frequencies. Here we quantified how various management intensities would influence these forests in terms of the net present value (NPV) of harvests, tree species and size diversity, and carbon stocks in four pools: aboveground biomass, fine roots, dead organic matters, and soil. Predictions were based on simulations of forest growth under uncertain fire and subject to low (20\%), medium (50\%), and high (80\%) management intensities in four IPCC future climate scenarios RCP2.6, 4.5, 6.0, and 8.5 from 2010 to 2100. Partial, diameter-limit, and diameter-cap harvesting practices were assessed with harvesting cycles of 10 and 20 years, respectively. The major findings are: low intensity (20\%) management would cause the highest carbon stock and size diversity, but the lowest NPV and species diversity; medium intensity (50\%) management would lead to a lower carbon stock, but produce satisfactory levels of species diversity, size diversity, and NPV; high intensity (80\%) management would result in the lowest carbon stock and size diversity, but the highest NPV and species diversity. The NPV of harvests with a 10-year harvesting cycle was more than twice of that with 20 years, yet the total carbon stock was only $1.3 \%-5.0 \%$ lower. An uncertainty analysis with fuzzy sets shows that when considering uncertain climate and fire, the NPV, size diversity, and total carbon stock would be distinctively different in climate scenarios RCP2.6 and RCP8.5 with high certainty. However, for species diversity, similar climatic effects on species diversity may exist across most management regimes. 


\section{Introduction}

Drastic changes have been predicted to take place in forests around the globe due to a warmer climate and shortened fire intervals (Bowman et al. 2009). A recent study by Ma et al. (2016) forecasts that, in the U.S. Central Hardwood Region (CHR), the dominant species would shift from oaks to maples and the total forest stock would decline considerably in the absence of management. It is naturally of great interest to assess how forest management will affect the economic viability and ecosystem services of these forests.

In the CHR, partial harvesting is the dominant form of timber management (Fajvan et al. 1998) and is recognized for its importance in mimicking the typical outcome of natural disturbances in the region (Franklin et al. 2007; Palik et al. 2002): frequent small-scale canopy gaps rather than stand replacement (Seymour et al. 2002). Biodiversity and ecosystem resiliency are affected as tree species are selectively removed during repeated partial harvesting (Schuler 2004), but quantifications of such impacts are lacking. Long deemed as a poor silvicultural practice in the CHR (Nyland 1992), selective harvesting removing only large-diameter trees, i.e., diameter-limit harvesting, degrades forest yields in the long run (Nyland 1996) and may result in patchy and reduced regeneration and increased abundance of less desirable shade-tolerant species such as sugar maple and red maple (Fajvan 2006; Schuler and Gillespie 2000; Smith and Miller 1987), reduced growth of desired residuals trees (Schuler 2004; Trimble 1971), and irregular yields with lower volume production (Nyland 2005).

It is an increasingly important goal of forest management to maintain biological diversity, genetic makeup, the variations in life forms, ecological niches, and biological process in a given area (Oliver, 1992). Moreover, management impacts on forest carbon stocks are of high interest for they are a crucial component of global carbon cycles. Worldwide, abundant studies have 
assessed how these carbon stocks can be influenced by forest management through varying regimes and intensities (Nilsen and Strand 2008; Ruiz-Peinado et al. 2013). For example, forest management modifies the structure and density of forest stands and consequently affects aboveground biomass (Ruiz-Peinado et al. 2013). It could also alter soil temperature and moisture conditions, and cause a decrease of soil carbon inputs followed by a reduction in litter fall rates (Roig et al. 2005; Vesterdal et al. 1995). But there is also plenty of evidence suggesting that soil organic carbon is more resistant to changes in forest management and disturbances than the carbon stored in living trees (Bradford et al. 2008; Peichl and Arain 2006). Most researchers have reported that only a small, temporal reduction in soil organic carbon occurs after harvesting (Nave et al. 2010; Peltoniemi et al. 2004; Yanai et al. 2000). Nonetheless, without quantification of these effects for this particular region, it is ambiguous whether forest management could lead to increased or decreased total carbon stocks in such ecosystems over a long time period. In addition, little information is available as to how forest ecosystems might respond to different harvesting intensities and strategies, making informed management and policymaking difficult (Zenner et al. 2013).

The primary objective of this study was to quantify how management of various harvesting intensities would influence the financial returns, tree diversity, and forest carbon stocks in the CHR when the fire regimes were expected to be changed by climate change. Based on a climate-sensitive matrix model and volume equations developed from the Forest Inventory and Analysis (FIA) database, a soil carbon model (YASSO07), and a mean fire interval (MFI) model, this work aimed at assessing the economic and ecological performances of the partial, diameter-limit, and diameter-cap harvesting regimes in terms of the net present value (NPV), tree species and size diversity, and carbon stocks under four IPCC RCP climate scenarios. In addition, 
I also explored two regimes addressing the species shift in the CHR. Two harvesting cycles were used, respectively, 10 and 20 years. Fuzzy sets were adopted to represent variability in predictions caused by uncertain fire and climate. 


\subsection{Materials and methods}

\subsubsection{Data}

The growth model and volume equations to predict forest dynamics and yield were built based on the Forest Inventory and Analysis (FIA) database (Sharon et al. 2011) with a total of 6,303 Permanent sample plots (PSPs) in the CHR forests of the United States, 5,196 of which were used for model calibration, and the rest for validation and prediction. There exist over 100 tree species in the region, thus they were categorized into seven groups: white oak (Quercus Quercus, QQ), red oak (Quercus - Lobatae, QL), Juglandaceae (JD), Sapindaceae (SD), Gymnosperms (GS), Fagus (FG), and Other species (OA). Within each species group, all trees were further grouped into seventeen diameter classes, except for the first class $(2.54-7 \mathrm{~cm})$ and the last class (82 cm and above), all the other classes were $5 \mathrm{~cm}$ increments (Ma et al. 2016).

In order to analyze the financial returns, the stumpage price data from 1989 to 2016 was retrieved from the West Virginia Timber Market Report (WVTMR, available online at http://ahc.caf.wvu.edu/ahc-resources-mainmenu-45/timber-market-report-mainmenu-62, last accessed May 10, 2016), adjusted for inflation by using Consumer Price Index (base year=2015), and the average was taken over the period for each individual price series. Four species groups in this study, QQ, QL, JD and OA, corresponded to the species definitions used by WVTMR and no adjustment of prices was needed for them. The average price of hard and soft maple reported by WVTMR was taken to represent the price of SD, $87.5 \%$ of white oak price to GS, and $50 \%$ of white oak to FG. Three commercial sizes were defined: poles (1-6 diameter classes), small sawtimber (7-12), and large sawtimber (13-17) (Miller et al., 1995, Miller et al., 1997). The 
method in Miller et al. (1997) was further used to modify all priced to these commercial sizes. The adjusted stumpage price of each species group and commercial size is shown in table 3-1.

Table 3-1 Adjusted real average stumpage prices $\left(\$ m^{-3}\right)($ base year=2015) for three commercial sizes and seven species groups.

\begin{tabular}{llll}
\hline $\begin{array}{l}\text { Species } \\
\text { group }\end{array}$ & \multicolumn{3}{c}{ Commercial size $\left(\$ \mathrm{~m}^{-3}\right)$} \\
\cline { 2 - 4 } & Pole & $\begin{array}{l}\text { Small } \\
\text { sawtimber }\end{array}$ & $\begin{array}{l}\text { Large } \\
\text { sawtimber }\end{array}$ \\
\cline { 2 - 4 } QQ & 50 & 80 & 110 \\
QL & 60 & 90 & 120 \\
JD & 30 & 40 & 50 \\
SD & 90 & 120 & 150 \\
GS & 40 & 70 & 100 \\
FG & 20 & 40 & 60 \\
OA & 40 & 60 & 80 \\
\hline
\end{tabular}

${ }^{*}$ QQ: Quercus-Quercus (white oak species), QL: Quercus-Lobatae (red oak species), JD: Juglandaceae (Hickory), SD: Sapindaceae (maple family), GS: Gymnosperms (Softwoods), FG: Fagus (American beech), OA: Other Angiosperms (other species).

In order to predict future climatic changes in the CHR, the future relative changes (trend ratio) over the region were extracted for the four climate scenarios (RCP2.6, RCP4.5, RCP6.0, RCP8.5) of the IPCC AR5 report (Blyth et al. 2007). The trend ratios of temperature and precipitation were obtained from the KNMI Climate Change Atlas (Available online at http://climexp.knmi.nl/, last accessed 10-August-2015). Then the historical temperature and precipitation were multiplied by the future trend ratios to estimate the future climate at the validation plots during 2010-2100. Assuming a constant CHR-nationwide population ratio, spatial- specific future population density across the region was estimated from the current CHR population density and the overall population trend in the United States in year 2000 for 2025 , 2050, 2075, and 2100 (Bos et al. 1994). For detailed estimations of future temperature, precipitation, and population density, see Ma et al. (2016). 


\subsubsection{Predicting Forest Dynamics under Climate Change}

A Climate-Sensitive Matrix (CSMatrix) model controls for temperature $(T)$ and precipitation $(P)$ on tree growth, mortality and recruitment as follows (Ma et al. 2016):

$\mathbf{y}_{t+1}=\mathbf{G}_{t}(T, P) \cdot \mathbf{y}_{t}+\mathbf{R}_{t}(T, P)+\varepsilon$

in which $\boldsymbol{G}_{t}$ is the growth matrix describing transition of trees between size classes as well as mortality. See Table B1 in the appendix for a complete list of variables.

The diameter growth of the $k^{\text {th }}$ tree of species $i$ and size class $j$ from $t$ and $t+l$ is represented by the following model:

$b_{i j k k}=\alpha_{i 1}+\alpha_{i 2} D_{t k}+\alpha_{i 3} D_{t k}{ }^{2}+\alpha_{i 4} B+\alpha_{i 5} C+\alpha_{i 6} E+\alpha_{i 7} S+\alpha_{i 8} H_{d}+\alpha_{i 9} H_{s}+\alpha_{i 10} T+\alpha_{i 11} P+\varepsilon_{i j}$

Tree mortality, $m_{i j t}$, was a Probit function:

$m_{i j t k}=\Phi\left(\delta_{i 1}+\delta_{i 2} D_{t k}+\delta_{i 3} D_{t k}{ }^{2}+\delta_{i 4} B+\delta_{i 5} C+\delta_{i 6} E+\delta_{i 7} S+\delta_{i 8} H_{d}+\delta_{i 9} H_{s}+\delta_{i 10} T+\delta_{i 11} P\right)+\xi_{i j}$

where $\Phi$ is the standard normal cumulative function.

Recruitment of species $i, R_{i}$ is a Tobit model (Tobin, 1958):

$R_{i t}=\Phi\left(\beta_{i} x_{i t} \sigma_{i}^{-1}\right) \beta_{i} x_{i t}+\sigma_{i} \varphi\left(\beta_{i} x_{i t} \sigma_{i}^{-1}\right)$

with

$\beta_{i} x_{i t}=\beta_{i 1}+\beta_{i 2} N+\beta_{i 3} N^{2}+\beta_{i 4} B+\beta_{i 5} C+\beta_{i 6} E+\beta_{i 7} S+\beta_{i 8} H_{d}+\beta_{i 9} H_{s}+\beta_{i 10} T+\beta_{i 11} P+\mu_{i j}$

where $\Phi$ is the standard normal cumulative distribution function and $\varphi$ is the standard normal probability density function. 


\subsubsection{Simulation of Uncertain Fires}

A mean fire interval (MFI) model developed by Guyette et al. (2010) and specifically designed for eastern and southern U.S. was used to simulate changes in fire frequencies induced by climate change, with the following equation:

$$
M F I=C \cdot e^{-0.139 a+1.50 b-2.41 \cdot c+0.00763 d}
$$

where $\boldsymbol{C}$ is a constant value (59.12) for average-intensity fire models. $a$ is the mean maximum temperature $\left({ }^{\circ} \mathrm{C}\right), b$ is the reciprocal moisture index $\left(1 / \mathrm{cm} /{ }^{\circ} \mathrm{C}\right), c$ is human population density $\left(\right.$ per $\left.\mathrm{km}^{2}\right)$, and $d$ is the mean annual total precipitation $(\mathrm{cm})$.

It is assumed that fire occurrence had an exponential distribution with its probability at time $t$ being $p(t)=1-e^{-t / M F I}$. In the simulations, $p(t)$ was uniformly distributed and drawn from 0 to 1 as a random variable. Thus, the $t$ was calculated with $-\ln (1-p(t)) M F I$. Because fire has various impacts on species and size classes, five fire tolerance classes were designed to reflect differences in impacts on species and five fire susceptibility classes to reflect differences in effects on tree sizes within each species group (For details, see Ma et al. 2016).

\subsubsection{Estimation of Carbon Stocks}

As part of my examinations of the ecological criteria, I quantified carbon storage in four pools in the CHR forests: aboveground biomass, fine roots, dead organic matters, and soil.

The single-stem volume by size and species $\left(v_{i j}\right)$ was represented by the following model:

$$
\ln \left(v_{i, j}+1\right)=\theta_{i 1}+\theta_{i 2} \ln \left(D_{t k}+1\right)+\theta_{i 3} \ln \left(D_{t k}+1\right)^{2}+\theta_{i 4} \ln (B+1)+\theta_{i 5} \ln (C+1)+\omega_{i j}
$$

See Table B2 in the appendix for a complete list of variables and estimated coefficients. The total volume was estimated as the product of the stem volume and the tree density. Tree stem 
biomass was them calculated as the total stand volume multiplied by wood density and $0.5-$ the conversion factor for dry biomass (Birdsey 1992). The models of Jenkins et al. (2003) were applied to determine the biomass of other tree components.

Given no readily available biomass models for fine roots, they were assumed to be forty percent of foliage biomass (Helmisaari et al. 2007). Dead trees and annual litter production were used as input to the dead organic matters pool. Litter production was calculated from biomass using turnover rates in Liski et al. (2006). The initial chemical compositions of different dead matter inputs (Table B3) were obtained from Liski et al. (2009). Since physical size of litter affects decomposition rates (Tuomi et al. 2011a), litter from different tree compartments is added up on the basis of litter size class. For instance, litter from branches and coarse roots are under the fine woody litter size class. Litter size classifications of the seven species groups were shown in table B4. Finally, soil carbon was estimated with the Yasso07 model (Liski et al. 2009; Tuomi et al. 2011a; Tuomi et al. 2011b) which simulates the transitions between acid-soluble, watersoluble, ethanol-soluble, nonsoluble and humus components (AWENH-components and total summing up to 1) of the soil organic matter, as well as the decomposition of each component (Tuomi et al. 2011a).

\subsubsection{Evaluation of Forest Management of Various Intensities}

\section{Economic Criteria}

The economic criteria chosen here was the NPV of harvests over the planning period (2010 to 2100),

$$
N P V=\sum_{t} \frac{v_{i j} x_{t} n p}{(1+r)^{t}}
$$


where $t$ was the harvesting cycle in years, $x_{t}=\left[\mathrm{x}_{\mathrm{ij}}\right] t$, a column vector representing the percentage of trees per unit of land area of species group $i(i=1, \ldots, 7)$ and diameter class $j(j=1, \ldots, 17)$ at time $t, n$ is number of trees, $v_{\mathrm{ij}}$, a row vector in which $v_{i j}$ was the volume of a single tree of species group $i$ and diameter $j . p$ represented the matrix of stumpage prices (Table 3-1), assumed constant over time, and $r$ was the annual interest rate, assumed 3\% here.

\section{Ecological Criteria}

Both species $\left(H_{s}\right)$ and size $\left(H_{d}\right)$ diversity were calculated with Shannon's formulas (Pielou 1977):

$$
H_{s}=-\sum_{i} \frac{B_{i}}{B} \ln \left(\frac{B_{i}}{B}\right) \quad H_{d}=-\sum_{j} \frac{B_{j}}{B} \ln \left(\frac{B_{j}}{B}\right)
$$

where $B_{i}, B_{j}$ and $B$ were, respectively, the basal area of species group $i$, diameter class $j$ and total basal area.

The total carbon stock $(Q)$ was the total of carbon estimated in the aforementioned four pools:

$$
Q=\sum_{z=1}^{4} Q_{z}
$$

\section{Management Regimes Descriptions}

Management regimes of low (20\% of trees removed), medium (50\%), and high (80\%) harvesting intensities and explorative measures adaptive to species shift were described below. harvesting cycles of 10 and 20 years were, respectively, applied to each management regime.

1. Partial harvesting practices: harvesting trees with varying intensities across different diameter classes and species groups;

2. Diameter-limit harvesting: harvesting trees larger than $37 \mathrm{~cm}$ in diameter with varying intensities across different diameter classes and species groups; 
3. Diameter-cap harvesting: harvesting trees smaller than $42 \mathrm{~cm}$ in diameter with varying intensities across different diameter classes and species groups;

4. Adaptive measures: Adaptive1- harvest $50 \%$ of trees smaller than $42 \mathrm{~cm}$ in diameter of QQ and QL, 20\% of trees smaller than $42 \mathrm{~cm}$ of JD, $5 \%$ of trees larger than $37 \mathrm{~cm}$ of SD. Adaptive2 harvest $10 \%$ of trees larger than $37 \mathrm{~cm}$ in diameter of QQ and QL, $5 \%$ of trees larger than $37 \mathrm{~cm}$ of JD, and $80 \%$ of trees smaller than $42 \mathrm{~cm}$ of SD.

\subsubsection{Fuzzy Sets Representing Uncertainty}

Uncertain climate and wild fires led to high variability in predicted values of NPV, tree diversity, and carbon stocks. The averages of these predicted criteria are useful point estimations but to understand the associated risk, ranges or sets indicating uncertainty in predictions are essential. Here I used fuzzy sets which involved defining membership functions that determined the level of uncertainty (Zadeh 1965). A trapezoidal fuzzy set was used, mathematically expressed as f (x; $a, b, c, d)=\max (\min (x-a b-a, 1, d-x d-c), 0) .[b, c]$ represented the certainty interval for which the membership degree is $1 .[a, b)$ and $(c, d]$ were the uncertainty intervals with membership degrees ranging from 0 to 1 . [a, d] was a measure of total range of uncertainty arising from climate change and fire occurrences. Following Weckenmann and Schwan (2001), given the average value of one of the aforementioned criterion $(\bar{X})$ and its relative standard deviation $\left(S_{r}\right)$ from simulations, a, b, c, d values can be constructed as follows:

$$
\begin{aligned}
& \mathrm{b}=\frac{\bar{X}}{1+0.5 \mathrm{~S}_{r}} \\
& \mathrm{c}=\bar{X}\left(1+0.5 \mathrm{~S}_{\mathrm{r}}\right) \\
& \mathrm{a}=\mathrm{b}-\bar{X}\left(\frac{1}{1+0.5 \mathrm{~S}_{r}}-\frac{1}{1+2.5 \mathrm{~S}_{r}}\right) \\
& \mathrm{d}=\mathrm{c}+\bar{X} \cdot 2 \mathrm{~S}_{\mathrm{r}}
\end{aligned}
$$




\subsection{Results}

\subsubsection{Management of Various Intensities}

When both changes of climate and fire regimes were simultaneously accounted for, on average, the climate scenario RCP2.6 resulted in the highest values for NPV, size diversity and total carbon stock under all management intensities, and the highest species diversity under most intensities. In year 2100, in general, the 20-year harvesting cycle led to higher total carbon stock and size diversity but lower NPV and species diversity. Low-intensity management caused the highest total carbon stock (10 years: $823-854$ ton ha ${ }^{-1} ; 20$ years: $864-888$ ton ha $^{-1}$ ) and size diversity (10 years: $1.93-2.11 ; 20$ years: $1.95-2.10)$ but the lowest NPV (10 years: $\$ 9,318-$ $\$ 9,955 \mathrm{ha}^{-1} ; 20$ years: $\left.\$ 3,426-\$ 4,056 \mathrm{ha}^{-1}\right)$ and species diversity (10 years: $1.28-1.31 ; 20$ years: $1.18-1.22)$. Lower total carbon stock (10 years: $778-814$ ton ha ${ }^{-1} ; 20$ years: $800-828$ ton $\mathrm{ha}^{-1}$ ) were expected with medium intensity but satisfactory species diversity (10 years: $1.50-$ 1.53; 20 years: $1.36-1.39)$, size diversity (10 years: $1.47-1.59 ; 20$ years: $1.91-2.02)$, and NPV (10 years: $\$ 18,721-\$ 19,812$ ha $^{-1} ; 20$ years: $\$ 7,749-\$ 9,596$ ha $\left.^{-1}\right)$. High intensity resulted in the lowest total carbon stock $\left(10\right.$ years: $740-775$ ton ha ${ }^{-1} ; 20$ years: $768-794$ ton ha ${ }^{1}$ ) and size diversity (10 years: $0.89-1.02 ; 20$ years: $\left.1.27-1.40\right)$, but the highest NPV (10 years: $\$ 26,749-\$ 27,440 \mathrm{ha}^{-1} ; 20$ years: $\$ 13,302-\$ 13,757 \mathrm{ha}^{-1}$ ) and species diversity (10 years: $1.58-1.61 ; 20$ years: $1.53-1.56)$ (Tables $3-2,3-3,3-4)$.

Diameter-limit and diameter-cap harvesting with low, medium, and high intensities displayed similar trends as partial harvesting practices for NPV of harvests, size diversity, and carbon stocks, while diameter-cap harvesting with high intensity had lower species diversity. The NPV of harvests and species diversity with a 10-year harvesting cycle was more than with 20 
years, but carbon stocks were only $1.3 \%-5.0 \%$ lower. A 10 -year harvesting cycle produced lower size diversity than with a 20-year cycle under most intensities. In addition, soil carbon made up approximately $80 \%$ of total carbon stock and displayed relatively low variability in response to harvesting intensities (Table 3-4).

Table 3-2 Average net present value (\$ ha $\left.{ }^{-1}\right)$ for low, medium, and high intensities of partial harvesting, diameter-limit and diameter-cap harvesting, and two adaptive measures from 2010 to 2100.

\begin{tabular}{lllll}
\hline Management regimes & RCP2.6 & RCP4.5 & RCP6.0 & RCP8.5 \\
\hline Harvesting cycle (10 years) & & & & \\
Partial harvesting (low) & 9,955 & 9,594 & 9,425 & 9,318 \\
Partial harvesting (medium) & 19,812 & 19,361 & 19,018 & 18,721 \\
Partial harvesting (high) & $\mathbf{2 7 , 4 4 0}^{*}$ & $\mathbf{2 7 , 2 3 3}$ & $\mathbf{2 7 , 0 3 4}$ & $\mathbf{2 6 , 7 4 9}$ \\
Diameter-limit (low) & 4,655 & 4,442 & 4,298 & 4,059 \\
Diameter-limit (medium) & 9,738 & 9,461 & 9,290 & 9,058 \\
Diameter-limit (high) & 12,938 & 12,747 & 12,535 & 12,063 \\
Diameter-cap (low) & 7,046 & 6,872 & 6,727 & 6,402 \\
Diameter-cap (medium) & 15,112 & 15,048 & 14,823 & 14,531 \\
Diameter-cap (high) & 21,547 & 21,395 & 21,193 & 20,857 \\
Adaptive1 & 14,762 & 14,212 & 13,964 & 13,714 \\
Adaptive2 & 2,668 & 2,584 & 2,542 & 2,423 \\
Harvesting cycle (20 years) & & & & \\
Partial harvesting (low) & 4,056 & 3,886 & 3,650 & 3,426 \\
Partial harvesting (medium) & 9,596 & 8,926 & 8,354 & 7,749 \\
Partial harvesting (high) & $\mathbf{1 3 , 7 5 7}$ & $\mathbf{1 3 , 5 9 1}$ & $\mathbf{1 3 , 4 9 5}$ & $\mathbf{1 3 , 3 0 2}$ \\
Diameter-limit (low) & 1,960 & 1,887 & 1,854 & 1,763 \\
Diameter-limit (medium) & 4,661 & 4,426 & 4,318 & 4,209 \\
Diameter-limit (high) & 7,444 & 7,318 & 7,255 & 7,110 \\
Diameter-cap (low) & 2,863 & 2,635 & 2,560 & 2,446 \\
Diameter-cap (medium) & 6,524 & 6,191 & 5,985 & 5,722 \\
Diameter-cap (high) & 10,121 & 9,948 & 9,789 & 9,511 \\
Adaptive1 & 6,562 & 6,394 & 6,128 & 5,910 \\
Adaptive2 & 1,017 & 978 & 901 & 815 \\
\hline
\end{tabular}

* Numbers in bold were the highest values among all management regimes. 
Table 3-3 Average tree diversity for low, medium, and high intensities of partial harvesting,

diameter-limit and diameter-cap harvesting, and two adaptive measures in 2100.

\begin{tabular}{|c|c|c|c|c|}
\hline Management regimes & RCP2.6 & RCP4.5 & RCP6.0 & RCP8.5 \\
\hline \multicolumn{5}{|l|}{ Harvesting cycle (10 years) } \\
\hline \multicolumn{5}{|l|}{ Species diversity } \\
\hline Partial harvesting (low) & 1.30 & 1.28 & 1.31 & 1.29 \\
\hline Partial harvesting (medium) & 1.50 & 1.52 & 1.53 & 1.51 \\
\hline Partial harvesting (high) & $1.58 *$ & 1.61 & 1.60 & 1.59 \\
\hline Diameter-limit (low) & 1.12 & 1.14 & 1.15 & 1.14 \\
\hline Diameter-limit (medium) & 1.14 & 1.09 & 1.11 & 1.12 \\
\hline Diameter-limit (high) & 1.17 & 1.15 & 1.16 & 1.20 \\
\hline Diameter-cap (low) & 1.23 & 1.20 & 1.22 & 1.24 \\
\hline Diameter-cap (medium) & 1.21 & 1.19 & 1.21 & 1.22 \\
\hline Diameter-cap (high) & 1.20 & 1.18 & 1.19 & 1.17 \\
\hline Adaptive1 & 1.06 & 1.05 & 1.03 & 1.04 \\
\hline Adaptive2 & 1.33 & 1.31 & 1.30 & 1.28 \\
\hline \multicolumn{5}{|l|}{ Size diversity } \\
\hline Partial harvesting (low) & 2.11 & 2.07 & 2.01 & 1.93 \\
\hline Partial harvesting (medium) & 1.59 & 1.56 & 1.53 & 1.47 \\
\hline Partial harvesting (high) & 1.02 & 0.98 & 0.93 & 0.89 \\
\hline Diameter-limit (low) & 2.17 & 2.12 & 2.08 & 2.04 \\
\hline Diameter-limit (medium) & 1.97 & 1.95 & 1.95 & 1.88 \\
\hline Diameter-limit (high) & 1.84 & 1.81 & 1.77 & 1.69 \\
\hline Diameter-cap (low) & 1.95 & 1.91 & 1.90 & 1.81 \\
\hline Diameter-cap (medium) & 1.54 & 1.50 & 1.50 & 1.42 \\
\hline Diameter-cap (high) & 1.24 & 1.21 & 1.19 & 1.13 \\
\hline Adaptive1 & 2.09 & 2.05 & 2.03 & 1.93 \\
\hline Adaptive2 & 1.80 & 1.79 & 1.75 & 1.63 \\
\hline \multicolumn{5}{|l|}{ Harvesting cycle ( 20 years) } \\
\hline \multicolumn{5}{|l|}{ Species diversity } \\
\hline Partial harvesting (low) & 1.22 & 1.18 & 1.21 & 1.20 \\
\hline Partial harvesting (medium) & 1.36 & 1.37 & 1.38 & 1.39 \\
\hline Partial harvesting (high) & 1.53 & 1.55 & 1.56 & 1.54 \\
\hline Diameter-limit (low) & 1.11 & 1.13 & 1.14 & 1.12 \\
\hline Diameter-limit (medium) & 1.13 & 1.12 & 1.13 & 1.11 \\
\hline Diameter-limit (high) & 1.15 & 1.11 & 1.13 & 1.14 \\
\hline Diameter-cap (low) & 1.19 & 1.17 & 1.18 & 1.16 \\
\hline Diameter-cap (medium) & 1.25 & 1.20 & 1.22 & 1.23 \\
\hline Diameter-cap (high) & 1.14 & 1.11 & 1.13 & 1.21 \\
\hline Adaptive1 & 1.08 & 1.06 & 1.07 & 1.10 \\
\hline Adaptive2 & 1.31 & 1.28 & 1.30 & 1.29 \\
\hline \multicolumn{5}{|l|}{ Size diversity } \\
\hline Partial harvesting (low) & 2.10 & 2.06 & 2.02 & 1.95 \\
\hline Partial harvesting (medium) & 2.02 & 1.99 & 1.96 & 1.91 \\
\hline Partial harvesting (high) & 1.40 & 1.37 & 1.30 & 1.27 \\
\hline Diameter-limit (low) & 2.17 & 2.10 & 2.07 & 2.06 \\
\hline Diameter-limit (medium) & 2.10 & 2.06 & 2.05 & 2.00 \\
\hline Diameter-limit (high) & 1.97 & 1.89 & 1.85 & 1.80 \\
\hline Diameter-cap (low) & 2.06 & 2.01 & 2.00 & 1.89 \\
\hline Diameter-cap (medium) & 1.85 & 1.80 & 1.77 & 1.68 \\
\hline Diameter-cap (high) & 1.90 & 1.81 & 1.74 & 1.58 \\
\hline Adaptive1 & 2.09 & 2.06 & 2.04 & 1.94 \\
\hline Adaptive2 & 1.86 & 1.81 & 1.77 & 1.67 \\
\hline
\end{tabular}


Table 3-4 Average total carbon and soil carbon (ton ha $\left.{ }^{-1}\right)$ for low, medium, and high intensities of partial harvesting, diameter-limit and diameter-cap harvesting, and two adaptive measures in 2100.

\begin{tabular}{lllllllll}
\hline & \multicolumn{9}{c}{ Total carbon } & \multicolumn{4}{c}{ Soil carbon } \\
\hline Management regime & RCP2.6 & RCP4.5 & RCP6.0 & RCP8.5 & RCP2.6 & RCP4.5 & RCP6.0 & RCP8.5 \\
\hline Harvesting cycle (10 years) & & & & & & & & \\
Partial harvesting (low) & 854 & 845 & 834 & 823 & 681 & 675 & 668 & 659 \\
Partial harvesting (medium) & 814 & 803 & 790 & 778 & 650 & 642 & 633 & 624 \\
Partial harvesting (high) & 775 & 761 & 752 & 740 & 619 & 609 & 603 & 592 \\
Diameter-limit (low) & 897 & 882 & 866 & 852 & 718 & 705 & 692 & 681 \\
Diameter-limit (medium) & 859 & 849 & 838 & 826 & 688 & 678 & 670 & 662 \\
Diameter-limit (high) & 811 & 800 & 788 & 777 & 648 & 638 & 630 & 621 \\
Diameter-cap (low) & 914 & 902 & 891 & 878 & 731 & 720 & 712 & 703 \\
Diameter-cap (medium) & 883 & 872 & 860 & 848 & 706 & 696 & 688 & 677 \\
Diameter-cap (high) & 834 & 823 & 811 & 800 & 665 & 660 & 645 & 637 \\
Adaptive1 & $\mathbf{9 4 1 *}$ & $\mathbf{9 3 2}$ & $\mathbf{9 1 3}$ & $\mathbf{9 0 5}$ & $\mathbf{7 5 0}$ & $\mathbf{7 4 4}$ & $\mathbf{7 3 1}$ & $\mathbf{7 2 4}$ \\
Adaptive2 & 890 & 881 & 877 & 860 & 711 & 705 & 700 & 689 \\
Harvesting cycle (20 years) & & & & & & & & \\
Partial harvesting (low) & 888 & 879 & 872 & 864 & 711 & 702 & 696 & 690 \\
Partial harvesting (medium) & 828 & 818 & 809 & 800 & 660 & 652 & 649 & 641 \\
Partial harvesting (high) & 794 & 786 & 777 & 768 & 635 & 626 & 621 & 614 \\
Diameter-limit (low) & 928 & 919 & 910 & 897 & 741 & 736 & 730 & 715 \\
Diameter-limit (medium) & 878 & 870 & 861 & 850 & 701 & 698 & 688 & 682 \\
Diameter-limit (high) & 841 & 834 & 821 & 811 & 673 & 665 & 656 & 646 \\
Diameter-cap (low) & 941 & 933 & 921 & 912 & 753 & 745 & 738 & 730 \\
Diameter-cap (medium) & 902 & 891 & 883 & 871 & 720 & 711 & 706 & 695 \\
Diameter-cap (high) & 857 & 846 & 835 & 826 & 687 & 677 & 666 & 659 \\
Adaptive1 & $\mathbf{9 5 9}$ & $\mathbf{9 5 1}$ & $\mathbf{9 4 5}$ & $\mathbf{9 3 8}$ & $\mathbf{7 6 7}$ & $\mathbf{7 6 1}$ & $\mathbf{7 5 8}$ & $\mathbf{7 4 9}$ \\
Adaptive2 & 910 & 903 & 895 & 887 & 726 & 724 & 715 & 710 \\
\hline N & & & & & & \\
\end{tabular}

* Numbers in bold were the highest values among all management regimes.

\subsubsection{Measures Adaptive to Species Shift}

As expected, the projected outcomes of two adaptive measures demonstrated completely different patterns over the next 90 years. NPV, species diversity, size diversity and carbon stocks of Adaptive1, which entailed intensive harvesting of oak species and maintaining maple species, were $\$ 14,762 \mathrm{ha}^{-1}, 1.06,2.09$, and 941 ton ha ${ }^{-1}$ for the climate scenario RCP2.6 with harvesting cycle in 10 years, respectively, while the climate scenario RCP8.5 had $\$ 13,714 \mathrm{ha}^{-1}, 1.04,1.93$, and 905 ton ha ${ }^{-1}$ under the same harvesting cycle (Tables 3-2, 3-3, 3-4). In addition, the RCP4.5 had \$ 6,394 ha-1 $1.06,2.06,951$ ton ha ${ }^{-1}$ and the RCP6.0 had \$ 6,128 ha-1 $1.07,2.04,945$ ton ha- 
${ }^{1}$ with harvesting cycle in 20 years over the next 90 years, respectively (Tables 3-2, 3-3, 3-4). With Adaptive2 of intensive harvesting of maples, NPV, species diversity, size diversity, and carbon stocks under four climate scenarios converged to $\$ 2,423-\$ 2,668 \mathrm{ha}^{-1}, 1.28-1.33,1.63$ -1.80 , and $860-890$ ton $\mathrm{ha}^{-1}$ when harvested every 10 years, and $\$ 815-\$ 1,017 \mathrm{ha}^{-1}, 1.28-$ 1.31, $1.67-1.86$, and $887-910$ ton $\mathrm{ha}^{-1}$ when the harvesting cycle doubled, in 2100 , respectively (Tables 3-2, 3-3, 3-4). To summarize, Adaptive1 led to higher NPV (453\% - 625\%), size diversity $(14.5 \%-18.4 \%)$ and carbon stocks $(4.1 \%-5.8 \%)$, but lower species diversity (14.7\% - 20.3\%), than Adaptive2 with both harvesting cycles. It was also worth noting that Adaptive1 performed better than diameter-limit, diameter-cap and partial harvesting practices in terms of total carbon stocks. The two adaptive regimes exhibited totally different species composition at the end of $21^{\text {st }}$ century. Under Adaptive1, maple trees accounted for $38.3 \%-$ $45.5 \%$ of the total aboveground biomass, while oak trees made up $34.6 \%-43.1 \%$ in all four climate scenarios (Figure 3-1). When adopting Adaptive2, maple trees only made up 1.1\% $3.1 \%$, but oak trees maintained their dominance in the total aboveground biomass, ranging from $62.8 \%-72.9 \%$ under four climate scenarios. 

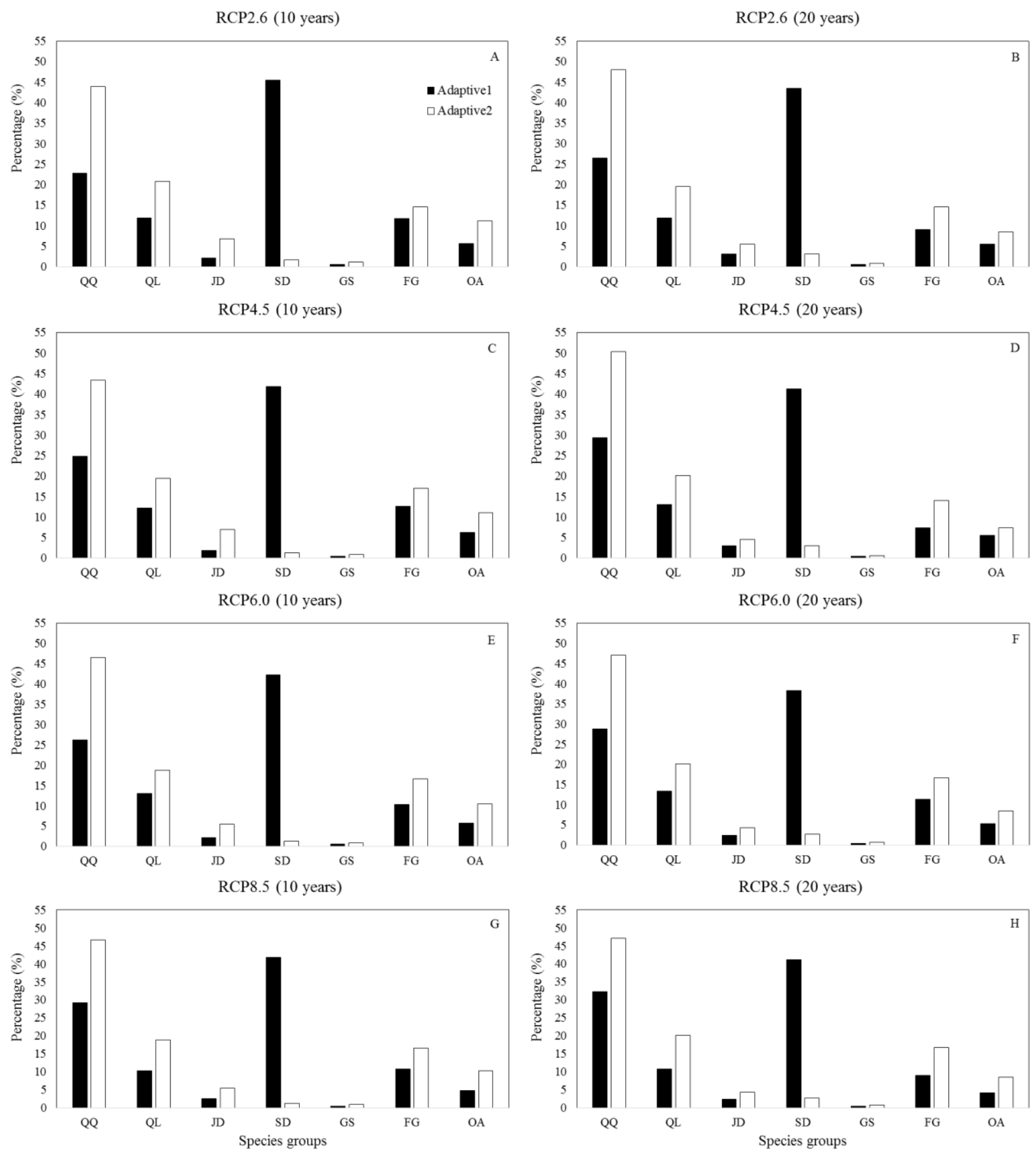

Figure 3-1 Percentages of above-ground biomass in seven species groups under management regimes Adaptive1 and Adaptive 2 and with harvesting cycles of 10 and 20 years, respectively. QQ: Quercus-Quercus (white oak species), QL: Quercus-Lobatae (red oak species), JD: 
Juglandaceae (hickory), SD: Sapindaceae (maple family), GS: Gymnosperms (softwoods), FG:

Fagus (American beech), OA: Other Angiosperms (other species).

\subsubsection{Uncertainty Analysis}

To account for variability in the simulation results, fuzzy sets were constructed for all management criteria based on equation 11 (Figures 3-2, 3-3, 3-4, 3-5) for the two harvesting cycles, respectively. Using a 10-year harvesting cycle, partial harvesting with low intensity and Adaptive1 clearly outperformed the other regimes financially under RCP 2.6, with high certainty. Adaptive 2 led to the lowest NPV with high certainty under RCP 8.5. Medium and high intensities could lead to similar NPVs under four climate scenarios, given the amount of overlap among the fuzzy sets. With a 20-year cycle, it was highly certain that the lowest NPV would occur under RCP 8.5 for all regimes except for Adaptive1 and medium-intensity harvesting would generate the highest NPV under RCP 2.6. Also with high certainty, RCP 2.6 would lead to higher NPV under all regimes than RCP 6.0 and 8.5. However, it is possible that all regimes except for medium-intensity harvesting would produce similar NPVs under RCP 2.6 and 4.5 (Figure 3-2).

In addition, when harvesting trees every 10 years, Adaptive1 led to the least species diversity with high certainty under RCP6.0 and Adaptive2 caused the lowest under RCP8.5 (Figure 3-3). All management regimes would lead to the lowest size diversity with high certainty under RCP8.5 (Figure 3-4). According to the overlaps among the fuzzy sets, low, medium, and high intensities could result in similar total carbon stocks under four climate scenarios.

Adaptive2 would have the least total carbon stock with high certainty under RCP8.5 (Figure 3-

5). When the harvesting cycle doubled, as shown in Figure 3, medium- and high-intensity harvesting practices could lead to similar species diversity under different climate scenarios, 
while RCP 4.5 resulted in much lower species diversity than the other scenarios under lowintensity regime. RCP 8.5 would generate the highest species diversity with high confidence under Adaptive1. Partial harvesting with low intensity, Adaptive1 and Adaptive2 could lead to the lowest size diversity with high certainty under RCP8.5 (Figure 3-4). However, all management regimes could lead to similar total carbon stocks under four climate scenarios based on the obvious overlap among the fuzzy sets (Figure 3-5).

In sum, there were no overlaps between fuzzy sets of NPV, size diversity and total carbon stock under RCP2.6 and RCP8.5 with both harvesting cycles (Figures 3-2, 3-4, 3-5), indicating that when considering uncertain climate and fire, these criteria would be distinctively different in RCP2.6 and RCP8.5 with high certainty. However, for species diversity, the existing overlaps among four climate scenarios (Figure 3-3) suggested the possibility of similar climatic effects on species diversity across most management regimes, when taking account of uncertainty. 

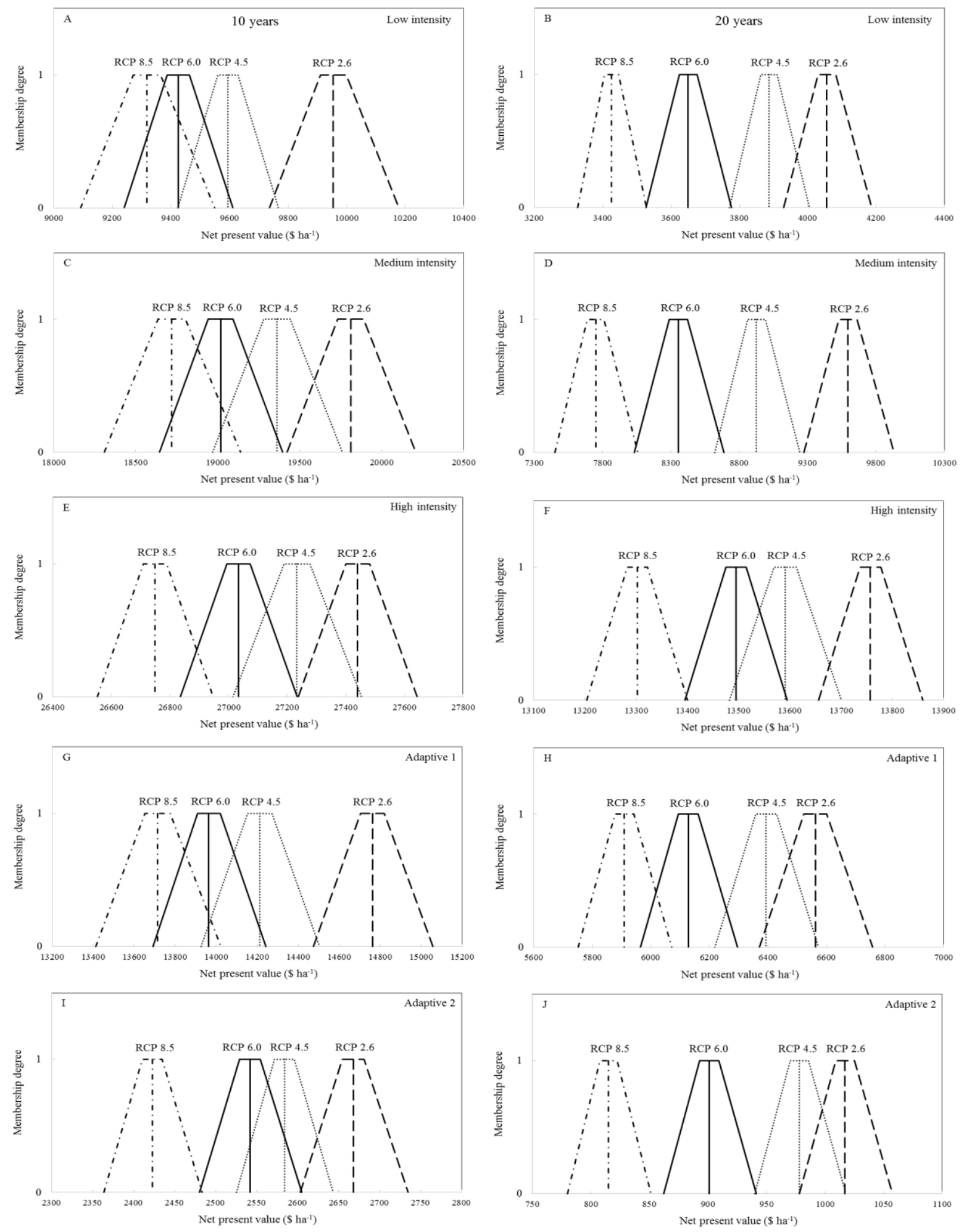

Figure 3-2 Fuzzy sets representing uncertainty in the NPV of low, medium, and high intensities of partial harvesting, adaptive1 and adaptive 2 with harvesting cycles of 10 and 20 years from 2010 to 2100. 

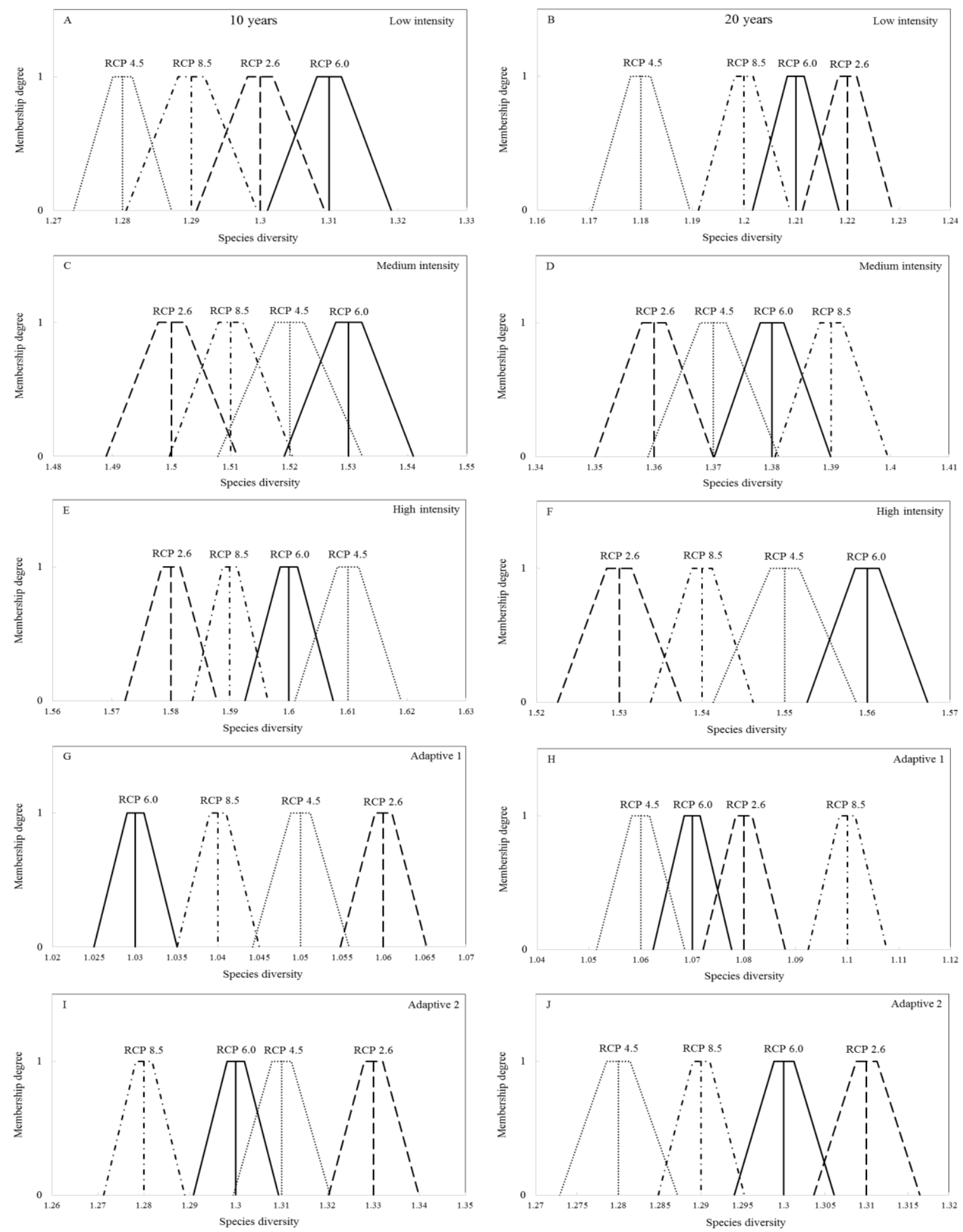

Figure 3-3 Fuzzy sets representing uncertainty in the species diversity of low, medium, and high intensities of partial harvesting, adaptive1 and adaptive2 with harvesting cycles of 10 and 20 years in 2100. 

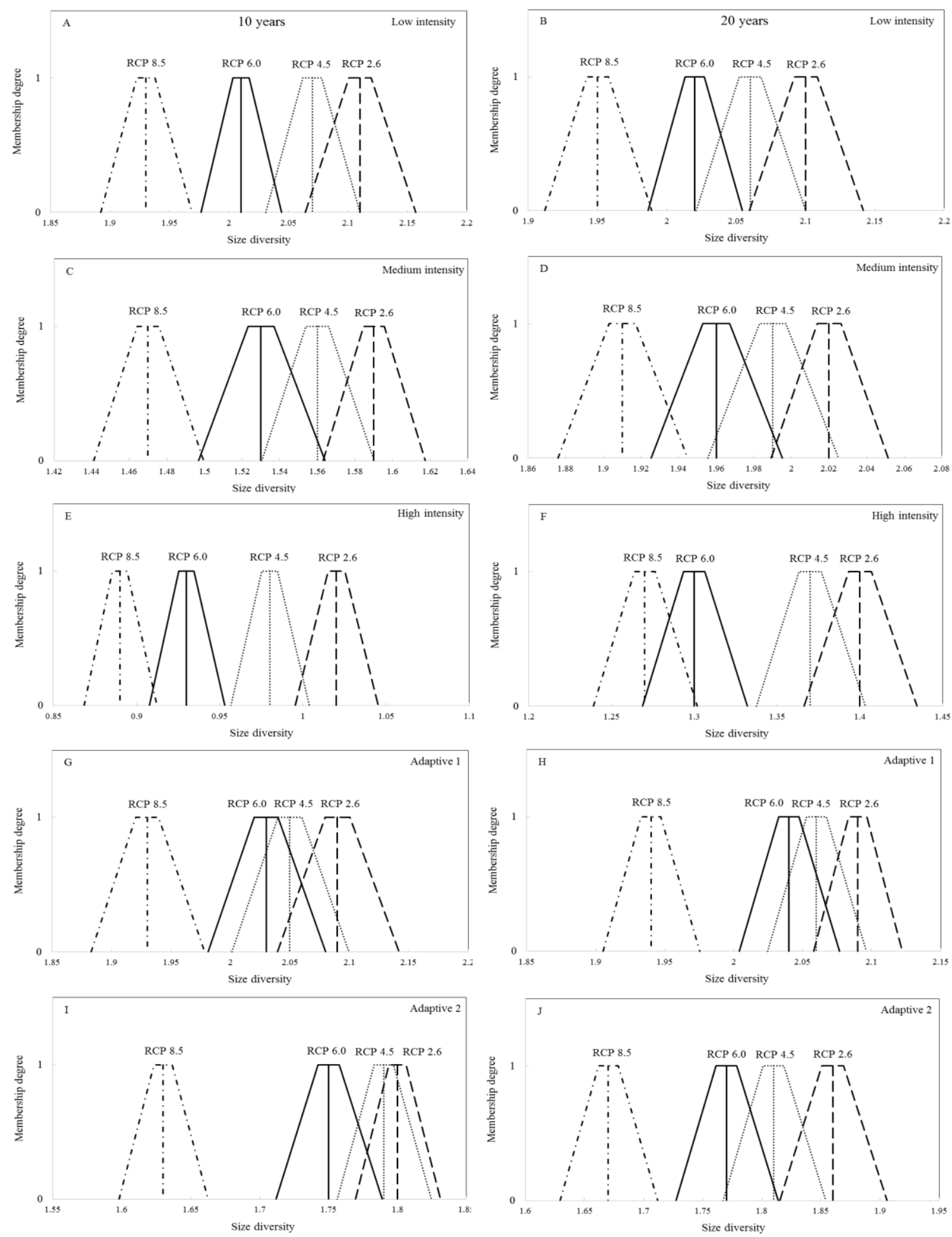

Figure 3-4 Fuzzy sets representing uncertainty in the size diversity of low, medium, and high intensities of partial harvesting, adaptive1 and adaptive 2 with harvesting cycles of 10 and 20 years in 2100. 

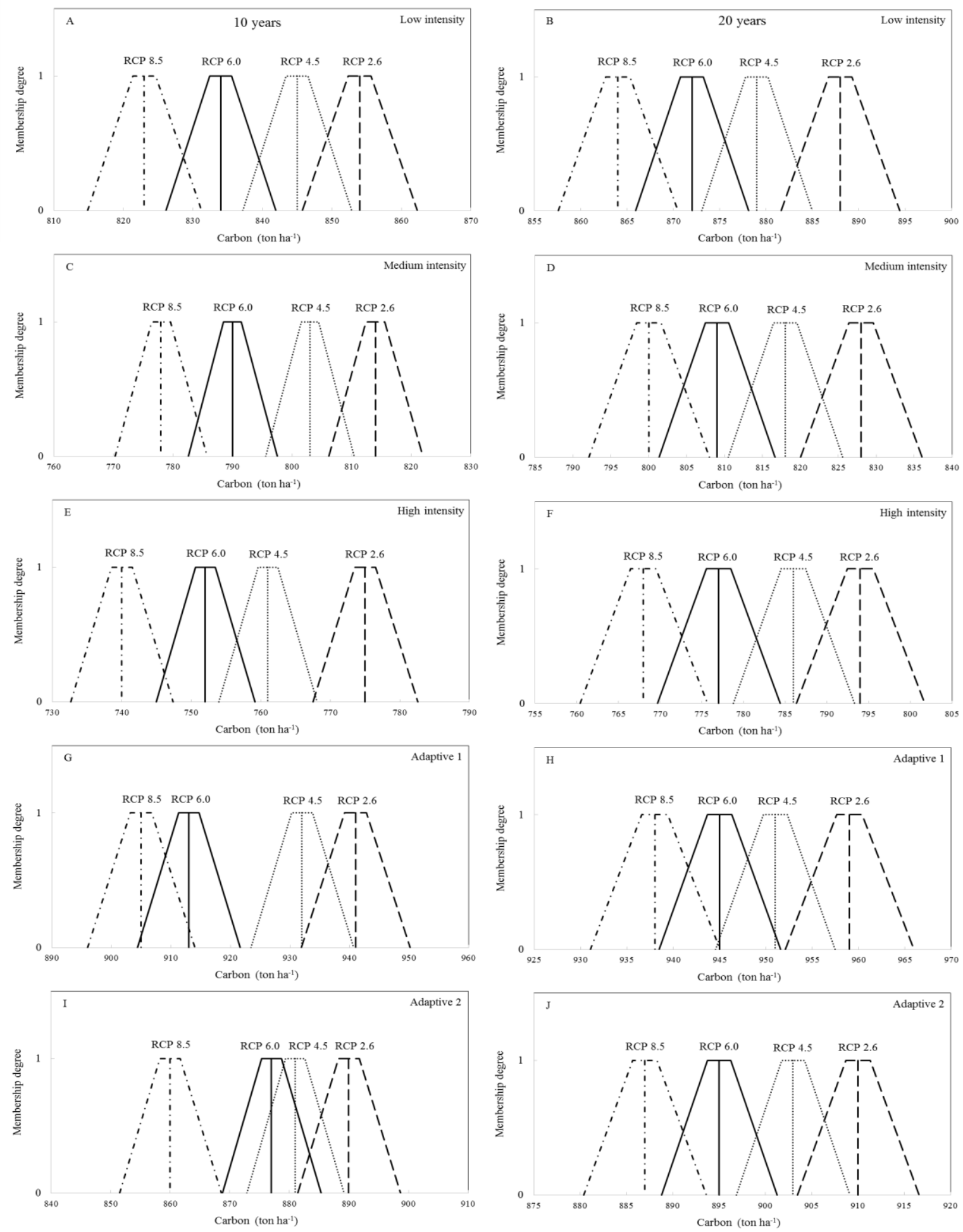

Figure 3-5 Fuzzy sets representing uncertainty in the carbon stocks of low, medium, and high intensities of partial harvesting, adaptive1 and adaptive 2 with harvesting cycles of 10 and 20 years in 2100. 


\subsection{Discussion and Conclusion}

In this study, I applied a climate-sensitive matrix model to quantify economic and ecological impacts of various harvesting intensities $(20 \%-80 \%)$ in the CHR when fire intervals were predicted to be considerably shortened by a changing climate. It is vital to consider climateinduced alterations to fire regimes to identify the way in which forest management affects stand carbon stocks (Rubio et al. 2011) and other ecosystem services. Nevertheless, existing dynamic global vegetation models such as, MC1 (Bachelet et al. 2001), LPJ (Sitch et al. 2003) and ORCHIDEE (Krinner et al. 2005), simulate ecosystem processes at the continental extent and thus do not capture frequent low-intensity fires and species-specific processes, such as tree mortality and regeneration. They, however, are important bottom-up forces on carbon balance (Loehman et al. 2014) and are essential for estimating stand-level tree growth and yield.

Management intensity is important for determining optimal carbon sequestration in managed forest ecosystems (Cooper 1983; Parker et al. 2000; Taylor et al. 2008), but it directly influences the financial return of harvested timber. $20 \%$ of trees removal management may be more effective than 50\% and $80 \%$ to enhance carbon sequestration at the expense of lower income for landowners. Similarly, harvesting treatments that maintain a large proportion of larger-diameter trees could be superior, in terms of maintaining carbon stocks, to those associated with more intensive removals (Harmon et al. 2009; Keyser 2010; Taylor et al. 2008), but lead to lower NPV of harvests. My simulation results agreed with these findings. The diameter-cap harvesting stored the most carbon, followed by diameter-limit and partial harvesting practice, also consistent with previous results (Harmon and Marks 2002; Peng et al. 2002). 
My work estimated forest carbon stocks in four pools. The soil organic carbon was predicted with YASSO07, which is applicable to both temperate and boreal forests (Liski et al. 2006). It was shown that soil organic carbon was highly resilient to varying intensities and accounted for nearly 80 percent of total stand carbon, thus in line with the previous studies arguing that harvesting does not significantly affect soil carbon (Johnson and Curtis 2001; Rashid 2013; Yanai et al. 2003). The result also indicated that appropriate management treatments may maintain or enhance forest carbon stocks, as opposed to no management, consistent with McKinley et al. (2011) and Stephens et al. (2012). My study further revealed that the NPV of harvests with a 10-year harvesting cycle was more than twice of 20 years, but carbon stocks were only $1.3 \%-5.0 \%$ lower for all management regimes. This suggested that more frequent harvests might produce higher NPVs without causing significant reductions of carbon stocks. The carbon stored in harvested wood products was not under consideration in this study and calls for an examination in the future.

Maintaining and increasing species and size diversity in forest stands have become a recent focus of forest management related to climate change adaptation (D'Amato et al. 2011; Puettmann et al. 2009; Liang et al. 2015). Ecosystems with low levels of diversity may be more vulnerable to potential changes in climate and disturbance regimes (Seidl et al. 2011). This study showed that $80 \%$ of trees removal may result in $18.6 \%-22.9 \%$ greater species diversity but $18.1 \%$ $-25.7 \%$ lower size diversity than $50 \%$ and $20 \%$. One possible explanation is that light gaps from intensive removals increased growth of shade-tolerant species and reduction in large-diameter trees decreased structural diversity. Warmer climates may have similar consequences on species and size diversity, probably because they caused more frequent fires that mimicked the effects of intensive harvests. 
I recognize that there is uncertainty in model projections related to climate change and fire disturbance (Nunery and Keeton 2010). Fire disturbance could impact carbon sequestration through rapid flux of carbon from living biomass to dead organic matters. In response to warmer and drier conditions, fire regimes are projected to alter in the coming decades not only in terms of shortened fire intervals, but also of prolonged fire season length and increased cumulative area burned (Flannigan et al. 2006; McKenzie et al. 2004). In my study, hindered by the complexity of modeling fundamental fire processes in forests including fuel particle ignition and fire spread, I only examined the climatic impacts on fire frequencies. Moreover, fires confer many important ecological benefits not discussed in this study. Besides, I did not account for wind damage, insect, disease, and other natural disturbances. Hence the model presented here had limited predictive power thus caution should be used to interpret the simulation results. On the other hand, more uncertainty is expected to rise in the projections when taking account of these missing aspects partly due to the incomplete knowledge of climate change and associated disturbances. How to take these sources of uncertainty into decision and policy making largely remains an open issue.

Tradeoffs between multiple management objectives are often necessary as enhancing one objective (economic or ecological) may inevitably compromise the others. For example, as shown here, $20 \%$ of trees removal led to higher carbon stocks but lower NPV while $80 \%$ of trees removal behaved the opposite way. Balancing economic and ecological objectives requires a constrained optimization paradigm. More detailed analyses assisted with stochastic optimization could examine what harvesting intensity optimizes ecological objectives while providing a satisfactory level of NPV. Determining the opportunity cost of carbon sequestration in forests will be one key to addressing the societal needs for environmental sustainability and economic viability simultaneously. That is what my future research will focus on. 


\section{Acknowledgement}

This study was supported by the Davis College of Agriculture, Natural Resources \& Design,

West Virginia University, under the US Department of Agriculture (USDA) McIntire-Stennis

Funds WVA00105. 


\section{References}

Bowman DM, Balch JK, Artaxo P et al. (2009) Fire in the Earth system. Science, 324, 481-484.

Bradford JB, Birdsey RA, Joyce LA, Ryan MG (2008) Tree age, disturbance history, and carbon stocks and fluxes in subalpine Rocky Mountain forests. Global Change Biology, 14, 2882-2897.

Blyth W, Yang M, Bradley R (2007) Climate policy uncertainty and investment risk. OECD Publishing.

Bos E, Vu M, Massiah E, Bulatao R (1994) World Population Projections 1994-95: Estimates and projections with related demographic statistics. New York: Johns Hopkins University Press.

Birdsey, RA (1992) Carbon storage and accumulation in United States forest ecosystems. USDA Forest Service General Technical Report. WO-59. Washington, DC.

Bachelet D, Neilson RP, Lenihan JM, Drapek RJ (2001) Climate change effects on vegetation distribution and carbon budget in the United States. Ecosystems, 4, 164-185.

Canadell JG, Raupach MR (2008) Managing forests for climate change mitigation. Science, 320, 1456-1457.

Cooper CF (1983) Carbon storage in managed forests. Canadian Journal of Forest Research, 13, $155-166$.

D’Amato AW, Bradford JB, Fraver S, Palik BJ (2011) Forest management for mitigation and adaptation to climate change: insights from long-term silviculture experiments. Forest Ecology and Management, 262, 803-816.

Fajvan MA, Grushecky ST, Hassler CC (1998) The effects of harvesting practices on West Virginia's wood supply. Journal of Forestry, 96, 33-39. 
Franklin JF, Mitchell RJ, Palik BJ (2007) Natural disturbance and stand development principles for ecological forestry. Gen. Tech. Rep. NRS-19, Newtown Square.

Fajvan MA (2006) Research on diameter-limit cutting in Central Appalachian forests. In: Proceedings of the conference on diameterlimit cutting in Northeastern Forests. USDA For. Serv. GTR NE-342, Newtown Square. 28-32.

Flannigan MD, Amiro BD, Logan KA, Stocks B, Wotton B (2006) Forest fires and climate change in the 21st century. Mitigation and Adaptation Strategies for Global Change, 11, 847-859.

Guyette RP, Stambaugh MC, Dey DC (2010) Developing and using fire scar histories in the Southern and Eastern United States. Joint Fire Science Program Final Report.

Hicks RR (1998) Ecology and management of central hardwood forests, John Wiley \& Sons. Harmon ME, Moreno A, Domingo JB (2009) Effects of partial harvest on the carbon stores in Douglas-fir/western hemlock forests: a simulation study. Ecosystems, 12, 777-791.

Harmon ME, Marks B (2002) Effects of silvicultural practices on carbon stores in Douglas-fir western hemlock forests in the Pacific Northwest, USA: results from a simulation model. Canadian Journal of Forest Research, 32, 863-877.

Jenkins JC, Chojnacky DC, Heath LS, Birdsey R (2003) National-scale biomass estimators for United States tree species. Forest Science, 49, 12-35.

Johnson DW, Curtis PS (2001) Effects of forest management on soil C and N storage: meta analysis. Forest Ecology and Management, 140, 227-238.

Krinner G, Viovy N, De noblet-ducoudré N et al. (2005) A dynamic global vegetation model for studies of the coupled atmosphere-biosphere system. Global Biogeochemical Cycles, 19. 
Keyser TL (2010) Thinning and site quality influence aboveground tree carbon stocks in yellowpoplar forests of the southern Appalachians. Canadian Journal of Forest Research, 40, 659-667.

Liski J, Tuomi M, Rasinmäki J (2009) Yasso07 User-Interface Manual. Finnish Environment Institute (Appendix).

Liski J, Lehtonen A, Palosuo T et al. (2006) Carbon accumulation in Finland's forests 19222004-an estimate obtained by combination of forest inventory data with modelling of biomass, litter and soil. Annals of Forest Science, 63, 687-697.

Loehman RA, Reinhardt E, Riley KL (2014) Wildland fire emissions, carbon, and climate: Seeing the forest and the trees-A cross-scale assessment of wildfire and carbon dynamics in fire-prone, forested ecosystems. Forest Ecology and Management. 317, 9-19.

Liang J, Zhou M, Tobin PC, Mcguire AD, Reich PB (2015) Biodiversity influences plant productivity through niche-efficiency. PNAS. 112, 5738-5743.

Ma W, Liang J, Cumming JR et al. (2016) Fundamental shifts of central hardwood forests under climate change. Ecological Modelling, 332, 28-41.

Miller GW, Schuler TM, Smith HC (1995) Method for applying group selection in central Appalachian hardwoods. USDA For. Serv. Res. Pap. NE-696.

Miller GW, Johnson JE, Baumgras JE (1997) Deferment cutting in central Appalachian hardwoods: an update. Forest Landowner, 56, 28-31.

Mckinley DC, Ryan MG, Birdsey RA et al. (2011) A synthesis of current knowledge on forests and carbon storage in the United States. Ecological Application, 21, 1902-1924.

Mckenzie D, Gedalof ZE, Peterson DL, Mote P (2004) Climatic change, wildfire, and conservation. Conservation Biology, 18, 890-902. 
Nyland RD (1992) Exploitation and greed in eastern hardwood forests. Journal of Forestry, 90, 33-37.

Nyland RD (1996) Silviculture: concepts and applications. McGraw-Hill, New York.

Nyland RD (2005) Diameter-limit cutting and silviculture: a comparison of long-term yields and values for uneven-aged sugar maple stands. Northern Journal of Applied Forestry, 22, $111-116$.

Nilsen P, Strand LT (2008) Thinning intensity effects on carbon and nitrogen stores and fluxes in a Norway spruce (Picea abies (L.) Karst.) stand after 33 years. Forest Ecology and Management, 256, 201-208.

Nave LE, Vance ED, Swanston CW, Curtis PS (2010) Harvest impacts on soil carbon storage in temperate forests. Forest Ecology and Management, 259, 857-866.

Nunery JS, Keeton WS (2010) Forest carbon storage in the northeastern United States: Net effects of harvesting frequency, post-harvest retention, and wood products. Forest Ecology and Management, 259, 1363-1375.

Oliver CD (1992) A landscape approach: achieving and maintaining biodiversity and economic productivity. Journal of Forestry, 90, 20-25.

Palik BJ, Mitchell RJ, Hiers JK (2002) Modeling silviculture after natural disturbance to sustain biodiversity in the longleaf pine (Pinus palustris) ecosystem: balancing complexity and implementation. Forest Ecology and Management, 155, 347-356.

Peichl M, Arain MA (2006) Above-and belowground ecosystem biomass and carbon pools in an age-sequence of temperate pine plantation forests. Agricultral and Forest Meteorology, 140, 51-63. 
Peltoniemi M, Mäkipää R, Liski J, Tamminen P (2004) Changes in soil carbon with stand age-an evaluation of a modelling method with empirical data. Global Change Biology, 10, 20782091.

Pielou E (1977) Mathematical ecology. John Wiley \& Sons, New York.

Parker WC, Colombo SJ, Cherry ML et al. 2000. Third millennium forestry: what climate change might mean to forests and forest management in Ontario. The Forestry Chronicle, 76, 445-463.

Peng C, Jiang H, Apps MJ, Zhang Y (2002) Effects of harvesting regimes on carbon and nitrogen dynamics of boreal forests in central Canada: a process model simulation. Ecological Modelling, 155, 177-189.

Puettmann K, Coates K, Messier C (2009) A critique of silviculture: managing for complexity. Island Press.

Ruiz-peinado R, Bravo-oviedo A, López-senespleda E, Montero G, Río M (2013) Do thinnings influence biomass and soil carbon stocks in Mediterranean maritime pinewoods? European Journal of Forest Research, 132, 253-262.

Roig S, Del río M, Canellas I, Montero G (2005) Litter fall in Mediterranean Pinus pinaster Ait. stands under different thinning regimes. Forest Ecology and Management, 206, 179-190.

Rubio A, Gavilán RG, Montes F et al. (2011) Biodiversity measures applied to stand-level management: Can they really be useful? Ecological Indicators, 11, 545-556.

Rashid MA (2013) Simulating the effect of thinning treatments on soil carbon stocks in Norway spruce in southern Sweden. Second cycle, A2E. Alnarp: SLU, Southern Swedish Forest Research Centre. 
Seymour RS, White AS, Demaynadier PG (2002) Natural disturbance regimes in northeastern North America - evaluating silvicultural systems using natural scales and frequencies. Forest Ecology and Management, 155, 357-367.

Schuler TM (2004) Fifty years of partial harvesting in a mixed mesophytic forest: composition and productivity. Canadian Journal of Forest Research, 34, 985-997.

Schuler TM, Gillespie AR (2000) Temporal patterns of woody species diversity in a central Appalachian forest from 1856 to 1997. The Journal of the Torrey Botanical Society, 127, $149-161$.

Smith HC, Miller GW (1987) Managing Appalachian hardwood stands using four regeneration practices: 34 year results. Northern Journal of Applied Forestry, 4, 180-185.

Sharon W, Barbara L, Barbara M et al. (2011) The forest inventory and analysis database: database description and users manual version 5.1 for phase 2 .

Sitch S, Smith B, Prentice IC et al. (2003) Evaluation of ecosystem dynamics, plant geography and terrestrial carbon cycling in the LPJ dynamic global vegetation model. Global Change Biology, 9, 161-185.

Stephens SL, Boerner RE, Moghaddas JJ et al. (2012) Fuel treatment impacts on estimated wildfire carbon loss from forests in Montana, Oregon, California, and Arizona. Ecosphere, 3, 1-17.

Seidl R, Rammer W, Lexer MJ (2011) Adaptation options to reduce climate change vulnerability of sustainable forest management in the Austrian Alps. Canadian Journal of Forest Research, 41, 694-706.

Trimble G (1971) Diameter-limit cutting in Appalachian hardwoods: boon or bane? USDA Forest Service RP-NE-208, Upper Darby. 
Tobin J (1958) Estimation of relationships for limited dependent variables. Econometrica: journal of the Econometric Society, 24-36.

Tuomi M, Rasinmäki J, Repo A, Vanhala P, Liski J (2011a) Soil carbon model Yasso07 graphical user interface. Model Software, 26, 1358-1362.

Tuomi M, Laiho R, Repo A, Liski J (2011b) Wood decomposition model for boreal forests. Ecological Modelling, 222, 709-718.

Taylor AR, Wang JR, Kurz WA (2008) Effects of harvesting intensity on carbon stocks in eastern Canadian red spruce (Picea rubens) forests: An exploratory analysis using the CBM-CFS3 simulation model. Forest Ecology and Management, 255, 3632-3641.

Vesterdal L, Dalsgaard M, Felby C, Raulund-rasmussen K, Jørgensen BB (1995) Effects of thinning and soil properties on accumulation of carbon, nitrogen and phosphorus in the forest floor of Norway spruce stands. Forest Ecology and Management, 77, 1-10.

Weckenmann A, Schwan A (2001) Environmental life cycle assessment with support of fuzzysets. The International Journal of Life Cycle Assessment, 6, 13-18.

Yanai RD, Arthur MA, Siccama TG, Federer CA (2000) Challenges of measuring forest floor organic matter dynamics:: Repeated measures from a chronosequence. Forest Ecology and Management, 138, 273-283.

Yanai RD, Currie WS, Goodale CL (2003) Soil carbon dynamics after forest harvest: an ecosystem paradigm reconsidered. Ecosystems, 6, 197-212.

Zenner EK, Dickinson YL, Peck JE (2013) Recovery of forest structure and composition to harvesting in different strata of mixed even-aged central Appalachian hardwoods. Annals of Forest Science. 70, 151-159.

Zadeh LA (1965) Fuzzy sets. Information and Control. 8, 338-353. 


\section{Multi-criteria management of the central hardwood forest under climate and fire uncertainty with scenario-based models*}

\footnotetext{
* This chapter will be submitted to Forest Ecology and Management with coauthor M. Zhou.
} 


\section{Abstract}

I developed multi-stage scenario-based optimization models for managing Central Hardwood Forests under uncertainty in climate change and associated fire. Based on a climate-sensitive matrix growth model and a mean fire interval model, four future climate scenarios and attendant fire intervals combined with two fire severity regimes were transformed into 36 and 20 tree growth scenarios for harvesting cycles of 10 and 20 years, respectively. Three alternatives of optimization formulations were proposed: 1) optimize for the maximum objective value under each individual scenario independently; 2) based on results from 1), find the compromise management plan that's feasible for all scenarios while minimizing the weighted sum of deviations between the realized and maximum objective values; and 3) derive the optimal management plan over the entire scenario tree. Four objectives were considered: the net present value (NPV) of harvests, total carbon stock, tree species diversity, and tree size diversity. Finally I determined the trade-off between economic and ecological benefits by quantifying the opportunity cost of increasing ecological benefits in terms of NPV. Without considering any constraints for the optimization approach, the maximum NPV varied from $\$ 30,396$ to $\$ 35,378$ $\mathrm{ha}^{-1}$ for 36 scenarios with harvesting every 10 years, and $\$ 17,838$ to $\$ 18,992$ ha $^{-1}(53.7 \%-58.7 \%$ of 10 years) for 20 scenarios with doubled harvesting cycle. The optimization approach produced $9.7 \%-22.4 \%$ (10 years) and $29.7-38.1 \%$ (20 years) more NPV than the deterministic approach. Among the values of the same criterion derived with all three methods, as expected, the one from optimizing the individual scenario was the highest. With harvesting cycles of 10 and 20 years, the feasible NPV declined \$ $123-\$ 944 \mathrm{ha}^{-1}, \$ 435-\$ 1,270 \mathrm{ha}^{-1}, \$ 376-\$ 2,011 \mathrm{ha}^{-1}$, and \$ 73 $-\$ 483 \mathrm{ha}^{-1}, \$ 229-\$ 646 \mathrm{ha}^{-1}, \$ 204-\$ 1,022 \mathrm{ha}^{-1}$ when each unit of species diversity, size 
diversity, and carbon weights increased from 1 to 10 , respectively, while the other criterions were held fixed. 


\subsection{Introduction}

Forest management decision-making faces uncertainty and risk in diverse forms: climate change, natural disturbances (e.g., wildfire, wind damage, insect damage), market fluctuations, changing social acceptability of silvicultural treatments (Liang et al. 2006), etc. Consequently, the consideration of stochastic factors is vital to modern forest management and plays a critical role in establishing optimal harvesting rules (Perry and Maghembe 1989; Garcia-Gonzalo et al. 2016). Inclusion of randomness in optimization models, however, is not straightforward and presents major computational challenges, rendering them intractable in many cases.

Hildebrandt and Knoke (2011) give a comprehensive overview of this subject under market uncertainty whereas Yousefpour et al. (2012) survey the approaches that handle uncertainty and risk under climate change. A few prominent examples are included here. Gove and Fairweather (1992) adopt a nonparametric bootstrap method and randomize the parameters of a deterministic programming model for uneven-aged northern hardwood management. Reeves and Haight (2000) apply Markowitz portfolio optimization to deal with timber price uncertainty in even-aged management and find optimal forest plans are highly sensitive to assumptions about the range of future prices. Tahvonen and Kallio (2006) analyze optimal harvesting decisions with different age classes under price uncertainty and conclude that optimal harvesting is too sensitive to periodic price level compared to the random walk case. Eyvindson and Kangas (2014) apply stochastic goal programming to balance competing criteria in forest planning under uncertainty in a systematic fashion. Millar et al. (2007) introduce a conceptual framework for managing forested ecosystems under climate change. Hanewinkel et al. (2011) provide a general scheme on 
how to integrate risk from hazards (Strom, snow, insects, fire) under climate change into forest management decisions.

Among the prevalent methods, Markov Decision Process (MDP) models are readily adaptable to forest management under multiple sources of uncertainty and standard solution methods are well developed, including linear programming and dynamic programming. Thus, MDPs have been applied to forest decision making with a mix of economic and ecological criteria under uncertainty (Lin and Buongiorno 1998; Zhou et al. 2008a; Zhou et al. 2008b). Zhou and Buongiorno (2006) incorporate Markov chain models describing stand transitions under the influence of natural disturbances into a stochastic optimization model to study the tradeoffs between landscape diversity and timber production. Recently, Zhou and Buongiorno (2011), and Buongiorno and Zhou (2011) extend the classical MDP models to account for fluctuations in the interest rate. Zhou (2015) couple a regime-switching model of climate policy with a MDP model to discuss the effects of uncertainty timing and magnitude of climate policy on sustainable forestry. For this study, however, MDP may not be the most appropriate candidate for three reasons: 1) Current knowledge of climate change is incomplete while MDP, as a probability/frequency based approach, usually assumes complete information of uncertainty; 2) Regimes of fire disturbance are expected to alter in the future, but MDP relies on stationary, i.e., non-time-varying, transitions between states; and 3) MDP calculates the optimal decision rules in the steady state, but, at present, it is most crucial to derive adaptive strategies before entering a new steady state.

Another line of work on stochastic decision-making uses multi-stage scenario-based optimization models: decisions are revised at each stage and optimizations are based on the 
uncertainty realized so far (Ahmed et al. 2003). Applications of such an approach are rare in forestry context with the following exceptions. Alonso-Ayuso et al. (2011) handle stochasticity in forest planning with uncertainty in price and future wood demand represented through 16 scenarios. Veliz et al. (2015) incorporate uncertainty in forest growth and consider both harvesting and road construction decisions with up to 324 scenarios. This method is likely to be successful for this study because first, uncertainty in climate change is prevalently represented as climate scenarios thus could be readily incorporated in the optimization model; other forms of uncertainty, fire disturbances, could also be translated into scenarios thus compatible with the model too; lastly, decisions were adaptive and revised at each stage as new information of climate change becomes available.

The primary objective of the current study was to develop a multi-stage optimization model that accounts for climate and fire uncertainty. A recent study by Ma and Zhou (2016) quantifies the impacts of various management intensities on ecological and economic criteria under climate change and fire disturbance using Monte-Carlo simulations. The next step is to derive the best management plan adaptive to different climate scenarios and fire regimes and determine the tradeoff between financial benefits and ecosystem services. Four climate scenarios and attendant fire intervals and two fire severity regimes were transformed into 36 and 20 tree growth scenarios with harvesting cycles of 10 years and 20 years, respectively. Three formulations were proposed to determine the optimal management plan: 1) optimize for the maximum objective value under each individual scenario independently; 2) based on results from 1), find the compromise management plan that's feasible for all scenarios while minimizing the weighted sum of deviations between the realized and maximum objective values; and 3) derive the optimal management plan over the entire scenario tree. Four objectives were considered: the 
net present value (NPV) of harvests, total carbon stock, tree species diversity, and tree size diversity. Finally, I determined the trade-off between economic and ecological benefits by quantifying the opportunity cost of increasing ecological benefits in terms of NPV. 


\subsection{Materials and Methods}

\subsubsection{Data}

Data used for developing the matrix growth model consisted of 6,303 re-measured permanent sample plots (PSP's) from the Forest Inventory and Analysis (FIA) database (Sharon et al. 2011). Due to the high diversity in the CHR, I classified all tree species into seven species groups: Quercus-Quercus (QQ), Quercus-Lobatae (QL), Juglandaceae (JD), Sapindaceae (SD), Gymnosperms (GS), Fagus (FG), and Other Angiosperms (OA). In each species group, seventeen diameter classes were categorized for all the trees (Ma et al. 2016).

The stumpage price data (1989 - 2016) in West Virginia Timber Market Report (WVTMR, available online at http://ahc.caf.wvu.edu/ahc-resources-mainmenu-45/timbermarket-report-mainmenu-62, last accessed May 10, 2016) was used for financial analysis, which was adjusted for inflation with Consumer Price Index (2015 =100) (Ma and Zhou, 2016). Four commercial species groups were defined: oak (QQ, QL), hickory (JD), maple (SD), other (GS, FG, and OA). In addition, three commercial sizes were defined: poles (1-6 diameter classes, $\mathrm{cm}$ ), small saw timber (7-12), and large saw timber (13-17) (Miller et al. 1995; Miller et al. 1997). The adjusted stumpage price of each commercial species and size is shown in table 4-1.

Table 4-1 Adjusted real average stumpage prices $\left(\$ m^{-3}\right)($ base year=2015) for three commercial sizes and four commercial species groups.

\begin{tabular}{cccc}
\hline $\begin{array}{c}\text { Commercial } \\
\text { species }\end{array}$ & \multicolumn{3}{c}{ Commercial size $\left(\$ \mathrm{~m}^{-3}\right)$} \\
\hline Oak & Pole & Small sawtimber & Large sawtimber \\
Hickory & 30 & 85 & 115 \\
Maple & 90 & 40 & 50 \\
Other & 33 & 57 & 150 \\
\hline
\end{tabular}

* Oak: Quercus-Quercus (white oak species) and Quercus-Lobatae (red oak species); Hickory: Juglandaceae (Hickory); Maple: Sapindaceae (maple family); Other: Gymnosperms (Softwoods), Fagus (American beech), and Other Angiosperms (other species). 
For future climate trends, at first I extracted the future trend ratio over the CHR for the four scenarios (RCP2.6, RCP4.5, RCP6.0, and RCP8.5) of the IPCC AR5 report predicting future climatic changes (Blyth et al. 2007). Then, I multiplied the historical temperature and precipitation by the future trend ratios to estimate the future climate during 2010-2100. Future population density over the CHR was estimated from the current CHR population density and the overall population trend in America in year 2000 for 2025, 2050, 2075, and 2100 (Bos et al. 1994). For detailed estimations of future temperature, precipitation, and population density, see Ma et al. (2016).

\subsubsection{Defining Scenarios}

Uncertainty in climate change and fire from 2010 to 2100 were described as scenarios - tree growth under combinations of four IPCC climate scenarios (C) and two fire severity regimes (S). I used a climate-sensitive matrix model and a mean fire interval model to predict forest growth per period (10 and 20 years, respectively) under climate change and associated fire intervals over the planning horizon. The climate-sensitive matrix model was extended from a conventional matrix model to control for the effects of temperature and precipitation on tree growth, mortality, and recruitment (Ma et al. 2016). To account for impacts of fire induced by climate change, the growth model was coupled with a mean fire interval (MFI) model (Guyette et al. 2010) designated for fire management in the eastern and southern United States. It is a common practice to vary disturbance severities in ecological studies (Sturtevant et al. 2009). Thus the climate-sensitive matrix model, MFI model, and fire regime switches were combined to simulate the effects of climate change on fire disturbances and subsequently on the CHR forests. Two fire severity regimes, representing a baseline fire regime and a regime of more severe fires (see Table A6 in the appendix for the definition of fire severity classes) were hypothesized as follows: for 
fire severity classes 1 to 5 , in regime $S 1$, the probability of each class was 40,25, 20, 10, and 5\%, respectively; in regime $\mathrm{S} 2$, it was $30,25,20,15$, and $10 \%$, respectively, similar to the fire regimes specified in Yang et al. 2004 and Gonzalez et al. 2006. The more severe fire regime S2 would affect larger areas of CHR forests through direct mortality and structural and species alterations, as well as incur larger economic losses. Consequently S2 would require more public firefighting resources.

The following rule was used to establish tree growth scenarios (TGSs). When $t=1$, there were 8 possible combinations of 4 climate scenarios and 2 fire severity regimes. For any $\mathrm{t}>1$, the climate scenario stayed the same as the previous node; in addition, if the previous node had S1, two branched came out of that node, one containing S1 and the other S2. If the previous node had S2, only one branch came out of that node and it contained S2. The underlying assumption was that once the fire severity regime changed to S2, it would stay in S2 for the rest of the planning period. This above described rule insured that: 1) there was a base TGS for each climate scenario with the constant fire severity regime S1;2) there was one TGS for each climate scenario representing the alteration of fire intensity regime from S1 to S2 at any stage greater than 1 . This rule generated 36 scenarios in total with a harvesting cycle of 10 years (Figure 4-1) and 20 scenarios with 20 years (Figure 4-2). 


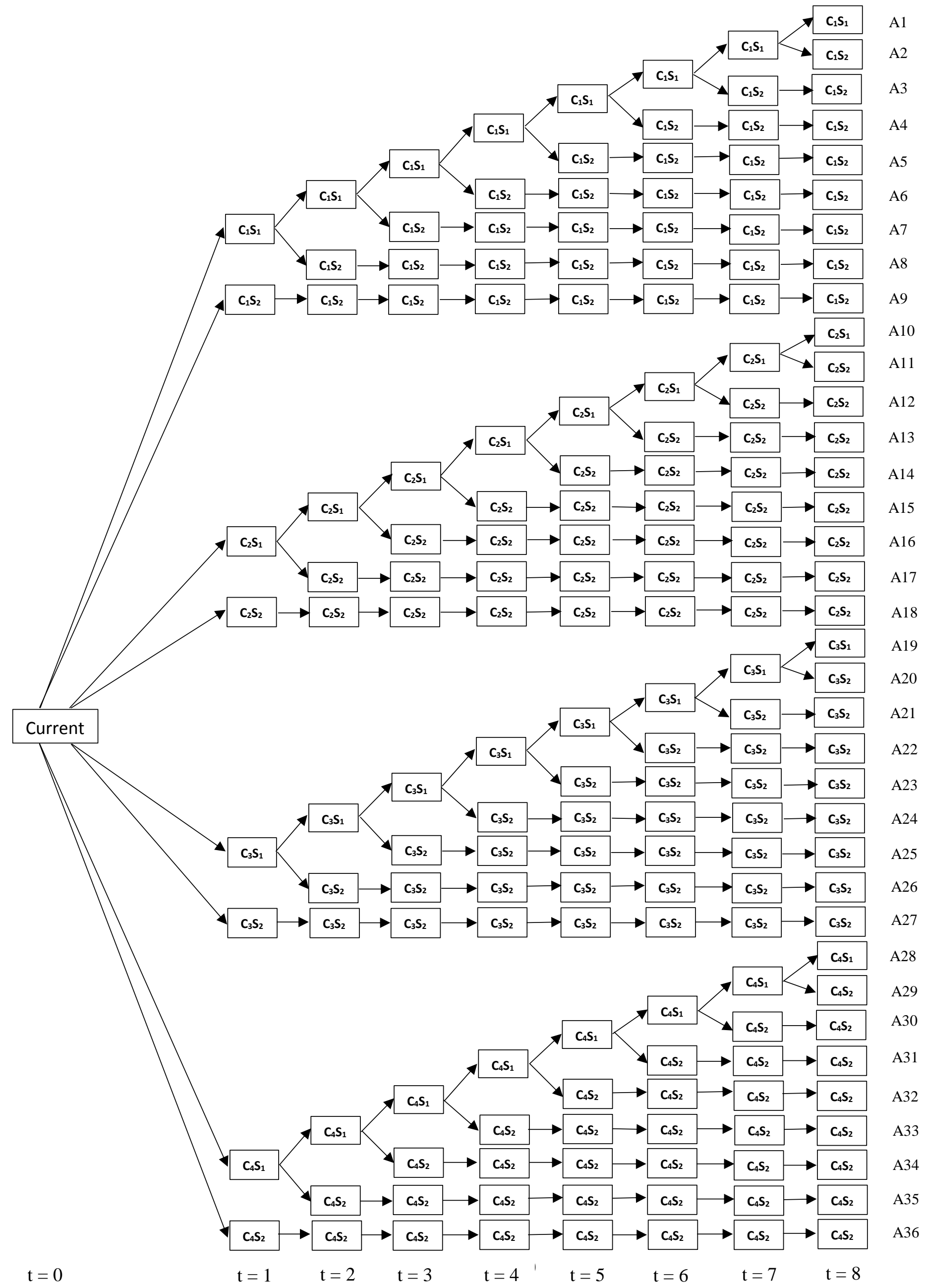


Figure 4-1 Scenario tree of with harvesting cycle of 10 years under 4 climate scenarios and 2 fire severity levels. C1: RCP2.6; C2: RCP4.5; C3: RCP6.0; C4: RCP8.5; S1: Fire severity 1, S2: Fire severity 2; t: Harvesting stage; A: Scenario. 


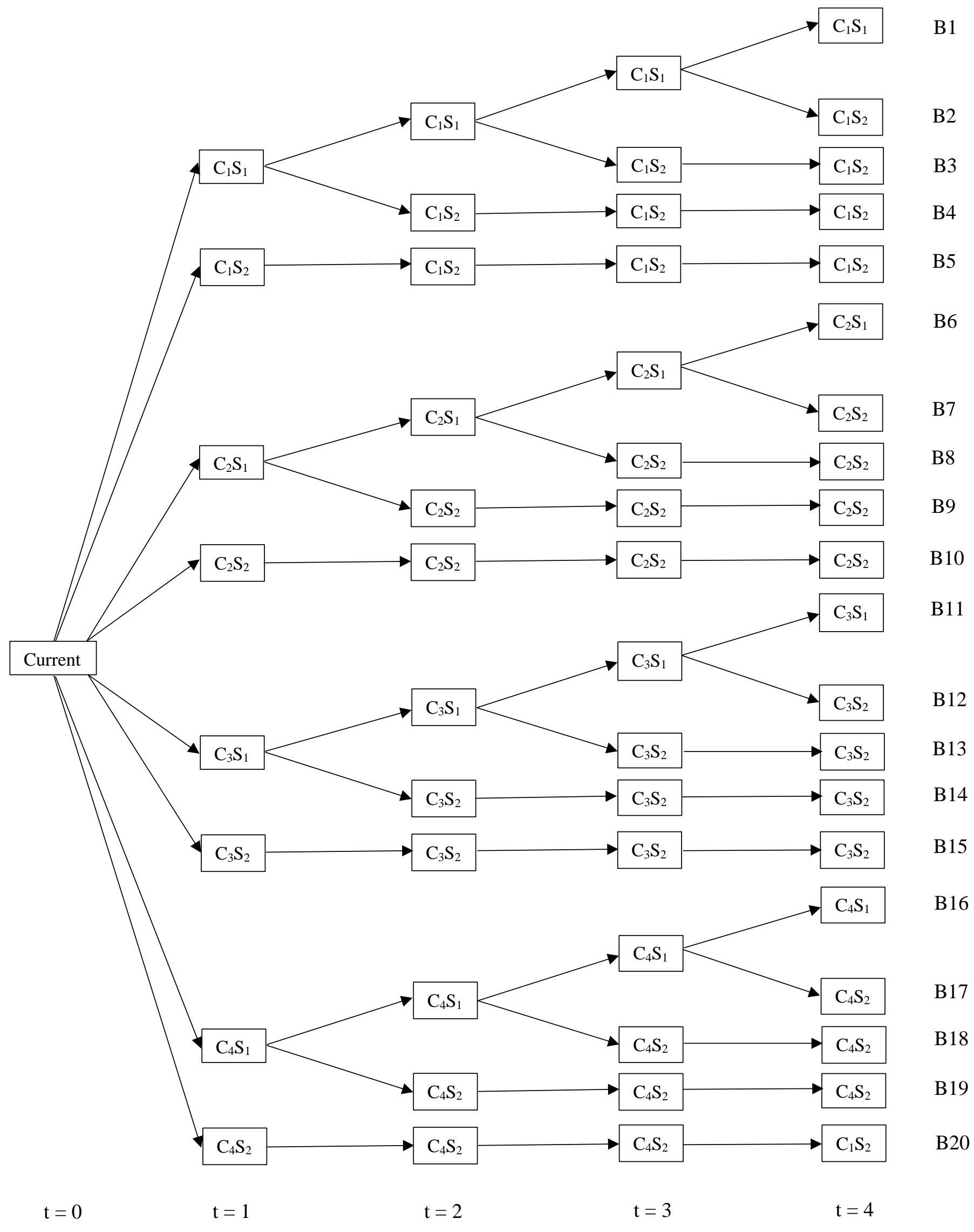


Figure 4-2 Scenario tree of with harvesting cycle of 20 years under 4 climate scenarios and 2 fire severity levels. C1: RCP2.6; C2: RCP4.5; C3: RCP6.0; C4: RCP8.5; S1: Fire severity 1, S2: Fire severity 2; t: Harvesting stage; B: Scenario.

\subsubsection{Optimization of individual scenario}

Given a harvesting cycle, for each planning stage, twelve decision variables were needed at each stage for four commercial species groups and three commercial sizes: 1 (QQ, QL, 1-6), 2 (QQ, QL, 7-12), 3 (QQ, QL, 13-17), 4 (JD, 1-6), 5 (JD, 7-12), 6 (JD, 13-17), 7 (SD, 1-6), 8 (SD, 7-12), 9 (SD, 13-17), 10 (GS, FG, OA, 1-6), 11 (GS, FG, OA, 7-12), 12 (GS, FG, OA, 13-17). I defined $x_{h k}^{t}$ as the percentage of number of trees would be harvested in commercial species group $\mathrm{h}$ and commercial size $\mathrm{k}$ at stage $\mathrm{t}$.

Additionally, the following notation will be used:

Sets

$T=$ period in planning horizon.

$t=$ harvesting cycle in years.

$z=$ scenarios.

\section{Deterministic parameters}

$v_{h k}=$ volume of a tree in commercial species $\mathrm{h}$ and commercial size $\mathrm{k}$.

$n=$ number of trees in commercial species $\mathrm{h}$ and commercial size $\mathrm{k}$.

$r=$ interest rate per year.

$P_{h k}=$ stumpage price of a tree in commercial species $\mathrm{h}$ and commercial size $\mathrm{k}$.

$P_{r o b}(z)=$ probability of the occurrence of scenarios. 
The first approach I proposed was to formulate a deterministic model for each individual TGS, $\mathrm{z}$, often referred to as a scenario subproblem, as

$$
\max N P V^{z}=\sum_{t} \frac{x_{h k}^{t} n v_{h k} P_{h k}}{(1+r)^{t}}
$$

or $\max H_{s}^{z}=-\sum_{i} \frac{B_{i}}{B} \ln \left(\frac{B_{i}}{B}\right)$

or max $H_{d}^{z}=-\sum_{j} \frac{B_{j}}{B} \ln \left(\frac{B_{j}}{B}\right)$

or max Carbon $^{z}=\sum_{t}$ Carbon $_{t}$

where $B_{i}, B_{j}$ and $B$ were, respectively, the basal area of species group $i$, diameter class $j$ and total basal area. The carbon was the total of carbon estimated in the four pools: above-ground biomass, fine roots, dead organic matters, and soil (Ma and Zhou, 2016).

The additional constraints were growth equations under TGS and bound constraints ensuring feasible harvest. These models were solved for each TGS, z, for the optimal unconstrained value that can be achieved for each criterion, u, denoted by $M_{u}^{Z}$.

\subsubsection{Global feasible-plan optimization}

Using the maximum values solved from models (4-1) to (4-4), I set up global models which linked all TGSs through the same decision variables, $x_{h k}^{t}$. For a single criterion, $u$, the model took the following form:

$\operatorname{Min} \sum_{z} P_{r o b}(z)\left(M_{u}^{z}-f_{u}^{z}\left(x_{h k}^{t}\right)\right)$ 
in which $P_{r o b}(z)$ represented the probability of TGS z and $f_{u}^{z}$ represented the evaluation function of criterion $u$ under TGS $z$, as described in models (4-1) to (4-4). The probabilities added up to 1 . Growth equations under all TGSs and bound constraints were necessary too. This model sought a solution that was feasible for all TGSs and minimized the weighted sum of deviations of one achieved criterion from the maximum criterion over all TGSs.

To pursue multiple objectives in this setup, one could augment model (4-5) by adding weighted sum of deviations of additional criteria. Altering the weights would change the management priority/importance of the extra criteria: larger weights implied higher priority/importance because the deviations would be more penalized in minimization. It is important to note that this class of models only derived nonadaptive solutions for the decision was identical for a certain species-size category and planning stage no matter the TGS.

\subsubsection{Scenario-tree optimization}

Here I proposed a third approach for global optimization across all the TGSs that determined TGS-specific optimal decisions. Thus, the approach was adaptive to uncertainty in climate and fire. Optimization of the scenario tree requires compliance with the well-known nonanticipativity principle (Birge and Louveaux 2011; Rockafellar and Wets 1991; Wets 1975). According to this principle, the values of the decision variables must be identical up to a given stage if two different scenarios are identical up to that stage in the time horizon. This guarantees that the decision obtained from the scenario-based optimization model up to a given stage does not depend on information that is not yet available (Alonso-Ayuso et al. 2011; Garcia-Gonzalo et al. 2016). For example, for the scenario tree as described in figure 2 , the values of decision 
variables were identical up to stage 2 for scenarios 1, 2 and 3, and for scenarios 1 and 2, they were the same up to stage 3 .

This approach employed a much large set of decision variables because it was scenario specific. Let's define $x_{h k}^{t, z}$ as the percentage of number of trees would be harvested in commercial species group $\mathrm{h}$ and commercial size $\mathrm{k}$ at harvesting cycle $\mathrm{t}$ under scenario $\mathrm{z}$. For maximizing the NPV, the objective function became

$$
\max N P V=\sum_{z} \sum_{t} \frac{P_{r o b}(z) x_{h k}^{t, z} n v_{h k} P_{h k}}{(1+r)^{t}}
$$

Growth equations under each TGS bound constraints, and the constraint on that the sum of all scenarios added up to one still applied. Moreover, there were a set of non-anticipative constraints as described above.

The following constraints reflected multiple objectives in addition to the financial consideration.

1. Minimum level for species diversity.

$$
H_{s} \geq S P \min
$$

2. Minimum level for size diversity.

$$
H_{d} \geq S Z \min
$$

3. Minimum level for total carbon stock (ton ha $\left.{ }^{-1}\right)$.

Totalcarbon $\geq C \min$

The trade-off between economic and ecological criteria would be changed in the values of the objective function by relaxing one of the constraints while keeping everything else the same. 


\subsubsection{Integrated framework}

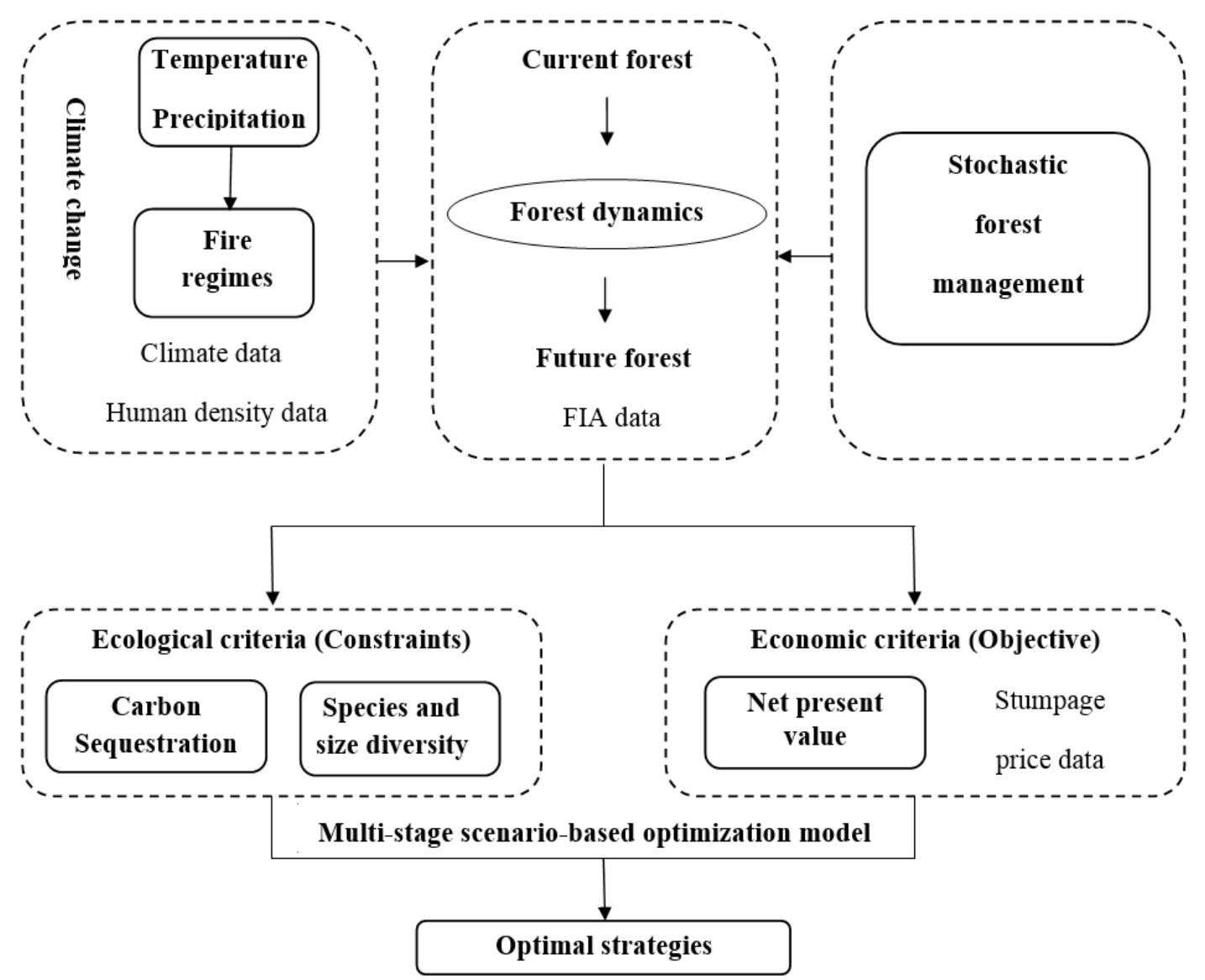

Figure 4-3 The integrated multi-stage scenario-based optimization framework.

Figure 4-3 illustrated the integrated multi-stage scenario-based optimization framework incorporating uncertainty in climate change and fire. In this framework, I coupled (1) forest dynamics, (2) mean fire interval, (3) population density, (4) future climate scenarios, (5) forest management, and (6) multi-stage scenario-based optimization to derive the optimal decision between economic and ecological criteria.

\subsection{Results}

When optimizing individual scenario, the maximum net present value (NPV) changed from $\$ 30,396$ to $\$ 35,378 \mathrm{ha}^{-1}$ for 36 scenarios with a harvesting cycle of 10 years, and $\$ 17,838$ to 
$\$ 18,992 \mathrm{ha}^{-1}(53.7 \%-58.7 \%$ of 10 years $)$ for 20 scenarios with doubled harvesting cycle. In addition, with a harvesting cycle of 10 years, maximum average species diversity varied from 1.69 to 2.02 and maximum average size diversity changed from 2.23 to 2.99 ; maximum carbon stocks varied from 1,041 to 1,420 ton $\mathrm{ha}^{-1}$. When harvesting every 20 years, maximum species diversity was consistently slightly lower, ranging from $1.59-1.88(93.1 \%-94.1 \%$ of 10 years $)$. The other two criteria were in general larger: the maximum average size diversity was between 2.38 and $2.91(97.3 \%-106.7 \%$ of 10 years $)$ while the maximum carbon stocks ranged from 1,492 to 1,672 ton $\mathrm{ha}^{-1}(117.8 \%-143.3 \%$ of 10 years) (Tables $4-2$ and $4-3)$. 
Table 4-2 The maximum, feasible and adaptive net present values (NPV) $\left(\$ h^{-1}\right)$, species

diversity $(\mathrm{Hs})$, size diversity $(\mathrm{Hd})$, and total carbon stocks (ton ha $\left.{ }^{-1}\right)$ in 2100 in each scenario, with harvesting cycle of 10 years, respectively.

\begin{tabular}{|c|c|c|c|c|c|c|c|c|c|c|c|c|}
\hline & \multicolumn{4}{|c|}{ Maximum values } & \multicolumn{4}{|c|}{ Feasible values } & \multicolumn{4}{|c|}{ Adaptive maximum values } \\
\hline Scenarios & $\mathrm{NPV}^{1}$ & $\mathrm{H}_{\mathrm{s}}$ & $\mathrm{H}_{\mathrm{d}}$ & Carbon & NPV & $\mathrm{H}_{\mathrm{s}}$ & $\mathrm{H}_{\mathrm{d}}$ & Carbon & NPV & $\mathrm{H}_{\mathrm{s}}$ & $\mathrm{H}_{\mathrm{d}}$ & Carbon \\
\hline A1 & $\mathbf{3 5 3 7 8}^{2}$ & 1.74 & 2.99 & 1420 & 35183 & 1.70 & 2.94 & 1354 & 35281 & 1.72 & 2.97 & 1387 \\
\hline A2 & 35180 & 1.79 & 2.96 & 1409 & 34791 & 1.75 & 2.87 & 1346 & 35096 & 1.73 & 2.92 & 1358 \\
\hline A3 & 34913 & 1.71 & 2.92 & 1392 & 34720 & 1.62 & 2.86 & 1338 & 34817 & 1.67 & 2.89 & 1314 \\
\hline A4 & 34496 & 1.69 & 2.87 & 1361 & 34287 & 1.65 & 2.79 & 1294 & 34390 & 1.65 & 2.83 & 1328 \\
\hline A5 & 33997 & 1.77 & 2.82 & 1323 & 33796 & 1.72 & 2.77 & 1245 & 33897 & 1.75 & 2.80 & 1284 \\
\hline A6 & 33384 & 1.81 & 2.73 & 1277 & 32998 & 1.77 & 2.68 & 1206 & 33110 & 1.76 & 2.71 & 1242 \\
\hline A7 & 32731 & 1.82 & 2.65 & 1214 & 32519 & 1.76 & 2.62 & 1150 & 32625 & 1.79 & 2.61 & 1182 \\
\hline A8 & 31924 & 1.88 & 2.56 & 1144 & 31735 & 1.82 & 2.49 & 1083 & 31830 & 1.81 & 2.53 & 1114 \\
\hline A9 & 31010 & 1.89 & 2.46 & 1066 & 30623 & 1.84 & 2.43 & 996 & 30727 & 1.87 & 2.42 & 1031 \\
\hline A10 & 35165 & 1.79 & 2.79 & 1405 & 34974 & 1.75 & 2.74 & 1336 & 34889 & 1.77 & 2.77 & 1371 \\
\hline A11 & 34979 & 1.83 & 2.78 & 1392 & 34805 & 1.78 & 2.71 & 1332 & 34692 & 1.81 & 2.75 & 1362 \\
\hline A12 & 34708 & 1.76 & 2.73 & 1373 & 34519 & 1.72 & 2.68 & 1319 & 34414 & 1.74 & 2.71 & 1292 \\
\hline A13 & 34277 & 1.72 & 2.71 & 1351 & 33884 & 1.67 & 2.64 & 1292 & 33991 & 1.70 & 2.68 & 1322 \\
\hline A14 & 33776 & 1.79 & 2.62 & 1307 & 33583 & 1.72 & 2.54 & 1241 & 33680 & 1.76 & 2.58 & 1274 \\
\hline A15 & 33159 & 1.82 & 2.57 & 1264 & 32973 & 1.77 & 2.50 & 1193 & 33066 & 1.80 & 2.54 & 1229 \\
\hline A16 & 32508 & 1.85 & 2.52 & 1192 & 32316 & 1.74 & 2.47 & 1135 & 32220 & 1.82 & 2.45 & 1107 \\
\hline A17 & 31696 & 1.91 & 2.40 & 1120 & 31503 & 1.87 & 2.36 & 1060 & 31600 & 1.85 & 2.38 & 1090 \\
\hline A18 & 30810 & 1.93 & 2.32 & 1055 & 30460 & 1.89 & 2.25 & 991 & 30565 & 1.91 & 2.29 & 1023 \\
\hline A19 & 34973 & 1.85 & 2.64 & 1382 & 34786 & 1.79 & 2.60 & 1314 & 34693 & 1.82 & 2.62 & 1348 \\
\hline A20 & 34788 & 1.88 & 2.62 & 1371 & 34602 & 1.82 & 2.58 & 1301 & 34595 & 1.85 & 2.56 & 1336 \\
\hline A21 & 34519 & 1.83 & 2.59 & 1353 & 34135 & 1.79 & 2.55 & 1290 & 34227 & 1.81 & 2.55 & 1260 \\
\hline A22 & 34096 & 1.81 & 2.57 & 1332 & 33903 & 1.76 & 2.52 & 1268 & 33807 & 1.79 & 2.53 & 1226 \\
\hline A23 & 33592 & 1.88 & 2.50 & 1287 & 33393 & 1.83 & 2.46 & 1223 & 33493 & 1.86 & 2.48 & 1195 \\
\hline A24 & 32960 & 1.85 & 2.47 & 1235 & 32787 & 1.79 & 2.39 & 1159 & 32874 & 1.82 & 2.43 & 1197 \\
\hline A25 & 32333 & 1.89 & 2.39 & 1174 & 31934 & 1.85 & 2.36 & 1112 & 32034 & 1.83 & 2.38 & 1143 \\
\hline A26 & 31532 & 1.94 & 2.28 & 1105 & 31329 & 1.88 & 2.24 & 1036 & 31431 & 1.91 & 2.27 & 1071 \\
\hline A27 & 30651 & 1.95 & 2.25 & 1048 & 30450 & 1.91 & 2.22 & 981 & 30551 & 1.93 & 2.21 & 1015 \\
\hline A28 & 34675 & 1.95 & 2.53 & 1364 & 34482 & 1.92 & 2.50 & 1309 & 34579 & 1.94 & 2.52 & 1337 \\
\hline A29 & 34499 & 1.99 & 2.52 & 1353 & 34299 & 1.92 & 2.47 & 1288 & 34399 & 1.95 & 2.50 & 1321 \\
\hline A30 & 34238 & 1.92 & 2.51 & 1335 & 34046 & 1.87 & 2.44 & 1275 & 34142 & 1.85 & 2.48 & 1305 \\
\hline A31 & 33824 & 1.88 & 2.48 & 1314 & 33407 & 1.82 & 2.41 & 1267 & 33516 & 1.88 & 2.45 & 1244 \\
\hline A32 & 33322 & 1.93 & 2.37 & 1269 & 33127 & 1.88 & 2.30 & 1212 & 33225 & 1.91 & 2.34 & 1201 \\
\hline A33 & 32691 & 1.89 & 2.34 & 1217 & 32495 & 1.85 & 2.26 & 1140 & 32592 & 1.87 & 2.30 & 1179 \\
\hline A34 & 32075 & 1.97 & 2.30 & 1156 & 31892 & 1.92 & 2.24 & 1086 & 31801 & 1.92 & 2.27 & 1121 \\
\hline A35 & 31282 & 1.99 & 2.25 & 1087 & 31092 & 1.95 & 2.19 & 1022 & 31187 & 1.94 & 2.22 & 1055 \\
\hline A36 & 30396 & 2.02 & 2.23 & 1041 & 30063 & 1.98 & 2.17 & 978 & 30165 & 1.99 & 2.20 & 1010 \\
\hline Weighted $^{3}$ & 33348 & - & - & - & 33108 & - & - & - & 33172 & - & - & - \\
\hline
\end{tabular}


Table 4-3 The maximum, feasible and adaptive net present values (NPV) $\left(\$ h^{-1}\right)$, species

diversity $(\mathrm{Hs})$, size diversity $(\mathrm{Hd})$, and total carbon stocks (ton ha $\left.{ }^{-1}\right)$ in 2100 in each scenario, with harvesting cycle of 20 years, respectively.

\begin{tabular}{|c|c|c|c|c|c|c|c|c|c|c|c|c|}
\hline & \multicolumn{4}{|c|}{ Maximum values } & \multicolumn{4}{|c|}{ Feasible values } & \multicolumn{4}{|c|}{ Adaptive maximum values } \\
\hline Scenarios & $\mathrm{NPV}^{1}$ & $\mathrm{H}_{\mathrm{s}}$ & $\mathrm{H}_{\mathrm{d}}$ & Carbon & NPV & $\mathrm{H}_{\mathrm{s}}$ & $\mathrm{H}_{\mathrm{d}}$ & Carbon & NPV & $\mathrm{H}_{\mathrm{s}}$ & $\mathrm{H}_{\mathrm{d}}$ & Carbon \\
\hline B1 & $18992^{2}$ & 1.61 & 2.91 & 1672 & 18693 & 1.59 & 2.85 & 1596 & 18749 & 1.56 & 2.87 & 1642 \\
\hline B2 & 18893 & 1.63 & 2.89 & 1656 & 18572 & 1.60 & 2.82 & 1581 & 18524 & 1.61 & 2.83 & 1623 \\
\hline B3 & 18764 & 1.59 & 2.86 & 1635 & 18354 & 1.51 & 2.79 & 1557 & 18407 & 1.54 & 2.82 & 1591 \\
\hline B4 & 18551 & 1.62 & 2.82 & 1595 & 18237 & 1.52 & 2.73 & 1522 & 18296 & 1.54 & 2.77 & 1560 \\
\hline B5 & 18302 & 1.66 & 2.77 & 1573 & 17999 & 1.64 & 2.68 & 1496 & 17955 & 1.63 & 2.72 & 1471 \\
\hline B6 & 18812 & 1.68 & 2.72 & 1666 & 18504 & 1.62 & 2.66 & 1571 & 18565 & 1.64 & 2.69 & 1599 \\
\hline B7 & 18724 & 1.74 & 2.70 & 1634 & 18322 & 1.68 & 2.63 & 1556 & 18265 & 1.69 & 2.65 & 1595 \\
\hline B8 & 18589 & 1.67 & 2.67 & 1607 & 18295 & 1.60 & 2.61 & 1534 & 18358 & 1.63 & 2.59 & 1506 \\
\hline B9 & 18385 & 1.59 & 2.65 & 1576 & 17988 & 1.53 & 2.59 & 1503 & 18034 & 1.54 & 2.58 & 1534 \\
\hline B10 & 18144 & 1.67 & 2.59 & 1528 & 17750 & 1.62 & 2.53 & 1448 & 17807 & 1.64 & 2.55 & 1476 \\
\hline B11 & 18680 & 1.73 & 2.56 & 1624 & 18375 & 1.70 & 2.49 & 1545 & 18423 & 1.69 & 2.52 & 1578 \\
\hline B12 & 18595 & 1.76 & 2.54 & 1603 & 18286 & 1.69 & 2.46 & 1528 & 18240 & 1.71 & 2.49 & 1501 \\
\hline B13 & 18464 & 1.74 & 2.53 & 1582 & 18148 & 1.66 & 2.43 & 1510 & 18191 & 1.69 & 2.47 & 1552 \\
\hline B14 & 18262 & 1.72 & 2.50 & 1564 & 17846 & 1.68 & 2.39 & 1492 & 17892 & 1.65 & 2.42 & 1530 \\
\hline B15 & 18009 & 1.81 & 2.43 & 1501 & 17703 & 1.75 & 2.37 & 1430 & 17756 & 1.78 & 2.35 & 1459 \\
\hline B16 & 18497 & 1.84 & 2.49 & 1611 & 18085 & 1.79 & 2.45 & 1538 & 18136 & 1.81 & 2.42 & 1572 \\
\hline B17 & 18427 & 1.86 & 2.46 & 1587 & 18123 & 1.80 & 2.41 & 1513 & 18172 & 1.78 & 2.40 & 1543 \\
\hline B18 & 18293 & 1.83 & 2.42 & 1566 & 17987 & 1.78 & 2.40 & 1485 & 18051 & 1.79 & 2.37 & 1522 \\
\hline B19 & 18095 & 1.87 & 2.41 & 1543 & 17784 & 1.70 & 2.36 & 1474 & 17830 & 1.74 & 2.34 & 1509 \\
\hline B20 & 17838 & 1.88 & 2.38 & 1492 & 17520 & 1.83 & 2.23 & 1413 & 17483 & 1.84 & 2.27 & 1449 \\
\hline Weighted $^{3}$ & 18466 & & - & - & 18129 & & & - & 18157 & & & \\
\hline
\end{tabular}

${ }^{1}$ The NPV was maximized with an annual interest rate of $3 \%$.

${ }^{2}$ The number in bold were the highest value achieved for one criterion among all scenarios.

${ }^{3}$ Weighted NPV $=\sum^{20} \frac{1}{20} N P V^{z}$.

With the global feasible-plan optimization, the highest NPV, species diversity, size

diversity, and carbon stocks were $\$ 35,183 \mathrm{ha}^{-1}, 1.98,2.94,1,354$ ton ha ${ }^{-1}$ with a harvesting cycle of 10 years, respectively. With cutting cycle of 10 years, the lowest NPV, species diversity, size diversity, and carbon stocks of all scenarios were $\$ 30,063 \mathrm{ha}^{-1}, 1.62,2.17$, and 978 , ton ha ${ }^{-1}$, respectively. Similarly, harvesting every 20 years led to much lower NPV, lower species diversity and size diversity, but significantly higher total carbon stock. The scenario B1 led to the highest NPV ( $\$ 18,693 \mathrm{ha}^{-1}, 53.1 \%$ of 10 years), size diversity $(2.85,96.9 \%$ of 10 years $)$, and carbon stocks $\left(1,596\right.$ ton ha ${ }^{-1}, 117.9 \%$ of 10 years), and the scenario B20 resulted in the highest species diversity. 
Using scenario-tree optimization, I found that the range of NPV, species diversity, size diversity, and carbon stocks were $\$ 30,165-\$ 35,281 \mathrm{ha}^{-1}, 1.65-1.99,2.20-2.97$, and 1,010 1,387 ton $\mathrm{ha}^{-1}$ when harvesting every 10 years. If the harvesting cycle doubled, the NPV, species diversity, size diversity, and carbon stocks varied from $\$ 17,483 \mathrm{ha}^{-1}, 1.54,2.27$, and 1,449 ton ha ${ }^{-1}$ to $\$ 18,749 \mathrm{ha}^{-1}, 1.84,2.87$, and 1,642 ton $\mathrm{ha}^{-1}$.

Clearly, with all three approaches, scenarios A1 and B1, both representing climate scenario RCP2.6 and the constant fire severity regime S1 consistently resulted in the highest values for NPV, size diversity, and total carbon stock; A36 and B20, denoting RCP 8.5 and change of fire severity regime from $\mathrm{S} 1$ to $\mathrm{S} 2$ in the last planning period produced the highest species diversity with both harvesting cycles. Among the values of the same criterion derived with all three methods, as expected, the one from optimizing the individual scenario was the highest. The values of the same criterion derived from scenario-tree optimization were higher than those from the feasible plan under most scenarios. In addition, warmer climate scenario and more severe fires resulted in lower NPV, size diversity, and total carbon stocks, but for species diversity, there existed no obvious trend.

When the species diversity, size diversity, and carbon weight increased from 1 to 10 , representing accelerating managerial priority on these ecological criteria, the NPV decreased from $\$ 32,214$ to $\$ 27,328 \mathrm{ha}^{-1}, \$ 32,214$ to $\$ 24,558 \mathrm{ha}^{-1}$, and $\$ 32,214$ to $\$ 21,489 \mathrm{ha}^{-1}$, respectively, with a cycle of 10 years, and from $\$ 17,577$ to $\$ 15,062 \mathrm{ha}^{-1}, \$ 17,577$ to $\$ 13,650$ $\mathrm{ha}^{-1}$, and $\$ 17,577$ to $\$ 12,071 \mathrm{ha}^{-1}$ when it doubled. In addition, one additional increase in one of these three weights would lead to a decline in the NPV decreased significantly at the beginning and less and less later when each unit of these weights increased from 1 to 10 (Figure 4-4). 

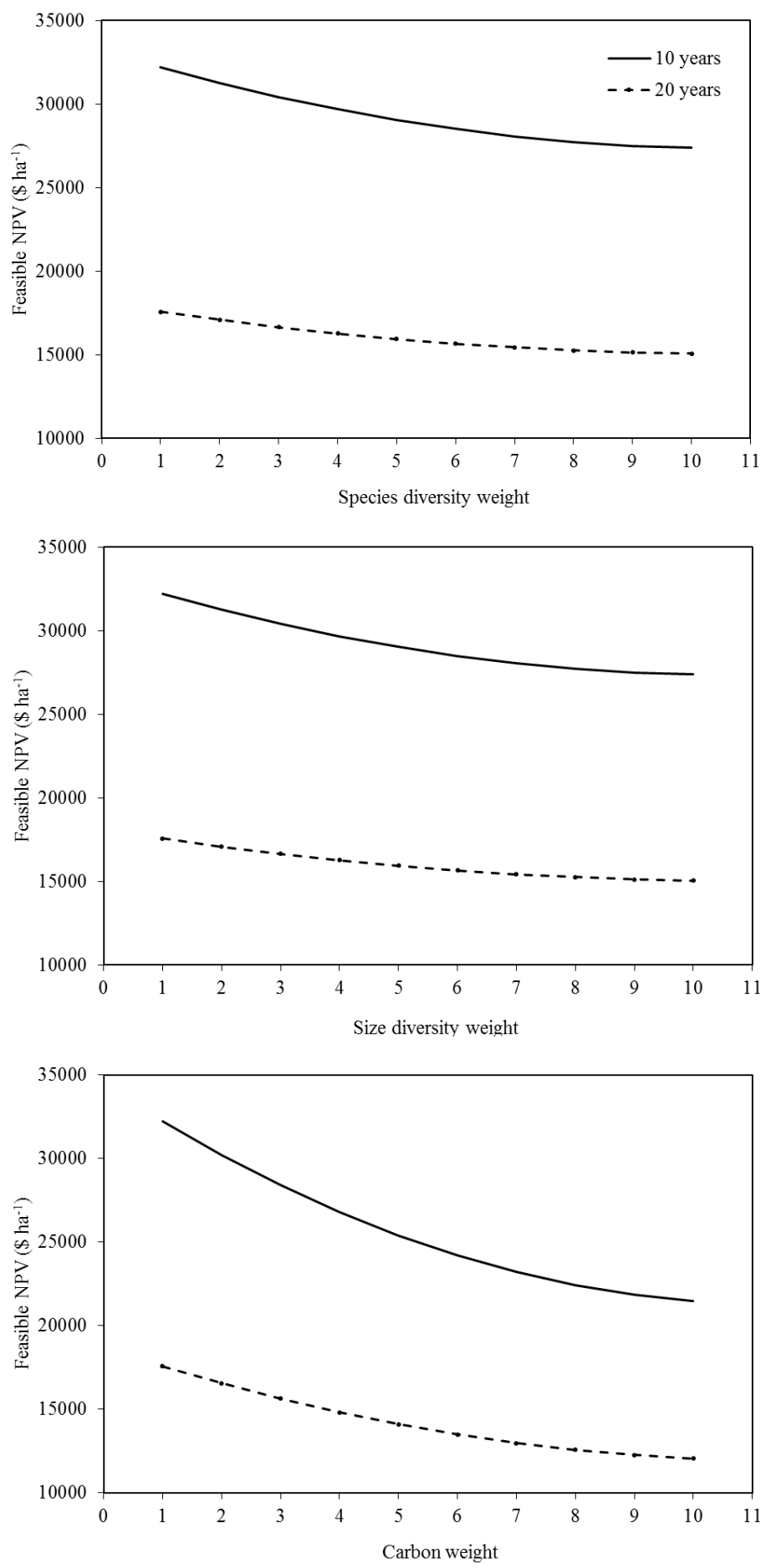

Figure 4-4 Changes of feasible net present value (NPV) over altering the weights of species diversity, size diversity, and carbon when other criterions fixed under global feasible-plan optimization. 
The average total harvesting basal area by planning stages, commercial sizes, and species groups with both harvesting cycles were shown in the Table 4-4. With a cycle of 10 years, the highest harvested basal areas were $3.51 \mathrm{~m}^{2} \mathrm{ha}^{-1}$ at stage 4 (2050), $9.65 \mathrm{~m}^{2} \mathrm{ha}^{-1}$ for large sawtimber, and $7.75 \mathrm{~m}^{2} \mathrm{ha}^{-1}$ for oak. The lowest were $2.03 \mathrm{~m}^{2} \mathrm{ha}^{-1}$ at stage 5 (2060), $5.19 \mathrm{~m}^{2} \mathrm{ha}^{-1}$ for poles, $3.78 \mathrm{~m}^{2} \mathrm{ha}^{-1}$ for maple. When the harvesting cycle doubled, the highest and lowest harvesting basal areas were $5.52 \mathrm{~m}^{2} \mathrm{ha}^{-1}$ at stage $2,3.56 \mathrm{~m}^{2} \mathrm{ha}^{-1}$ at stage $3,6.55 \mathrm{~m}^{2} \mathrm{ha}^{-1}$ for large sawtimber, $4.68 \mathrm{~m}^{2} \mathrm{ha}^{-1}$ for poles, and $6.56 \mathrm{~m}^{2} \mathrm{ha}^{-1}$ for oak, $2.52 \mathrm{~m}^{2} \mathrm{ha}^{-1}$ for other, respectively. 
Table 4-4. Summary statistics of feasible decision variables $\left(\mathrm{m}^{2} \mathrm{ha}^{-1}\right)$ by harvesting stages, commercial size classes, and commercial species classes with harvesting cycles of 10 years and 20 years.

\begin{tabular}{|c|c|c|}
\hline Harvest every 10 years & Mean & SD \\
\hline \multicolumn{3}{|l|}{ Harvest by stages } \\
\hline 1 & 2.26 & 0.14 \\
\hline 2 & 3.23 & 0.19 \\
\hline 3 & 3.01 & 0.17 \\
\hline 4 & $3.51 *$ & 0.18 \\
\hline 5 & 2.03 & 0.15 \\
\hline 6 & 2.24 & 0.13 \\
\hline 7 & 2.43 & 0.40 \\
\hline 8 & 2.63 & 0.37 \\
\hline \multicolumn{3}{|l|}{ Harvest by sizes } \\
\hline Poles & 5.19 & 1.39 \\
\hline Small sawtimber & 6.48 & 0.81 \\
\hline Large sawtimber & 9.65 & 1.42 \\
\hline \multicolumn{3}{|l|}{ Harvest by species } \\
\hline Oak & 7.45 & 1.01 \\
\hline Hickory & 4.05 & 0.41 \\
\hline Maple & 3.78 & 0.38 \\
\hline Other & 6.05 & 1.37 \\
\hline \multicolumn{3}{|l|}{ Harvest every 20 years } \\
\hline \multicolumn{3}{|l|}{ Harvest by stages } \\
\hline 1 & 4.52 & 0.28 \\
\hline 2 & 5.52 & 0.38 \\
\hline 3 & 3.56 & 0.29 \\
\hline 4 & 3.68 & 0.80 \\
\hline \multicolumn{3}{|l|}{ Harvest by sizes } \\
\hline Poles & 4.68 & 1.39 \\
\hline Small sawtimber & 6.06 & 0.81 \\
\hline Large sawtimber & 6.55 & 1.40 \\
\hline \multicolumn{3}{|l|}{ Harvest by species } \\
\hline Oak & 6.56 & 1.01 \\
\hline Hickory & 3.06 & 0.41 \\
\hline Maple & 2.52 & 0.38 \\
\hline Other & 5.15 & 1.29 \\
\hline
\end{tabular}

\subsection{Discussion and Conclusion}

In this study, multi-stage optimization models were developed for determining management plans under climate and fire uncertainty. Four climate scenarios and two fire severity regimes 
were transformed into tree growth scenarios, which were the basis for the proposed approaches, using a climate-sensitive matrix growth model and a mean fire interval model. A total of 36 scenarios for a harvesting cycle of 10 years and 20 scenarios for a harvesting cycle of 20 years were constructed. These scenarios were integrated into the optimization model to determine how much timber would be cut in each future period so that four management objectives were maximized.

Considering uncertainty is necessary in the development of forest management (Pasalodos et al., 2013). The principal contribution of this work consisted in formally incorporating uncertainty of climate change and associated fire into forest management through the analysis and optimization of discrete scenarios. Although the scenario-tree optimization moderately outperformed the global feasible plan in most scenarios, the latter was remarkably simpler to formulate and easier to solve. Besides, it had practical appeal to private landowners who usually do not modify forest management practices to adaptive changes as the other landowners. Thus, a management plan that was feasible under all scenarios while producing results relatively close to a much more sophisticated adaptive plan would appeal more to private landowners, especially NIPF owners in practice.

Uncertainty in climate affects economic and ecological returns for forest landowners and managers in the long term (Bodin and Wiman, 2007; Zhou, 2015). Wildfires have impacts on vast areas and cause great damages with significant and lasting effects on ecosystem services, economy, and society (Lampin-Maillet et al., 2010). As shown in this study, when a warmer climate and more severe fires were simultaneously considered, the NPV and carbon stocks decreased. This was as expected because shorter and more severe fires would damage forests and cause loss in biomass and consequent timber income. This work also suggested that higher 
species diversity and lower size diversity would be produced by warmer climate and more severe fire disturbance. One possible explanation is that warmer climate and more serious fires reduced large-diameter trees and increased growth of shade-tolerant species thus decreased size diversity and increased species diversity.

In addition, the results presented here had major implications for fire prevention and protection policy and practices. The switch to more frequent and severe fires under climate change would require more public resources towards prevention in the CHR forests most of which are owned privately, in particular towards regions at higher risk of fire. Improving communication with communities, especially with private landowners, and establishing partnerships with insurers would be part of a broad spectrum of prevention approaches (Calkin et al. 2011) and help to direct private resources towards effective fire prevention. Improving the effectiveness of prevention program and rapid-response suppression operations should be prioritized (Thompson and Calkin, 2011). Overall, fire prevention and protection should be a central piece of climate change mitigation strategies for the CHR forests.

Applying stochastic scenarios is proved to be superior to only using fixed management regimes (Alonso-Ayuso et al. 2011; Veliz et al. 2015), because the stochastic scenarios were generated as variations in historical data. Without considering any constraints for the optimization approach, the maximum NPV varied from $\$ 30,396$ to $\$ 35,378 \mathrm{ha}^{-1}$ for 36 scenarios with harvesting every 10 years, and $\$ 17,838$ to $\$ 18,992 \mathrm{ha}^{-1}(53.7 \%-58.7 \%$ of 10 years) for 20 scenarios with doubled harvesting cycle. Under both harvesting cycles, all the maximum NPVs were higher than the highest NPVs (10 years: $\$ 27,440$ ha $^{-1}, 20$ years: $\$ 13,757$ $\mathrm{ha}^{-1}$ ) in the fixed management (Chapter 3). The optimization approach produced 9.7\%-22.4\% (10 years) and $29.7 \%-38.1 \%$ (20 years) more NPV than the deterministic approach. The results 
suggested that the fixed management regimes were always inferior and landowners could benefit substantially from adopting optimization-based management rules, consistent with studies such as Garcia-Gonzalo et al., (2016). This study further revealed that the NPVs with a 10-year harvesting cycle were almost twice of 20 years, but carbon stocks were only $15.1 \%-30.2 \%$ lower for all scenarios. This indicated that more frequent harvests might produce higher NPVs without causing significant reductions of carbon stocks.

The global feasible model seeks to overcome limitations of classical optimization approaches for dealing with uncertainty (Better and Glover, 2008). In this study, the global feasible model was augmented with additional constraints on ecological criteria, resulting in multiple-objective management. For all three criteria, the marginal change in NPV for one additional unit of weight continuously declined as the ecological criteria improved (Figure 4-4). This illustrates that the opportunity cost of ecological conservation is not linear with the change in ecosystem conditions, suggesting that conservation incentives or subsidies for private landowners should not be "flat-rate". Furthermore, increasing carbon storage would cost more than enhancing species and size diversity. However, if these additionally stored carbon stocks were to be traded in a carbon market, the loss in NPV could be at least partially offset by the income from selling carbon credits. For example, with a ten-year cutting cycle, changing the carbon weight from 1 to 10 was equivalent to storing 524 ton ha ${ }^{-1}$ of additional carbon by 2100 . At the present national average carbon price of $\$ 5$ ton $^{-1}$, the potential carbon income could be up to $\$ 2,620 \mathrm{ha}^{-1+}$ while a carbon price of $\$ 30$ ton $^{-1}$ as suggested by the U.S. Environmental Protection Agency (EPA) could generate an income up to $\$ 15,720 \mathrm{ha}^{-1}$, if no enrollment and inventory costs were to be considered. Therefore, both ecological and financial gains could stem from sustainably managing CHR forests in the presence of an active carbon market. However, 
high uncertainty in the U.S. climate policy renders the economic potential of sustainably managing forests for carbon credits highly uncertain, discouraging landowners from participating in such practices (Zhou, 2015). It would be of interest to incorporate uncertain carbon prices in the current framework to shed lights on the economic and ecological consequences of policy uncertainty. Note that only four carbon pools were accounted for in this study as suggested by (Penman et al. 2003). Carbon stored in coarse roots and harvested wood products calls for an examination in the future.

With the global feasible-plan optimization, the decisions for each planning stage, species, and size provided valuable guidelines for CHR landowners and managers. As suggested by Table 4-4, more harvest at the middle stage of large oak trees and less harvest of small softwoods, beech, and maple trees thereafter might produce greater NPV with both harvesting cycles.

This study demonstrated the value of explicitly introducing uncertainty of climate change and associated fire using an optimization approach. This enabled the forest planner to make more informed and robust decisions based on a range of climate and fire scenarios over time instead of merely analyzing a deterministic situation. A possible extension of this work would be to consider uncertainty from other sources, such as wind, insects, timber market fluctuation and policy changes. In particular, the timber market would likely experience structural changes given the predicted species shift from oaks to maples. Thus it would be of importance to address this issue for managerial purposes. In addition, future research efforts could also be directed towards solving large-scale landscape management problems for two reasons: 1 . Forest stands interact through disturbances, such as fire diffusion. 2. The provision of ecosystem services are impacted by the extent and structure of forested landscape. But the major difficulty lies in the curse of dimensionality - as more scenarios and more stands were to be included over time, the number of 
decision variables would increase exponentially. Therefore the presentation of a realistic problem for a long period would become intractable. Even approximate solutions may sometimes be difficult to achieve. How to compactly represent and efficiently solve large-scale problems within the scenario-optimization framework remains an open question and deserve future research efforts.

\section{Acknowledgement}

This study was supported by the Davis College of Agriculture, Natural Resources \& Design, West Virginia University, under the US Department of Agriculture (USDA) McIntire-Stennis Funds WVA00105. 


\section{References}

Ahmed S, King AJ, Parija G (2003) A multi-stage stochastic integer programming approach for capacity expansion under uncertainty. Journal of Global Optimization, 26, 3-24.

Alonso-Ayuso A, Escudero LF, Guignard M, Quinteros M, Weintraub A (2011) Forestry management under uncertainty. Annals of Operations Research, 190, 17-39.

Buongiorno J, Zhou M (2011) Further generalization of Faustmann's formula for stochastic interest rates. Journal of Forest Economics, 17, 248-257.

Blyth W, Yang M, Bradley R (2007) Climate policy uncertainty and investment risk. OECD Publishing.

Bos E, Vu M, Massiah E, Bulatao R (1994) World Population Projections 1994-95: Estimates and projections with related demographic statistics. New York: Johns Hopkins University Press.

Birge JR, Louveaux F (2011) Introduction to stochastic programming. Springer Science \& Business Media.

Bodin P, Wiman BL (2007) The usefulness of stability concepts in forest management when coping with increasing climate uncertainties. Forest Ecology and Management, 242, 541552.

Better M, Glover F (2008) Scenario-based risk management and simulation optimization. Encyclopedia of Quantitative Risk Analysis and Assessment.

Calkin DC, Finney MA et al. (2011) Progress towards and barriers to implementation of a risk framework for US federal wildland fire policy and decision making. Forest Policy and Economics, 13, 378-389. 
Eyvindson K, Kangas A (2014) Stochastic goal programming in forest planning. Canadian Journal of Forest Research, 44, 1274-1280.

Garcia-Gonzalo J, Pais C, Bachmatiuk J, Weintraub A (2016) Accounting climate change in a stochastic optimization model in forest planning. Canadian Journal of Forest Research(ja).

Gove JH, Fairweather SE (1992) Optimizing the management of uneven-aged forest stands: a stochastic approach. Forest Science, 38, 623-640.

Guyette RP, Stambaugh MC, Dey DC (2010) Developing and using fire scar histories in the Southern and Eastern United States. Joint Fire Science Program Final Report.

Gonzalez JR, Palahi M, Trasobares A, Pukkala T (2006) A fire probability model for forest stands in Catalonia (north-east Spain). Annals of Forest Science, 63,169-176.

Hildebrandt P, Knoke T (2011) Investment decisions under uncertainty-a methodological review on forest science studies. Forest Policy and Economics, 13, 1-15.

Hanewinkel M, Hummel S, Albrecht A (2011) Assessing natural hazards in forestry for risk management: a review. European Journal of Forest Research, 130, 329-351.

Hicks RR (1998) Ecology and management of central hardwood forests, John Wiley \& Sons.

Liang J, Buongiorno J, Monserud RA (2006) Bootstrap simulation and response surface optimization of management regimes for Douglas-fir/western hemlock stands. Forest Science, 52, 579-594.

Lin CR, Buongiorno J (1998) Tree diversity, landscape diversity, and economics of maple-birch forests: implications of Markovian models. Management Science, 44, 1351-1366. 
Lampin-Maillet C, Jappiot M et al. (2010) Mapping wildland-urban interfaces at large scales integrating housing density and vegetation aggregation for fire prevention in the South of France. Journal of Environmental Management, 91, 732-741.

Ma W, Zhou M (2016) Assessments of management impacts on central hardwood forests under climate and fire uncertainty. Forest Science (Under review).

Ma W, Liang J, Cumming JR et al. (2016) Fundamental shifts of central hardwood forests under climate change. Ecological Modelling, 332, 28-41.

Millar CI, Stephenson NL, Stephens SL (2007) Climate change and forests of the future: managing in the face of uncertainty. Ecological applications, 17, 2145-2151.

Miller GW, Schuler TM, Smith HC (1995) Method for applying group selection in central Appalachian hardwoods. USDA For. Serv. Res. Pap. NE-696.

Miller GW, Johnson JE, Baumgras JE (1997) Deferment cutting in central Appalachian hardwoods: an update. Forest Landowner, 56, 28-31.

Perry DA, Maghembe J (1989) Ecosystem concepts and current trends in forest management: time for reappraisal. Forest Ecology and Management, 26, 123-140.

Pasalodos-Tato M, Makinen A, et al. (2013). Assessing uncertainty and risk in forest planning and decision support systems: review of classical methods and introduction of new approaches. Forest Systems. 22, 282-303.

Penman J, Gytarsky M, et al. (2003) Good practice guidance for land use, land-use change and forestry. Institute for Global Environmental Strategies.

Reeves LH, Haight RG (2000) Timber harvest scheduling with price uncertainty using Markowitz portfolio optimization. Annals of Operations Research, 95, 229-250. 
Rockafellar RT, Wets RJ (1991) Scenarios and policy aggregation in optimization under uncertainty. Mathematics of operations research, 16, 119-147.

Sharon W, Barbara L, Barbara M, et al. (2011) The forest inventory and analysis database: database description and users manual version 5.1 for phase 2 .

Sturtevant BR, Scheller RM, et al. (2009) Simulating dynamic and mixed-severity fire regimes: a process-based fire extension for LANDIS-II. Ecological Modelling, 220, 3380-3393.

Tahvonen O, Kallio M (2006) Optimal harvesting of forest age classes under price uncertainty and risk aversion. Natural Resource Modeling, 19, 557-585.

Thompson MP, Calkin DE (2011) Uncertainty and risk in wildland fire management: a review. Journal of Environmental Management, 92, 1895-1909.

Veliz FB, Watson JP, Weintraub A et al. (2015) Stochastic optimization models in forest planning: A progressive hedging solution approach. Annals of Operations Research, 232, 259-274.

Wets RJ (1975) On the relation between stochastic and deterministic optimization. Control Theory, Numerical Methods and Computer Systems Modelling.

Yousefpour R, Jacobsen JB, et al. (2012) A review of decision-making approaches to handle uncertainty and risk in adaptive forest management under climate change. Annals of Forest Science, 69, 1-15.

Yang J, He HS, Gustafson EJ (2004) A hierarchical fire frequency model to simulate temporal patterns of fire regimes in LANDIS. Ecological Modelling, 180, 119-133.

Zhou M, Liang J, Buongiorno J (2008a) Adaptive versus fixed policies for economic or ecological objectives in forest management. Forest Ecology and Management, 254, 178187. 
Zhou M, Buongiorno J, Liang J (2008b) Economic and ecological effects of diameter caps: a Markov decision model for Douglasfir/Western hemlock forests. Forest Science, 54, 397407.

Zhou M, Buongiorno J (2006) Forest landscape management in a stochastic environment, with an application to mixed loblolly pine-hardwood forests. Forest Ecology and Management, 223, 170-182.

Zhou M, Buongiorno J (2011) Effects of stochastic interest rates in decision making under risk: a Markov decision process model for forest management. Forest Policy and Economics, 13, 402-410.

Zhou M (2015) Adapting sustainable forest management to climate policy uncertainty: A conceptual framework. Forest Policy and Economics, 59, 66-74. 
5. Summary 
At first, I built an integrated framework to synchronously couple forest dynamics, mean fire interval, population density, and future climate scenarios for the CHR forests. The framework predicted a transition of dominant species from oak and hickory to maple species, reduced species diversity, and substantial declines in stand basal area and volume, from the present to 2100. These projections may have profound ecological and economic implications and call for adaptive management strategies and policies in response to predicted species shifts and associated changes in ecosystem services. Additionally, I quantified how various management intensities would influence the CHR forests in terms of the NPV, tree diversity, and carbon stocks in four pools. Predictions were based on simulations of forest growth under fire uncertain and subject to low, medium, and high management intensities in four IPCC future climate scenarios. Partial harvesting practice, diameter-limit harvesting, and diameter-cap harvesting were assessed with harvesting cycles of 10 and 20 years. Finally, I developed a multi-stage scenario-based optimization model that accounts for uncertainty in climate change and associated fire disturbance in an effort to determine the tradeoff between economic and ecological benefits and derive optimal decision. According to the results obtain from this study, the following conclusions can be drawn:

(1) The total stand basal area in CHR would decline dramatically and converge to around $14.9 \mathrm{~m}^{2} \mathrm{ha}^{-1}$ for RCP2.6, followed by $14.2 \mathrm{~m}^{2} \mathrm{ha}^{-1}$ for RCP4.5, $14.0 \mathrm{~m}^{2} \mathrm{ha}^{-1}$ for RCP6.0, and the lowest $13.0 \mathrm{~m}^{2} \mathrm{ha}^{-1}$ for RCP8.5. Similarly, total stand volume converged to $330 \mathrm{~m}^{3} \mathrm{ha}^{-1}$ for RCP2.6, followed by $313 \mathrm{~m}^{3} \mathrm{ha}^{-1}$ for RCP4.5, $310 \mathrm{~m}^{3} \mathrm{ha}^{-1}$ for RCP6.0, and $308 \mathrm{~m}^{3} \mathrm{ha}^{-1}$ for RCP8.5. Tree size diversity increased by 27.9 - 30.6\% over the first 20 years, and then decreased to a level similar to the present. In contrast, tree species diversity would gradually decline by 9.6 
$-11.5 \%$ over the next 90 years. These changes in forest structure within the CHR will have regional ecological and economic repercussions.

(2) Low intensity would have the highest carbon stocks and size diversity but generate the lowest NPV and species diversity; medium intensity would lead to lower carbon stocks but produce satisfactory species diversity, size diversity, and NPV; high intensity would result in the lowest carbon stocks and size diversity while have the highest NPV and species diversity. However, diameter-cap harvesting had opposite trend for species diversity. The NPV of harvests with a harvesting cycle 10-year was more than twice of that with 20 years, but carbon stocks were only $1.3 \%-5.0 \%$ lower. In addition, more intensive harvests of oak trees, which produced highest carbon stocks among all management criteria, would lead to higher NPV (453\%-625\%), size diversity $(14.5 \%-18.4 \%)$ and carbon stocks $(4.1 \%-5.8 \%)$, but lower species diversity $(14.7 \%-20.3 \%)$, than of maple trees with both harvesting cycles.

(3) Four future climate scenarios and attendant fire intervals combined with two fire severity regimes were transformed into 36 and 20 tree growth scenarios for harvesting cycles of 10 and 20 years, respectively. With a single management objective, the maximum NPV varied from $\$ 30,396$ to $\$ 35,378 \mathrm{ha}^{-1}$ for 36 scenarios with harvesting every 10 years, and $\$ 17,838$ to $\$ 18,992 \mathrm{ha}^{-1}(53.7 \%-58.7 \%$ of 10 years $)$ for 20 scenarios with doubled harvesting cycle. Under both harvesting cycles, the optimization approach produced $9.7 \%-22.4 \%$ (10 years) and $29.7 \%$ $-38.1 \%$ (20 years) more NPV than fixed management rules. The multi-criteria model revealed that the opportunity cost of storing additional carbon was much higher than enhancing tree species and size diversity. In addition, for all three criteria, the marginal change in NPV for one additional unit of weight continuously declined as the ecological criteria improved. 


\section{Appendix A. Supplemental Information for Chapter 2}

\section{Matrix Growth Model Structure}

$\mathbf{G}_{t}$ and $\mathbf{G}_{i t}$ are matrices used to model stand dynamics, where:

$\mathbf{G}_{t}=\left[\begin{array}{llll}\mathbf{G}_{1 t} & & & \\ & \mathbf{G}_{2 t} & & \\ & & \ddots & \\ & & & \mathbf{G}_{m, t}\end{array}\right]$

$\mathbf{G}_{i t}=\left[\begin{array}{ccccc}a_{i 1, t} & & & & \\ b_{i 1, t} & a_{i 2, t} & & & \\ & \ddots & \ddots & & \\ & & b_{i, n-2, t} & a_{i, n-1, t} & \\ & & & b_{i, n-1, t} & a_{i, n, t}\end{array}\right]$

in which $a_{i j t}$ represented the probability that a tree of species $i$ and diameter class $j$ stays alive in the same diameter class between $t$ and $t+1 . b_{i j t}$, the probability of upgrowth, was estimated as the tree diameter growth $g_{i j t}$ between $t$ and $t+1$ divided by the width of the diameter class, assuming that trees were evenly distributed within a diameter class. $a_{i j t}$ and $b_{i j t}$ were related by:

$a_{i j t}=1-b_{i j t}-m_{i j t}$

where $m_{i j t}$ was the probability of tree mortality between $t$ and $t+1$.

$\mathbf{R}$ was a state-, time-, and climate-dependent recruitment vector representing the number of trees naturally recruited in the smallest diameter class of each species, between $t$ and $t+1$ :

$\mathbf{R}_{t}=\left[\begin{array}{c}\mathbf{R}_{1 t} \\ \mathbf{R}_{2 t} \\ \vdots \\ \mathbf{R}_{m, t}\end{array}\right], \quad \mathbf{R}_{i t}=\left[\begin{array}{c}R_{i t} \\ 0 \\ \vdots \\ 0\end{array}\right]$ 
The diameter growth of the $k^{\text {th }}$ tree of species $i$ and size class $j$ from $t$ and $t+l$ was represented by the following model:

$g_{i j t k}=\alpha_{i 1}+\alpha_{i 2} D_{t k}+\alpha_{i 3} D_{t k}^{2}+\alpha_{i 4} B+\alpha_{i 5} C+\alpha_{i 6} E+\alpha_{i 7} S+\alpha_{i 8} H_{d}+\alpha_{i 9} H_{s}+\alpha_{i 10} T+\alpha_{i 11} P+\varepsilon_{i j}$

in which $\alpha_{i}$ 's were parameters to be estimated with the generalized least squares (GLS, see (Rao, 1973)) for species $i$. Diameter growth of species $i$ and diameter class $j, g_{i j t}$ was then calculated with Eq. (S4) in which $D_{t k}$ was replaced by the midpoint of each diameter class $D_{j}$.

Tree mortality, $m_{i j t}$, was estimated with a Probit function:

$m_{i j t k}=\Phi\left(\delta_{i 1}+\delta_{i 2} D_{t k}+\delta_{i 3} D_{t k}{ }^{2}+\delta_{i 4} B+\delta_{i 5} C+\delta_{i 6} E+\delta_{i 7} S+\delta_{i 8} H_{d}+\delta_{i 9} H_{s}+\delta_{i 10} T+\delta_{i 11} P\right)+\xi_{i j}$

where $\Phi$ was the standard normal cumulative function, $\delta_{i s}$ were parameters estimated by maximum likelihood. Mortality of species $i$ and diameter class $j, m_{i j t}$ was then calculated with Eq. (S5) in which $D_{t k}$ was replaced by the midpoint of each diameter class $D_{j}$.

Recruitment of species $i, R_{i}$ was estimated with a Tobit model (Tobin, 1958a, b):

$R_{i t}=\Phi\left(\beta_{i} x_{i t} \sigma_{i}^{-1}\right) \beta_{i} x_{i t}+\sigma_{i} \varphi\left(\beta_{i} x_{i t} \sigma_{i}^{-1}\right)$

with

$\beta_{i} x_{i t}=\beta_{i 1}+\beta_{i 2} N+\beta_{i 3} N^{2}+\beta_{i 4} B+\beta_{i 5} C+\beta_{i 6} E+\beta_{i 7} S+\beta_{i 8} H_{d}+\beta_{i 9} H_{s}+\beta_{i 10} T+\beta_{i 11} P+\mu_{i j}$

where $\Phi$ was the standard normal cumulative distribution function and $\varphi$ was the standard normal probability density function. The Tobit model explicitly accounts for unobserved recruitment values that are left-censored at the preset diameter limit $(2.54 \mathrm{~cm})$.

\section{Stand Volume Model}

Total stand volume are calculated with the following equation:

$\mathbf{v}_{i}=\mathbf{v}^{\prime} \mathbf{y}_{t}$ 
where $\mathbf{v}$ was a vector of single-stem volume by size and species $\left(v_{i j}\right)$, which was represented by the following full model:

$$
\ln \left(v_{i, j}+1\right)=\theta_{i 1}+\theta_{i 2} \ln \left(D_{t k}+1\right)+\theta_{i 3} \ln \left(D_{t k}+1\right)^{2}+\theta_{i 4} \ln (B+1)+\theta_{i 5} \ln (C+1)+\omega_{i j}
$$

Table 1 shows a complete list of the explanatory variables. Diameter and its square $(D$, $D^{2}$ ) were used in the individual tree models (diameter growth, mortality) to capture the nonlinear effects of diameter. The number of trees of that species and its square $\left(N_{i}, N_{i}{ }^{2}\right)$, representing the size of seed bank (Peterson et al., 2013), were only used in the stand-level recruitment model. Many existing Matrix models used basal area $(B)$ and site productivity $(C)$ as key predictors, due to their significant effects on forest dynamics (Namaalwa et al., 2005; Boltz and Carter, 2006). Physiographic variables, elevation $(E)$ and slope $(S)$ were used to control for the site productivity (Lennon et al., 2002). In addition, stand diversity metrics of structural and species diversity were included to explicitly account for the effects of diversity on forest dynamics (Gustafson and Crow, 1996). Both structural $\left(H_{\mathrm{s}}\right)$ and species diversity $\left(H_{\mathrm{d}}\right)$ were calculated with Shannon's formulas (Pielou, 1977a).

$$
H_{s}=-\sum_{i=1}^{m} \frac{B_{i}}{B} \ln \left(\frac{B_{i}}{B}\right) \quad H_{d}=-\sum_{j=1}^{n} \frac{B_{j}}{B} \ln \left(\frac{B_{j}}{B}\right)
$$

where $B_{i}, B_{j}$ and $B$ were, respectively, the basal area of species group $i$, size-class $j$ and total basal area.

\section{Mean Fire Interval Model}

The MFI was predicted with the following equation, in the unit of years:

$$
M F I=C \cdot e^{-0.139 a+1.50 b-2.41 \cdot c+0.00763 d}
$$

In which $\boldsymbol{C}$ was a constant and took the value of 59.12 for average-intensity fire models, 69.17 
for low severity fire models, and 108.19 for high severity fire models. $a$ was the mean maximum temperature $\left({ }^{\circ} \mathrm{C}\right), b$ was the reciprocal moisture index $\left(1 / \mathrm{cm} /{ }^{\circ} \mathrm{C}\right), c$ was human population density (per $\left.\mathrm{km}^{2}\right)$, and $d$ was the mean annual total precipitation $(\mathrm{cm})$.

Fire, as a bottom-up disturbance, has various impacts on species and affects smaller size classes first. Five fire tolerance classes (FTC's) were designed to reflect the difference in fire tolerance among species. Based on the biological characteristic, Fagus (FG) had the lowest fire tolerance (I) and Gymnosperms (GS) had the highest fire tolerance (V). Other Angiosperms (OA) and Sapindaceae (SD) are designated as categories II and III, respectively, while Quercus Quercus (QQ), Quercus - Lobatae (QL), and Juglandaceae (JD) are assigned to IV (Starker, 1934). Fire susceptibility classes (FSC's) were designed to reflect differences related to tree sizes within each species group. I defined the diameter size-span proportions (He and Mladenoff, 1999) as the ratio of diameter size to tree total diameter. Five diameter size-span proportions (0-20, 21-50, 51-70, 71-85, and 85-100\%) corresponded to diameter size classes 1-3, 4-8, 9-11, 12-14, and 15-17, and each represented a FSC from $\mathbf{A}$ to $\mathbf{E}$, respectively. Class $\mathbf{A}$ was the most susceptible to fire-induced mortality, and class $\mathbf{E}$ was the least susceptible. Whether a species group of a certain range of diameter sizes can survive a fire event of a given severity class were jointly determined by FTC and FSC. Five fire severity levels (He and Mladenoff, 1999) were defined and their impacts varied across FSC and FTC. For example, a severity level 1 fire would kill most FG) trees (FTC I) except for those with the largest diameter (FSC E), but had no impact on QQ, QL, and JD (FTC IV). When a severity level 5 fire occurred, all trees were to be removed (Table S6). 
Table A1. Species frequency in terms of basal area in the CHR.

\begin{tabular}{|c|c|c|}
\hline Common name & Scientific name & Frequency $(\%)$ \\
\hline \multicolumn{3}{|c|}{ Quercus - Quercus (QQ) } \\
\hline White oak & Quercus alba & 13.94 \\
\hline Chestnut oak & Quercus prinus & 3.33 \\
\hline Post oak & Quercus stellata & 3.10 \\
\hline Chinkapin oak & Quercus mиеhlenbergii & 2.09 \\
\hline Swamp white oak & Quercus bicolor & 0.06 \\
\hline Bur oak & Quercus macrocarpa & 0.03 \\
\hline Swamp chestnut oak & Quercus michauxii & 0.02 \\
\hline \multicolumn{3}{|c|}{ Quercus - Lobatae (QL) } \\
\hline Black oak & Quercus velutina & 10.94 \\
\hline Northern red oak & Quercus rubra & 5.77 \\
\hline Scarlet oak & Quercus coccinea & 2.70 \\
\hline Southern red oak & Quercus falcata & 1.03 \\
\hline Pin oak & Quercus palustris & 0.50 \\
\hline Blackjack oak & Quercus marilandica & 0.45 \\
\hline Shumard oak & Quercus shumardii & 0.21 \\
\hline Cherrybark oak & Quercus pagoda & 0.20 \\
\hline Shingle oak & Quercus imbricaria & 0.18 \\
\hline Willow oak & Quercus phellos & 0.05 \\
\hline Water oak & Quercus nigra & 0.04 \\
\hline \multicolumn{3}{|c|}{ Juglandaceae (JD) } \\
\hline Pignut hickory & Carya glabra & 4.67 \\
\hline Mockernut hickory & Carya alba & 3.10 \\
\hline Shagbark hickory & Carya ovata & 3.00 \\
\hline Hickory spp. & Carya spp. & 2.06 \\
\hline Bitternut hickory & Carya cordiformis & 1.39 \\
\hline Black walnut & Juglans nigra & 1.14 \\
\hline Black hickory & Carya texana & 0.79 \\
\hline Shellbark hickory & Carya laciniosa & 0.16 \\
\hline Sand hickory & Carya pallida & 0.05 \\
\hline Butternut & Juglans cinerea & 0.04 \\
\hline Red hickory & Carya ovalis & 0.02 \\
\hline Pecan & Carya illinoinensis & 0.01 \\
\hline \multicolumn{3}{|c|}{ Sapindaceae (SD) } \\
\hline Sugar maple & Acer saccharum & 4.50 \\
\hline Red maple & Acer rubrum & 4.42 \\
\hline Boxelder & Acer negundo & 0.14 \\
\hline Silver maple & Acer saccharinum & 0.07 \\
\hline Florida maple & Acer barbatum & 0.06 \\
\hline Striped maple & Acer pensylvanicum & 0.04 \\
\hline \multicolumn{3}{|c|}{ Gymnosperms (GS) } \\
\hline Eastern redcedar & Juniperus virginiana & 1.79 \\
\hline Shortleaf pine & Pinus echinata & 0.73 \\
\hline Virginia pine & Pinus virginiana & 0.68 \\
\hline Eastern white pine & Pinus strobus & 0.46 \\
\hline Eastern hemlock & Tsuga canadensis & 0.43 \\
\hline Pitch pine & Pinus rigida & 0.13 \\
\hline Loblolly pine & Pinus taeda & 0.09 \\
\hline Table mountain pine & Pinus pungens & 0.02 \\
\hline
\end{tabular}




\begin{tabular}{|c|c|c|}
\hline & & \\
\hline Hemlock spp. & Tsuga spp. & 0.01 \\
\hline Norway spruce & Picea abies & $<0.01$ \\
\hline Douglas fir & Pseudotsuga menziesii & $<0.01$ \\
\hline Scotch pine & Pinus sylvestris & $<0.01$ \\
\hline Carolina hemlock & Tsuga caroliniana & $<0.01$ \\
\hline \multirow[t]{2}{*}{ Red pine } & Pinus resinosa & $<0.01$ \\
\hline & Fagus (FG) & \\
\hline \multirow[t]{2}{*}{ American beech } & Fagus grandifolia & 1.94 \\
\hline & her Angiosperms (OA) & \\
\hline Yellow-poplar & Liriodendron tulipifera & 3.85 \\
\hline White ash & Fraxinus americana & 2.34 \\
\hline Black gum & Nyssa sylvatica & 1.91 \\
\hline Sassafras & Sassafras albidum & 1.42 \\
\hline Black cherry & Prunus serotina & 1.30 \\
\hline American elm & Ulmus americana & 1.10 \\
\hline Flowering dogwood & Cornus florida & 1.06 \\
\hline Sourwood & Oxydendrum arboreum & 0.96 \\
\hline Sweet gum & Liquidambar styraciflua & 0.95 \\
\hline Slippery elm & Ulmus rubra & 0.84 \\
\hline Black locust & Robinia pseudoacacia & 0.81 \\
\hline American sycamore & Platanus occidentalis & 0.70 \\
\hline Green ash & Fraxinus pennsylvanica & 0.69 \\
\hline Winged elm & Ulmus alata & 0.64 \\
\hline American basswood & Tilia americana & 0.58 \\
\hline Sweet birch & Betula lenta & 0.53 \\
\hline Eastern hophornbeam & Ostrya virginiana & 0.42 \\
\hline Hackberry & Celtis occidentalis & 0.38 \\
\hline Eastern redbud & Cercis canadensis & 0.32 \\
\hline Common persimmon & Diospyros virginiana & 0.31 \\
\hline Yellow buckeye & Aesculus flava & 0.29 \\
\hline Cucumbertree & Magnolia acuminata & 0.23 \\
\hline Bigtooth aspen & Populus grandidentata & 0.19 \\
\hline Ailanthus & Ailanthus altissima & 0.17 \\
\hline Honeylocust & Gleditsia triacanthos & 0.16 \\
\hline Red mulberry & Morus rubra & 0.15 \\
\hline American hornbeam, musclewood & Carpinus caroliniana & 0.14 \\
\hline Blue ash & Fraxinus quadrangulata & 0.12 \\
\hline Sugarberry & Celtis laevigata & 0.10 \\
\hline Serviceberry spp. & Amelanchier spp. & 0.07 \\
\hline Osage-orange & Maclura pomifera & 0.07 \\
\hline River birch & Betula nigra & 0.06 \\
\hline Ohio buckeye & Aesculus glabra & 0.05 \\
\hline Hawthorn spp. & Crataegus spp. & 0.04 \\
\hline Eastern cottonwood & Populus deltoides & 0.04 \\
\hline Basswood spp. & Tilia spp. & 0.03 \\
\hline Ash spp. & Fraxinus spp. & 0.03 \\
\hline Yellow birch & Betula alleghaniensis & 0.03 \\
\hline Paulownia, empress-tree & Paulownia tomentosa & 0.03 \\
\hline Basswood spp. & Tilia spp. & 0.03 \\
\hline Chittamwood, gum, bumelia & $\begin{array}{l}\text { Sideroxylon lanuginosum ssp. } \\
\text { lanuginosum }\end{array}$ & 0.02 \\
\hline Birch spp. & Betula spp. & 0.02 \\
\hline
\end{tabular}




\begin{tabular}{llr}
\hline Mountain or fraser, magnolia & Magnolia fraseri & 0.02 \\
Apple spp. & Malus spp. & 0.02 \\
Pawpaw & Asimina triloba & 0.02 \\
Quaking aspen & Populus tremuloides & 0.02 \\
Sweet cherry, domesticated & Prunus avium & 0.02 \\
Elm spp. & Ulmus spp. & 0.02 \\
Kentucky coffeetree & Gymnocladus dioicus & 0.01 \\
American holly & Ilex opaca & 0.01 \\
White basswood & Tilia americana var. heterophylla & 0.01 \\
Smoketree & Cotinus obovatus & 0.01 \\
Unknown dead hardwood & Tree broadleaf & 0.01 \\
Other or unknown live tree & Tree unknown & 0.01 \\
Downy hawthorn & Crataegus mollis & $<0.01$ \\
& All Species & 100.00 \\
\hline
\end{tabular}


Table A2. Summary statistics of plot-level variables.

\begin{tabular}{|c|c|c|c|c|}
\hline Variables & Mean & SD & Max & Min \\
\hline$B\left(\mathrm{~m}^{2} \mathrm{ha}^{-1}\right)$ & 23.44 & 12.69 & 108.89 & 0.11 \\
\hline$C\left(\mathrm{~m}^{3} \mathrm{ha}^{-1} \mathrm{yr}^{-1}\right)$ & 4.85 & 2.14 & 15.41 & 0.66 \\
\hline$H_{S}$ & 1.20 & 0.32 & 1.92 & 0.00 \\
\hline$H_{d}$ & 1.77 & 0.35 & 2.57 & 0.00 \\
\hline$T\left({ }^{\circ} \mathrm{C}\right)$ & 13.08 & 1.66 & 17.02 & 6.45 \\
\hline$P(100 \mathrm{~mm})$ & 1.03 & 0.20 & 1.74 & 0.55 \\
\hline$t$ (year) & 5.64 & 1.94 & 11.60 & 0.30 \\
\hline$E(\mathrm{~km})$ & 0.44 & 0.56 & 3.69 & 0.00 \\
\hline$S\left(^{\circ}\right)$ & 23.24 & 17.46 & 155.00 & 0.00 \\
\hline \multicolumn{5}{|l|}{$N\left(\right.$ trees $\left.\mathrm{ha}^{-1}\right)$} \\
\hline QQ & 153.22 & 221.66 & 2379.98 & 0.00 \\
\hline QL & 119.82 & 208.87 & 3422.14 & 0.00 \\
\hline JD & 164.33 & 257.61 & 3703.29 & 0.00 \\
\hline SD & 178.36 & 330.32 & 4162.80 & 0.00 \\
\hline GS & 59.29 & 180.65 & 3051.82 & 0.00 \\
\hline FG & 27.14 & 127.72 & 2740.95 & 0.00 \\
\hline $\mathrm{OA}$ & 503.27 & 569.70 & 4735.73 & 0.00 \\
\hline \multicolumn{5}{|l|}{$R\left(\right.$ trees $\left.\mathrm{ha}^{-1} \mathrm{yr}^{-1}\right)$} \\
\hline QQ & 2.46 & 12.70 & 302.21 & 0.00 \\
\hline QL & 2.38 & 12.94 & 344.49 & 0.00 \\
\hline JD & 3.20 & 15.52 & 255.40 & 0.00 \\
\hline SD & 5.64 & 22.32 & 370.33 & 0.00 \\
\hline GS & 1.99 & 13.02 & 272.77 & 0.00 \\
\hline FG & 1.18 & 9.71 & 236.38 & 0.00 \\
\hline $\mathrm{OA}$ & 18.84 & 48.13 & 673.32 & 0.00 \\
\hline \multicolumn{5}{|l|}{$B\left(\mathrm{~m}^{2} \mathrm{ha}^{-1}\right)$} \\
\hline QQ & 5.30 & 5.30 & 61.95 & 0.00 \\
\hline QL & 5.18 & 5.80 & 81.39 & 0.00 \\
\hline JD & 3.84 & 4.18 & 40.46 & 0.00 \\
\hline SD & 2.16 & 3.60 & 45.20 & 0.00 \\
\hline GS & 1.02 & 2.53 & 38.86 & 0.00 \\
\hline FG & 0.45 & 1.65 & 29.59 & 0.00 \\
\hline $\mathrm{OA}$ & 5.49 & 6.40 & 85.17 & 0.00 \\
\hline \multicolumn{5}{|l|}{ B for $R\left(\mathrm{~m}^{2} \mathrm{ha}^{-1}\right)$} \\
\hline QQ & 0.016 & 0.153 & 8.605 & 0.00 \\
\hline QL & 0.015 & 0.107 & 3.926 & 0.00 \\
\hline JD & 0.018 & 0.093 & 3.131 & 0.00 \\
\hline SD & 0.020 & 0.067 & 1.782 & 0.00 \\
\hline GS & 0.009 & 0.052 & 1.290 & 0.00 \\
\hline FG & 0.003 & 0.025 & 1.383 & 0.00 \\
\hline $\mathrm{OA}$ & 0.058 & 0.165 & 3.602 & 0.00 \\
\hline
\end{tabular}

Note: $t$ (interval) and $R$ (recruitment) are between the two inventories, and all the remaining variables are at the time of the first inventory. SD: standard deviation. 
Table A3. Summary statistics for tree level variables.

\begin{tabular}{|c|c|c|c|c|c|c|c|}
\hline & \multicolumn{7}{|c|}{ Species } \\
\hline & QQ & $\mathrm{QL}$ & JD & $\mathrm{SD}$ & GS & $\mathrm{FG}$ & $\mathrm{OA}$ \\
\hline & \multicolumn{7}{|c|}{$D(\mathrm{~cm})$} \\
\hline Mean & 25.71 & 28.21 & 22.45 & 18.51 & 19.30 & 24.32 & 18.25 \\
\hline SD & 12.19 & 13.24 & 10.23 & 10.27 & 9.16 & 17.19 & 11.26 \\
\hline Max & 101.09 & 119.89 & 87.12 & 103.38 & 83.57 & 125.48 & 115.57 \\
\hline Min & 2.54 & 2.54 & 2.54 & 2.54 & 2.54 & 2.54 & 2.54 \\
\hline \multirow[t]{2}{*}{$n$} & 28740 & 22521 & 24195 & 16122 & 6871 & 2188 & 37435 \\
\hline & \multicolumn{7}{|c|}{$g\left(\mathrm{~cm}\right.$ year $\left.^{-1}\right)$} \\
\hline Mean & 0.28 & 0.40 & 0.24 & 0.27 & 0.25 & 0.32 & 0.26 \\
\hline $\mathrm{SD}$ & 0.24 & 0.26 & 0.22 & 0.26 & 0.25 & 0.26 & 0.29 \\
\hline Max & 6.77 & 4.11 & 4.19 & 3.91 & 2.95 & 3.87 & 7.99 \\
\hline Min & -6.35 & -2.19 & -4.17 & -3.27 & -2.44 & -0.99 & -10.89 \\
\hline \multirow[t]{2}{*}{$n$} & 28740 & 22521 & 24195 & 16122 & 6871 & 2188 & 37435 \\
\hline & \multicolumn{7}{|c|}{$m\left(\right.$ year $\left.^{-1}\right)$} \\
\hline Mean & 0.018 & 0.034 & 0.016 & 0.018 & 0.048 & 0.013 & 0.041 \\
\hline $\mathrm{SD}$ & 0.062 & 0.080 & 0.060 & 0.063 & 0.103 & 0.049 & 0.097 \\
\hline Max & 1.000 & 1.000 & 1.000 & 1.000 & 1.000 & 0.476 & 1.000 \\
\hline Min & 0.000 & 0.000 & 0.000 & 0.000 & 0.000 & 0.000 & 0.000 \\
\hline$n$ & 31720 & 27224 & 26356 & 17699 & 8838 & 2350 & 46867 \\
\hline
\end{tabular}

Note: $D$ (diameter at breast height) was calculated at the first inventory, $g$ (annual diameter growth) and $m$ (annual mortality) were between the two inventories. SD: standard deviation; $n$ : number of trees. 
Table A4. Independent contribution (\%) of independent variables to the goodness-of-fit of dependent variables.

\begin{tabular}{|c|c|c|c|c|c|c|c|c|c|c|c|c|c|c|}
\hline & QQ & & QL & & JD & & SD & & GS & & FG & & $\mathrm{OA}$ & \\
\hline \multicolumn{15}{|c|}{ Diameter growth } \\
\hline$D$ & 16.8 & $*$ & 19.1 & $*$ & 20.0 & * & 18.7 & $*$ & 13.8 & $* *$ & 15.1 & $*$ & 19.1 & * \\
\hline$B$ & 7.1 & $* *$ & 8.0 & $* *$ & 8.2 & ** & - & & - & & - & & - & \\
\hline$H_{d}$ & - & & 8.2 & $* *$ & 7.6 & ** & - & & - & & 9.9 & $* *$ & - & \\
\hline$P$ & 2.9 & $* *$ & 1.7 & $* *$ & 1.5 & ** & 1.2 & $* * *$ & 1.4 & $* * *$ & 4.6 & $* *$ & 1.1 & $* * *$ \\
\hline$T$ & 1.8 & $* *$ & 1.3 & $* * *$ & 1.3 & $* *$ & 2.2 & $* *$ & 2.2 & $* * *$ & 4.6 & $* *$ & 1.0 & $* * *$ \\
\hline \multicolumn{15}{|c|}{ Mortality } \\
\hline$D$ & 15.0 & $* *$ & 11.0 & $* *$ & 9.7 & $* *$ & - & & - & & - & & 7.6 & $* *$ \\
\hline$B$ & 13.5 & $* *$ & 19.7 & $* *$ & 16.2 & ** & 37.3 & $* *$ & - & & - & & 22.1 & $* *$ \\
\hline$H_{s}$ & - & & - & & - & & - & & 30.3 & $* *$ & - & & - & \\
\hline$H_{d}$ & - & & - & & - & & - & & - & & 23.2 & $* *$ & - & \\
\hline$S$ & - & & - & & - & & - & & - & & 9.4 & $* *$ & - & \\
\hline$C$ & - & & - & & - & & - & & - & & 8.5 & $* *$ & - & \\
\hline$P$ & 2.3 & $* * *$ & 2.2 & $* * *$ & 5.4 & $* *$ & 1.9 & $* * *$ & 2.9 & $* * *$ & 4.7 & $* * *$ & 2.8 & $* * *$ \\
\hline$T$ & 1.8 & $* * *$ & 2.0 & $* * *$ & 4.1 & $* * *$ & 3.9 & $* * *$ & 5.5 & $* *$ & 4.4 & $* * *$ & 2.4 & $* * *$ \\
\hline \multicolumn{15}{|c|}{ Recruitment } \\
\hline$N$ & 10.7 & $* *$ & 20.0 & $* *$ & 13.4 & $* *$ & 19.4 & $* *$ & 22.4 & $* *$ & 20.5 & $*$ & 11.5 & ** \\
\hline$B$ & - & & - & & - & & - & & - & & - & & 7.3 & $* *$ \\
\hline$H_{s}$ & 9.5 & $* *$ & - & & - & & - & & - & & - & & - & \\
\hline$H_{d}$ & 10.3 & $* *$ & - & & 8.4 & ** & - & & - & & - & & - & \\
\hline$E$ & - & & - & & - & & - & & - & & - & & 7.2 & $* *$ \\
\hline$P$ & 9.1 & ** & 6.8 & $* *$ & 8.3 & $* *$ & 4.6 & $* *$ & 5.0 & $* *$ & 0.7 & $* * *$ & 11.4 & $* *$ \\
\hline$T$ & 3.4 & $* * *$ & 2.2 & $* * *$ & 3.1 & **** & 2.4 & $* * *$ & 1.3 & $* * *$ & 0.6 & $* * *$ & 5.9 & $* *$ \\
\hline
\end{tabular}


Table A5. Estimated parameters of each explanatory variable to the goodness-of-fit of the response variables for the matrix model.

\begin{tabular}{|c|c|c|c|c|c|c|c|c|c|c|c|c|c|c|}
\hline & QQ & & QL & & JD & & SD & & GS & & $\mathrm{FG}$ & & $\mathrm{OA}$ & \\
\hline \multicolumn{15}{|c|}{ Diameter growth } \\
\hline Const & 0.066 & $* * *$ & 0.202 & $* * *$ & 0.051 & *** & 0.077 & $* * *$ & 0.181 & $* * *$ & 0.492 & **** & 0.0619 & $* * *$ \\
\hline$D$ & 0.006 & $* * *$ & 0.007 & $* * *$ & 0.009 & $* * *$ & 0.004 & * & -0.001 & * & 0.004 & * & 0.0194 & $* * *$ \\
\hline$D^{2}$ & -0.0001 & $* * *$ & -0.0001 & $* * *$ & -0.0001 & $* * *$ & & & -0.0001 & $*$ & -0.0001 & $* * *$ & -0.0004 & $* * *$ \\
\hline$H_{d}$ & & & & & & & & & & & -0.167 & $* * *$ & & \\
\hline$P * D$ & 0.003 & **** & 0.001 & * & 0.001 & * & 0.002 & & -0.003 & * & 0.001 & $*$ & 0.0026 & ** \\
\hline$P * D^{2}$ & & & & & & & -0.0001 & $*$ & 0.0001 & * & & & -0.0001 & * \\
\hline$P * B$ & & & 0.018 & & -0.016 & * & & & & & & & & \\
\hline$T^{*} D$ & 0.0002 & $* * *$ & 0.0001 & & 0.00004 & & 0.001 & $* * *$ & 0.001 & $* * *$ & 0.0003 & $*$ & -0.0006 & $* * *$ \\
\hline$T^{*} D^{2}$ & & & & & & & -0.0001 & & -0.0001 & & & & 0.00002 & \\
\hline$T^{*} B$ & & & -0.002 & * & 0.001 & & & & & & & & & \\
\hline \multicolumn{15}{|c|}{ Mortality } \\
\hline Const & -0.418 & $* * *$ & -0.723 & $* * *$ & -0.570 & $* * *$ & -1.200 & $* * *$ & 0.066 & $*$ & -1.465 & $* * *$ & -0.5454 & **** \\
\hline$D$ & -0.007 & & 0.044 & **** & -0.051 & $* * *$ & & & & & & & & \\
\hline$D^{2}$ & 0.001 & $* * *$ & & & 0.001 & $* * *$ & & & & & & & & \\
\hline$B$ & -1.372 & $* * *$ & -1.631 & $* * *$ & -1.494 & *** & -0.953 & $* * *$ & & & & & -0.9055 & $* * *$ \\
\hline$H_{s}$ & & & & & & & & & -0.665 & $* * * *$ & & & & \\
\hline$H_{d}$ & & & & & & & & & & & -0.285 & & & \\
\hline$S$ & & & & & & & & & & & 0.018 & * & & \\
\hline$C$ & & & & & & & & & & & 0.035 & * & & \\
\hline$P * D$ & -0.021 & **** & -0.039 & $* * *$ & & & & & & & & & & \\
\hline$P * B$ & 0.567 & $* * *$ & 0.899 & $* * *$ & 0.459 & **** & 0.290 & ** & & & & & 0.1885 & $* * *$ \\
\hline$P^{*} H s$ & & & & & & & & & 0.079 & * & & & & \\
\hline$P * S$ & & & & & & & & & & & -0.002 & & & \\
\hline$P^{*} C$ & & & & & & & & & & & & & & \\
\hline$T * D$ & -0.002 & ** & & & & & & & & & & & & \\
\hline$T^{*} B$ & 0.036 & * & 0.025 & ** & 0.030 & ** & 0.029 & * & & & & & 0.0098 & \\
\hline$T^{*} H s$ & & & & & & & & & -0.004 & * & & & & \\
\hline$T^{*} S$ & & & & & & & & & & & -0.001 & * & & \\
\hline \multicolumn{15}{|c|}{ Recruitment } \\
\hline Const & 32.102 & & -79.636 & **** & -36.633 & $* * *$ & -80.766 & $* * *$ & -0.010 & **** & -0.012 & $* * *$ & 0.1220 & \\
\hline$N$ & 0.186 & **** & 0.313 & **** & 0.121 & *** & 0.166 & *** & 0.189 & ** & 0.212 & & 0.1020 & **** \\
\hline$N^{2}$ & -0.046 & $* * *$ & -0.004 & & -0.022 & $* * *$ & -0.041 & $* * *$ & & & -0.463 & $*$ & 0.0008 & \\
\hline$H_{d}$ & -18.360 & $* * *$ & & & & & & & & & & & & \\
\hline$H_{s}$ & -20.975 & & & & 3.572 & & & & & & & & & \\
\hline$P$ & -65.815 & * & & & & & & & & & & - & 0.5110 & * \\
\hline$P^{2}$ & 6.071 & & & & & & & & & & & & 0.0001 & * \\
\hline$P * N$ & -0.035 & * & -0.131 & $* * *$ & 0.010 & $*$ & -0.021 & $*$ & -0.028 & $*$ & -0.011 & $*$ & -0.0114 & \\
\hline$P^{*} H_{s}$ & 15.286 & & & & & & & & & & & & & \\
\hline$P^{*} H_{d}$ & & & & & -25.734 & **** & & & & & & & & \\
\hline$T^{*} N$ & -0.004 & * & -0.004 & * & -0.004 & * & -0.002 & & -0.005 & & 0.008 & & -0.0053 & ** \\
\hline$T^{*} N^{2}$ & & & -0.004 & & & & & & & & 0.023 & $*$ & & \\
\hline$T^{*} P$ & & & & & & & & & & & & & -0.8770 & \\
\hline
\end{tabular}

Note: Significance levels: $*<0.05 ; * *<0.01 ; * * *<0.001$. 
Table A6. Fire impacts on different species groups and size classes.

\begin{tabular}{|l|l|l|l|l|l|}
\hline FSC FTC & $\begin{array}{l}\text { FG } \\
I^{\text {a }}\end{array}$ & $\begin{array}{l}\text { OA } \\
\text { II }\end{array}$ & $\begin{array}{l}\text { SD } \\
\text { III }\end{array}$ & $\begin{array}{l}\text { QQ, QL, JD } \\
\text { IV }\end{array}$ & $\begin{array}{l}\text { GS } \\
\text { V }\end{array}$ \\
\hline $\begin{array}{l}\mathbf{A}^{\mathrm{b}} \\
(1-3)^{\mathrm{c}}\end{array}$ & $1^{\mathrm{d}}, 2,3,4,5$ & $1,2,3,4,5$ & $1,2,3,4,5$ & $2,3,4,5$ & $3,4,5$ \\
\hline $\begin{array}{l}\mathbf{B} \\
(4-8)\end{array}$ & $1,2,3,4,5$ & $1,2,3,4,5$ & $2,3,4,5$ & $3,4,5$ & 4,5 \\
\hline $\begin{array}{l}\mathbf{C} \\
(9-11)\end{array}$ & $1,2,3,4,5$ & $2,3,4,5$ & $3,4,5$ & 4,5 & 5 \\
\hline $\begin{array}{l}\mathbf{D} \\
(12-14)\end{array}$ & $1,2,3,4,5$ & $2,3,4,5$ & $3,4,5$ & 4,5 & 5 \\
\hline $\begin{array}{l}\mathbf{E} \\
(15-17)\end{array}$ & $2,3,4,5$ & $3,4,5$ & 4,5 & 5 & 5 \\
\hline
\end{tabular}

${ }^{\text {a }}$ Fire tolerance class (FTC).

${ }^{\mathrm{b}}$ Fire susceptibility class (FSC).

${ }^{c}$ Diameter size classes $(\mathrm{cm})$.

${ }^{\mathrm{d}}$ Fire severity level. 
Table A7. Estimation of stem volume equations.

\begin{tabular}{|c|c|c|c|c|c|}
\hline & \multicolumn{5}{|c|}{ Independence variable } \\
\hline & $\mathrm{D}$ & $\mathrm{D}^{2}$ & $\mathrm{~B}$ & $\mathrm{C}$ & Const \\
\hline \multicolumn{6}{|l|}{ QQ } \\
\hline Coeff. & -2.8444 & 0.5405 & 0.0066 & -0.1428 & 3.7477 \\
\hline SE & 0.0170 & 0.0026 & 0.0011 & 0.0263 & 0.0282 \\
\hline $\mathrm{R}^{2}$ & 0.9381 & & & & \\
\hline df & 28735 & & & & \\
\hline \multicolumn{6}{|l|}{ QL } \\
\hline Coeff. & -2.6014 & 0.5059 & 0.0046 & 0.0212 & 3.3537 \\
\hline SE & 0.0514 & 0.0027 & 0.0012 & 0.0013 & 0.0296 \\
\hline $\mathrm{R}^{2}$ & 0.9513 & & & & \\
\hline df & 22516 & & & & \\
\hline \multicolumn{6}{|l|}{ JD } \\
\hline Coeff & -3.0946 & 0.5856 & -0.0053 & 0.0238 & 4.1286 \\
\hline SE & 0.0004 & 0.0076 & 0.0029 & 0.0038 & 0.0868 \\
\hline $\mathrm{R}^{2}$ & 0.9704 & & & & \\
\hline df & 24190 & & & & \\
\hline \multicolumn{6}{|l|}{$\mathrm{SD}$} \\
\hline Coeff & -2.7661 & 0.5356 & -0.0007 & 0.0147 & 3.6105 \\
\hline SE & 0.0180 & 0.0028 & 0.0011 & 0.0013 & 0.0295 \\
\hline $\mathrm{R}^{2}$ & 0.9439 & & & & \\
\hline df & 16117 & & & & \\
\hline \multicolumn{6}{|l|}{ GS } \\
\hline Coeff & -2.8477 & 0.5453 & -0.0043 & 0.0110 & 3.7839 \\
\hline SE & 0.0177 & 0.0027 & 0.0011 & 0.0013 & 0.0291 \\
\hline $\mathrm{R}^{2}$ & 0.9570 & & & & \\
\hline df & 6866 & & & & \\
\hline \multicolumn{6}{|l|}{$\mathrm{FG}$} \\
\hline Coeff & -2.8420 & 0.5346 & 0.0052 & 0.0499 & 3.7400 \\
\hline SE & 0.0298 & 0.0046 & 0.0018 & 0.0019 & 0.0239 \\
\hline $\mathrm{R}^{2}$ & 0.9456 & & & & \\
\hline df & 2183 & & & & \\
\hline \multicolumn{6}{|l|}{$\mathrm{OA}$} \\
\hline Coeff & -2.9695 & 0.5617 & 0.0018 & 0.0248 & 3.9461 \\
\hline SE & 0.0144 & 0.0022 & 0.0008 & 0.0010 & 0.0051 \\
\hline $\mathrm{R}^{2}$ & 0.9410 & & & & \\
\hline $\mathrm{df}$ & 37430 & & & & \\
\hline
\end{tabular}

Note: Stem volume equations were estimated by ordinary least squares. Independent and response variables are $1 n+1$ transformed. The dependent variable, volume, is measured in units of trees. Coeff, coefficient; SE, standard error; $\mathrm{R}^{2}$, coefficient of determination; df, degrees of freedom. 


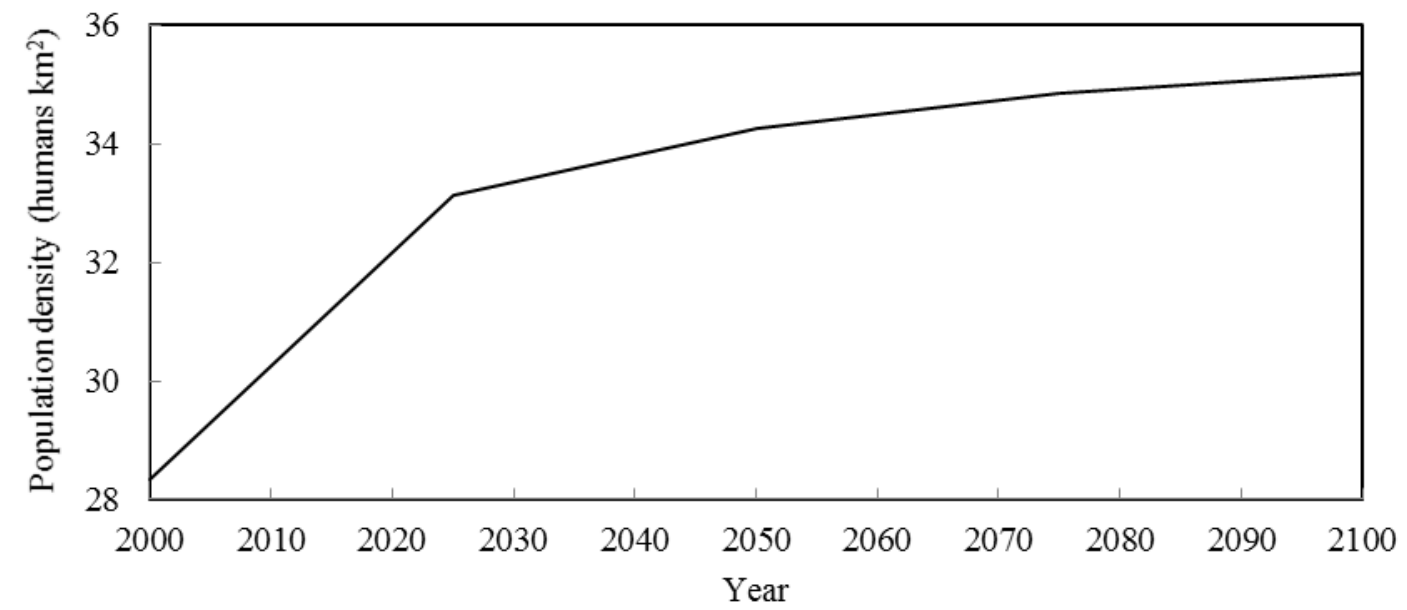

Figure A1. The projected population density of CHR from year 2000-2100. 

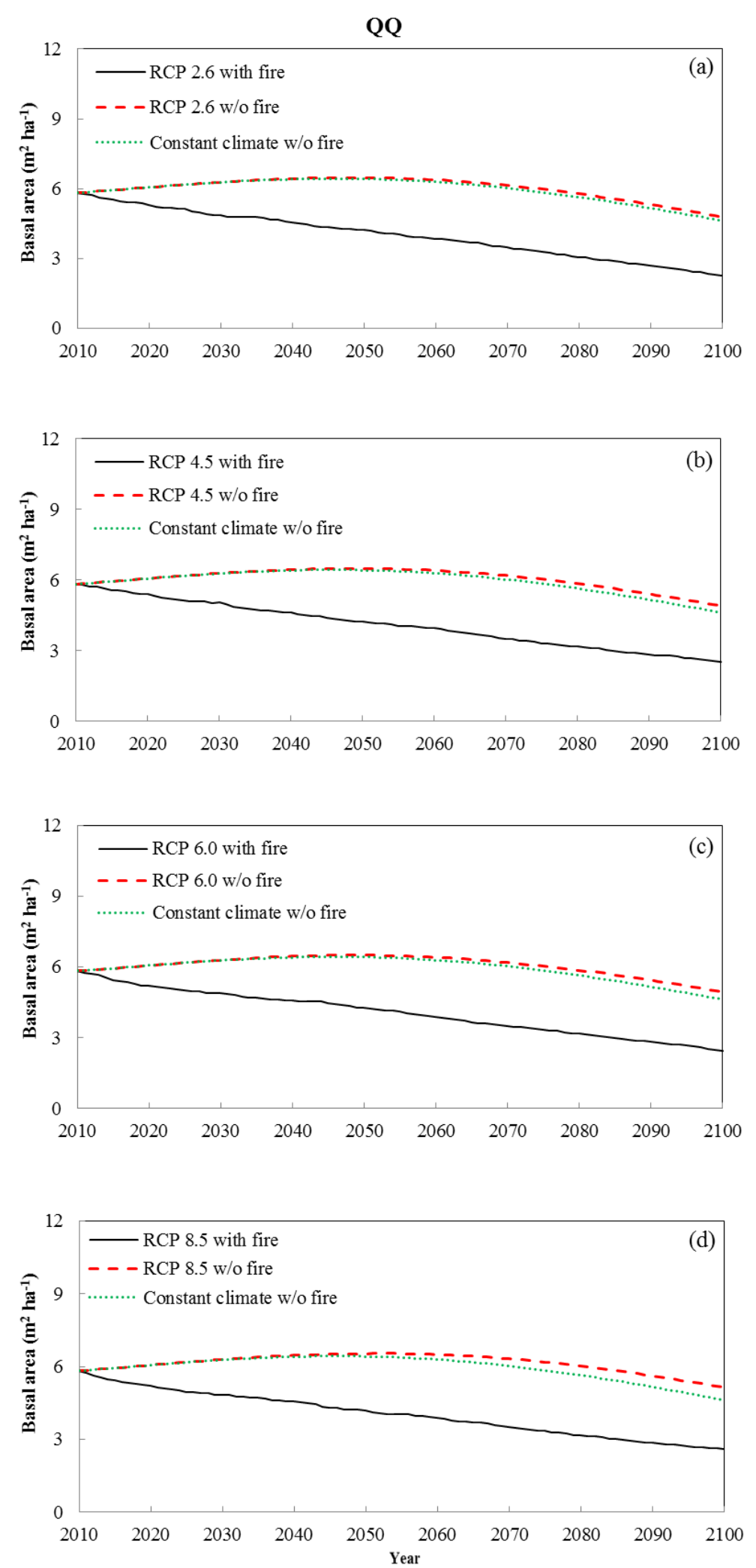

Figure A2. The basal area for QQ under wildfire disturbance with four climate scenarios RCP2.6, RCP4.5, RCP6.0, and RCP8.5 from year 2010-2100. 

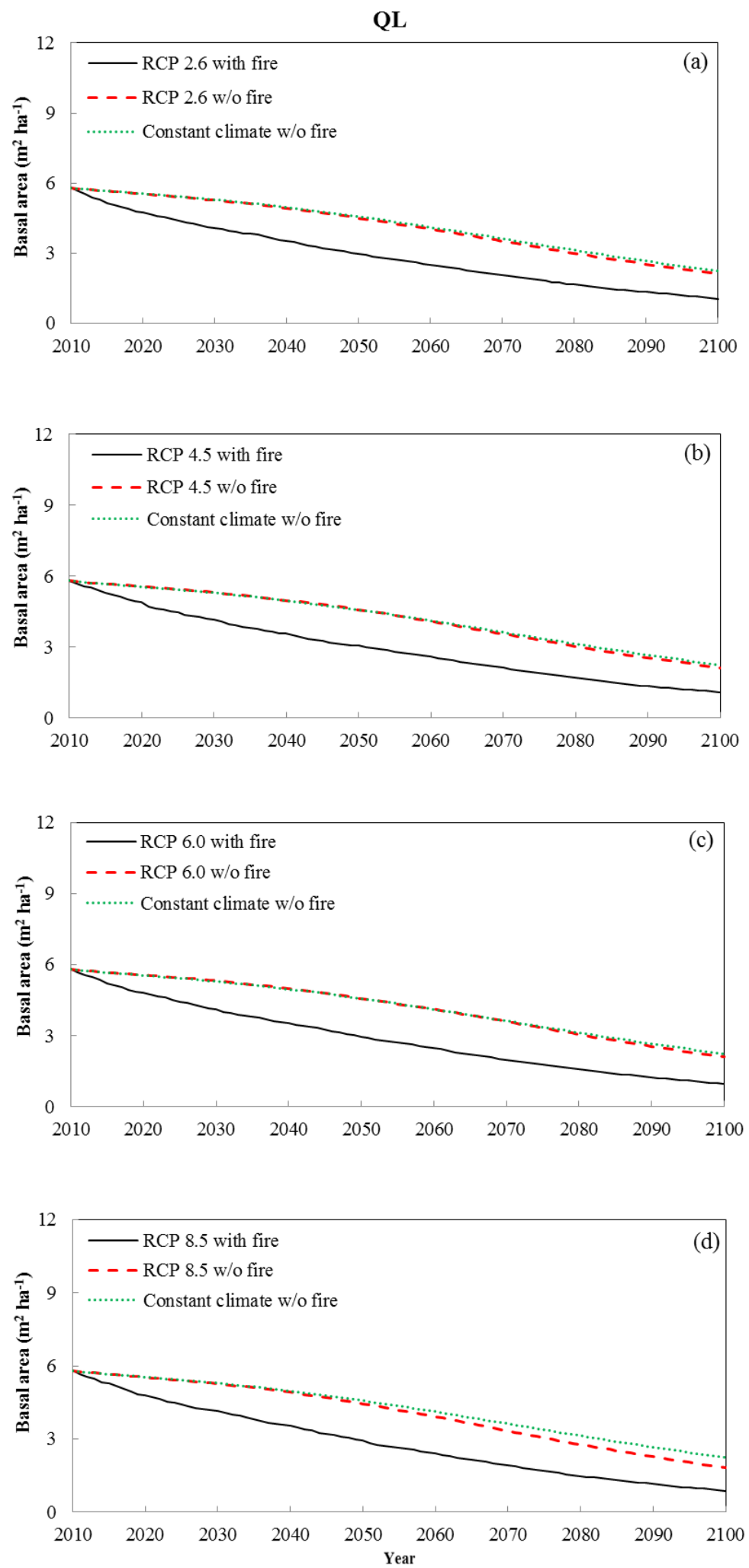

Figure A3. The basal area for QL under wildfire disturbance with four climate scenarios RCP2.6, RCP4.5, RCP6.0, and RCP8.5 from year 2010-2100. 

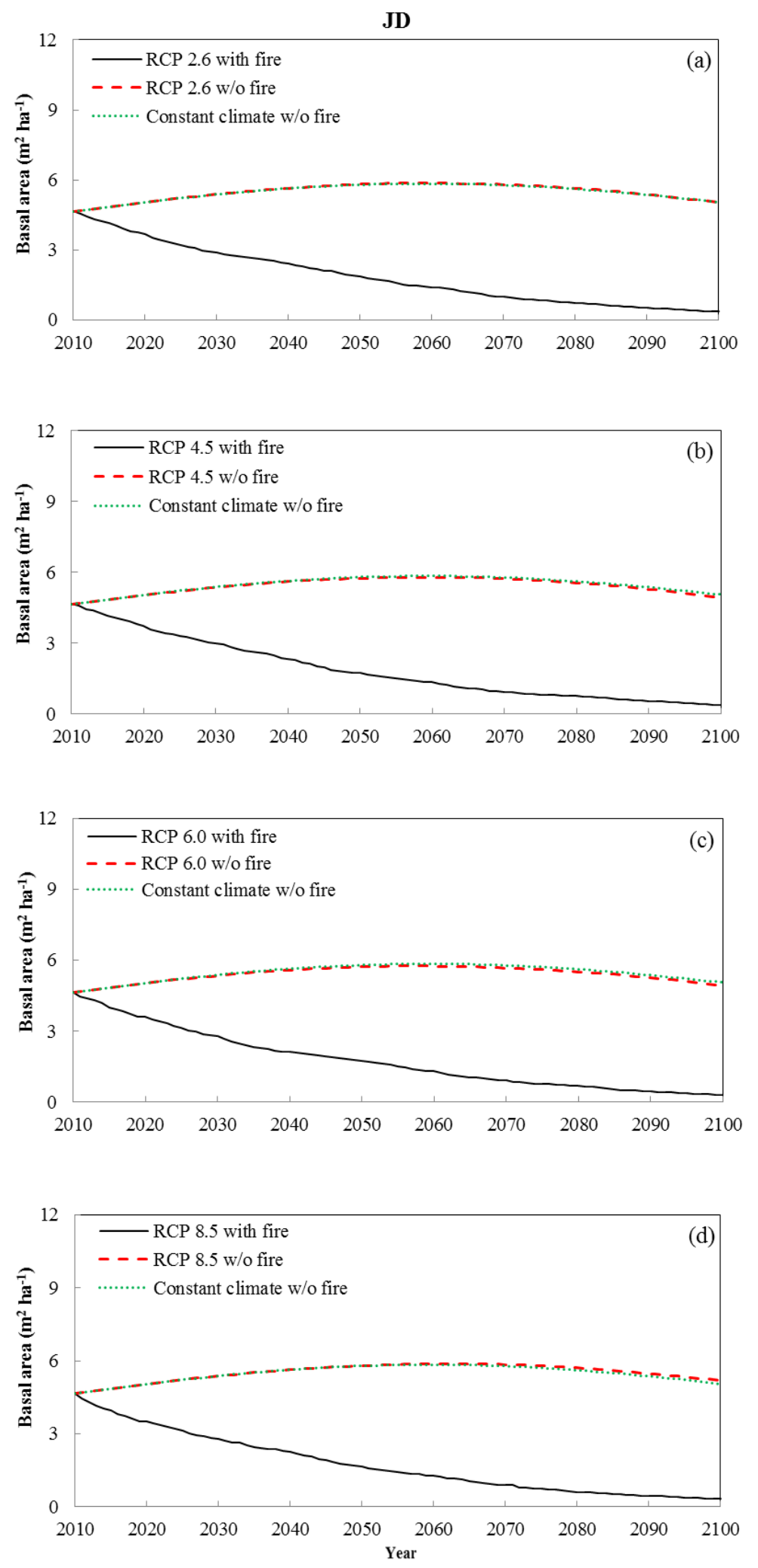

Figure A4. The basal area for JD under wildfire disturbance with four climate scenarios RCP2.6, RCP4.5, RCP6.0, and RCP8.5 from year 2010-2100. 

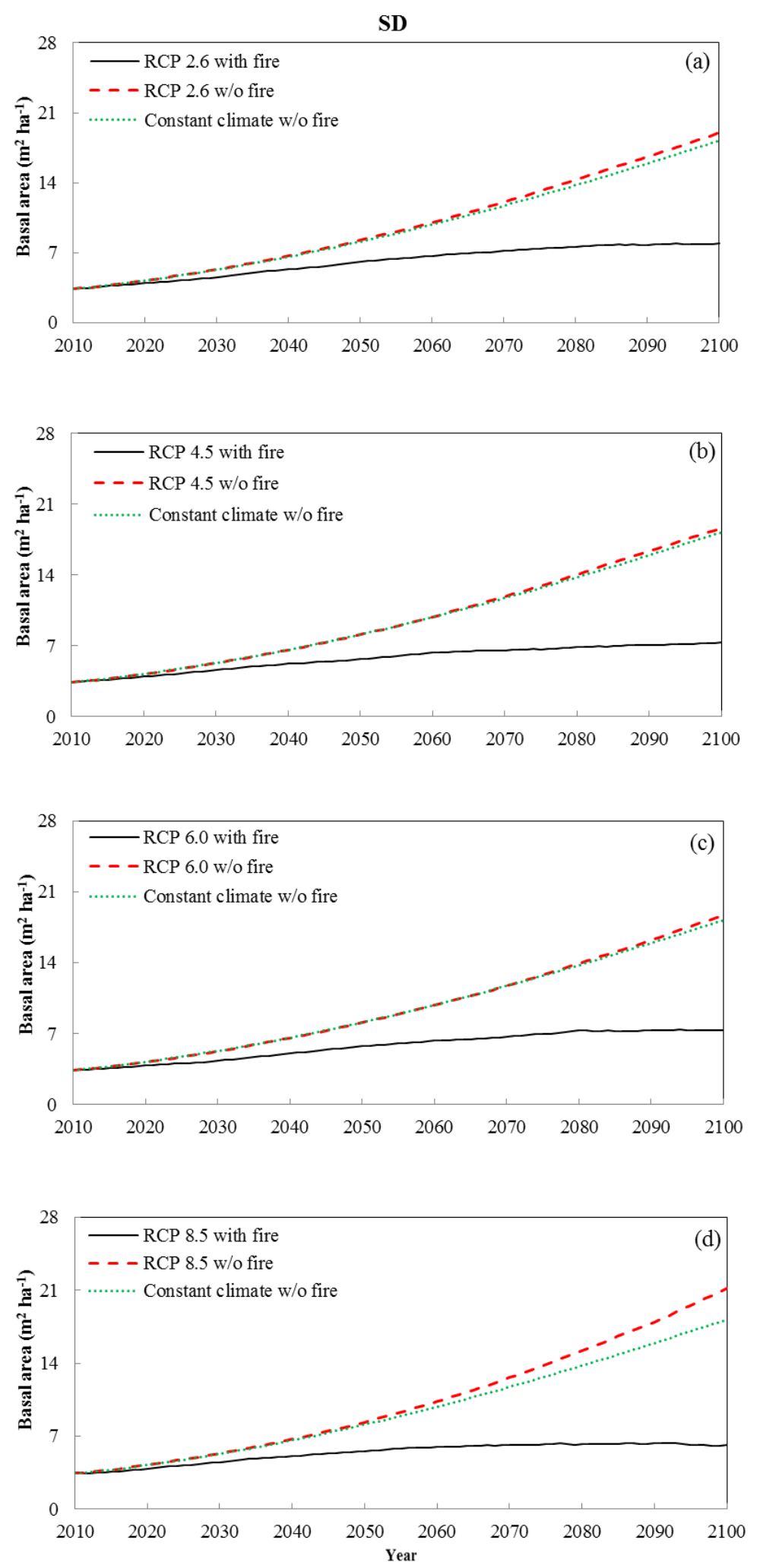

Figure A5. The basal area for SD under wildfire disturbance with four climate scenarios RCP2.6, RCP4.5, RCP6.0, and RCP8.5 from year 2010-2100. 
GS
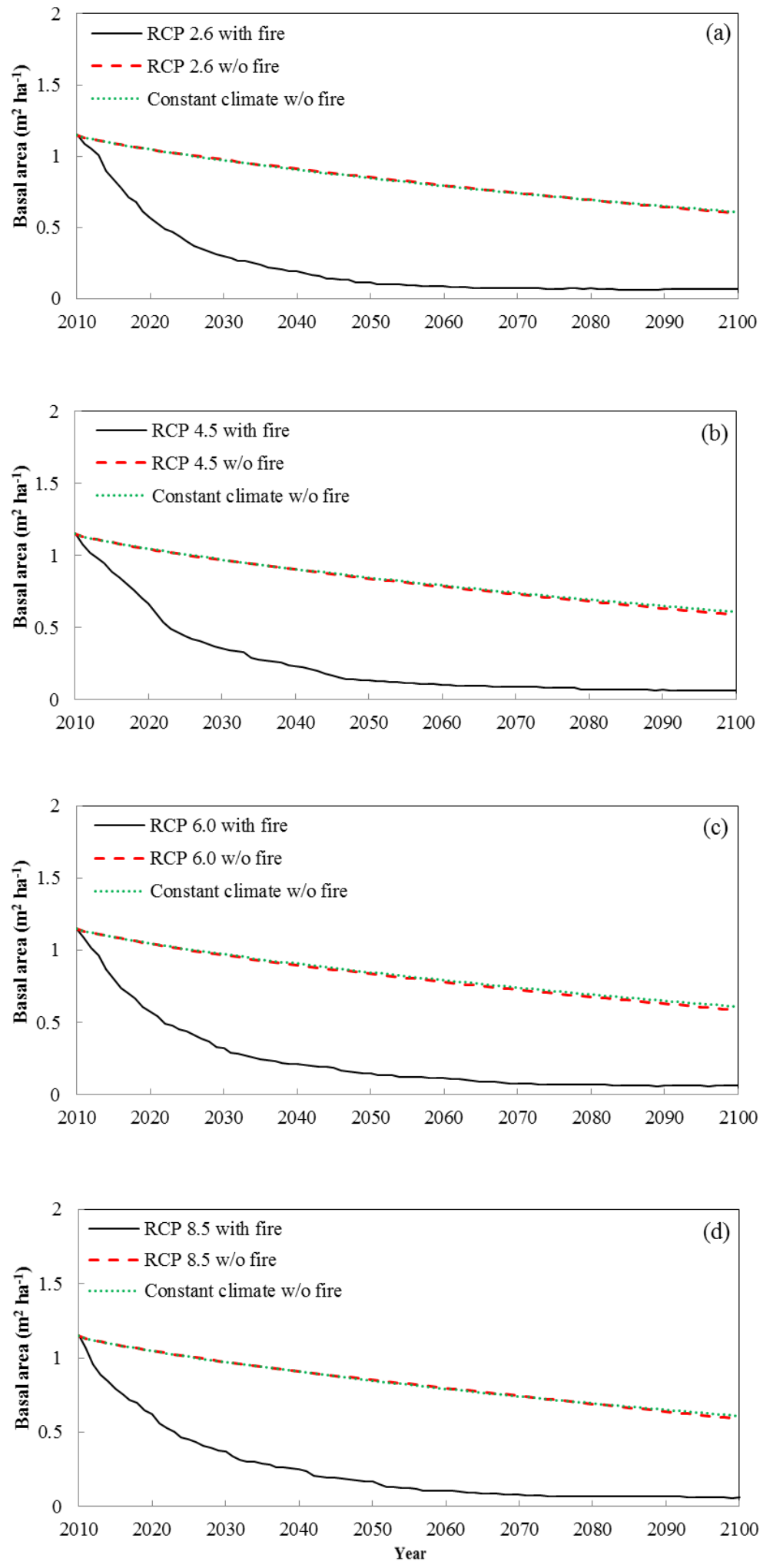

Figure A6. The basal area for GS under wildfire disturbance with four climate scenarios RCP2.6, RCP4.5, RCP6.0, and RCP8.5 from year 2010-2100. 


\section{FG}
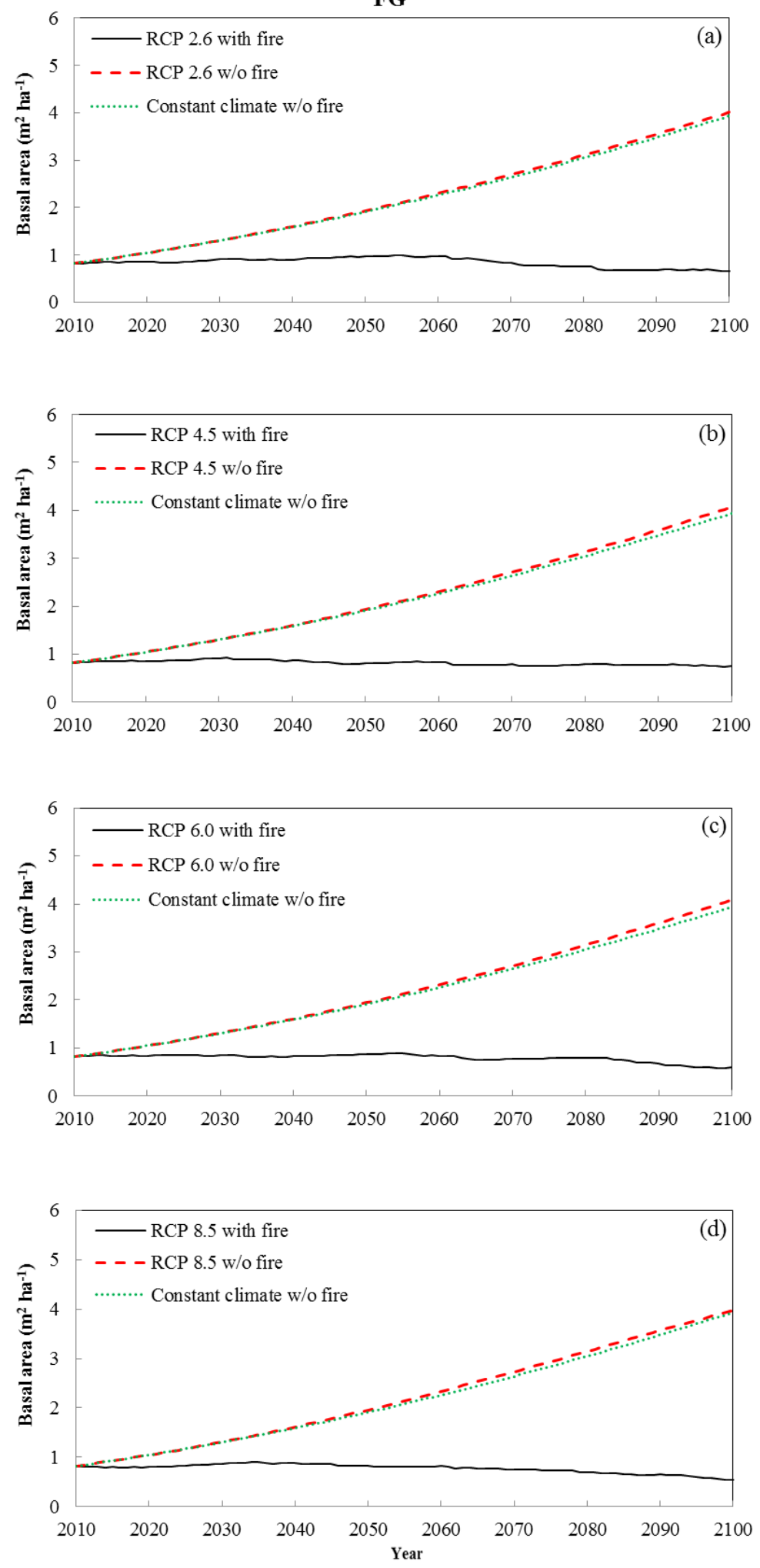

Figure A7. The basal area for FG under wildfire disturbance with four climate scenarios RCP2.6, RCP4.5, RCP6.0, and RCP8.5 from year 2010-2100. 

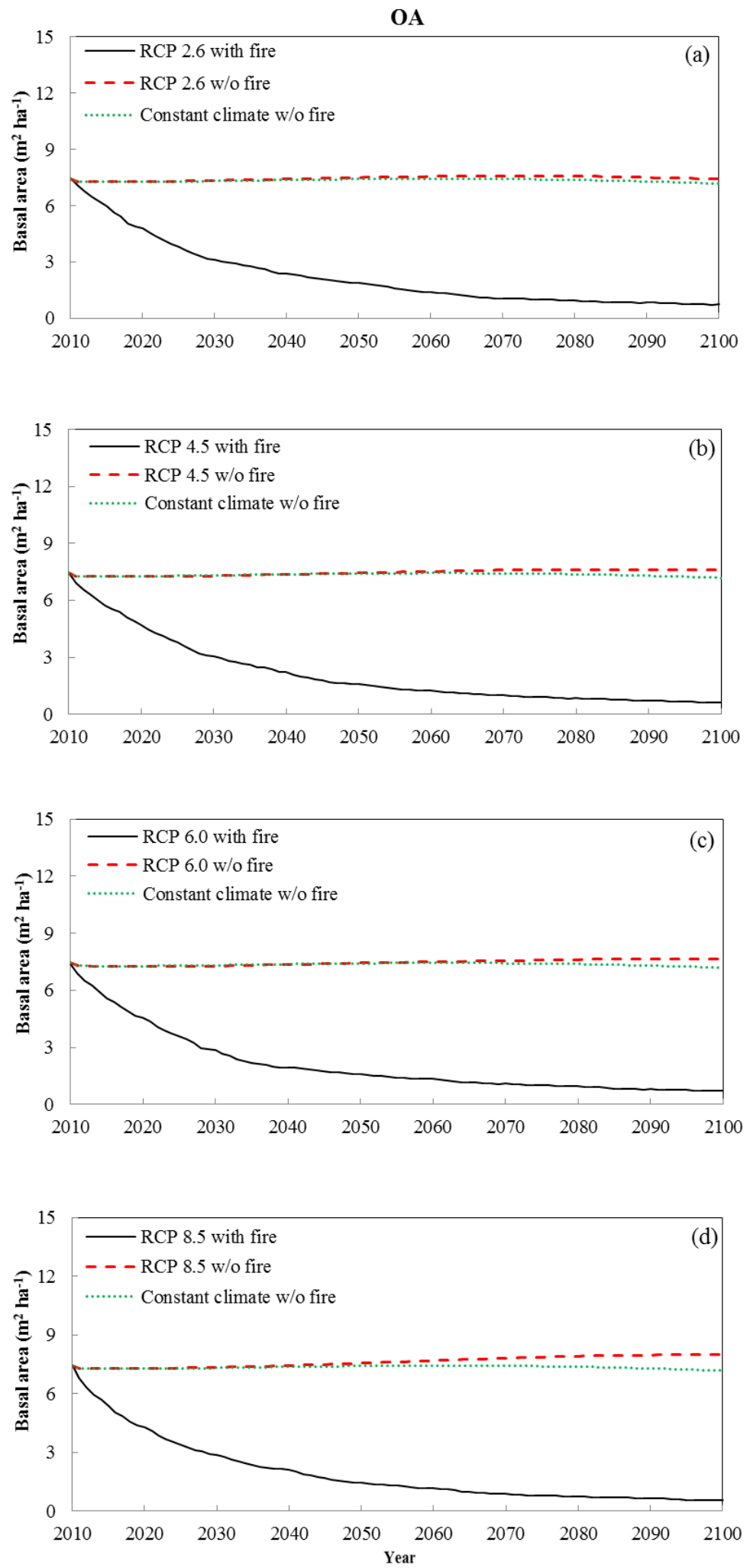

Figure A8. The basal area for OA under wildfire disturbance with four climate scenarios RCP2.6, RCP4.5, RCP6.0, and RCP8.5 from year 2010-2100. 


\section{Appendix B. Supplemental Information for Chapter 3}

Table B1. Definitions and units of variables used in the climate-sensitive matrix model for the Central Hardwood forests.

\begin{tabular}{lll}
\hline Variable & Unit & Definition/explanation \\
\hline$B$ & $\mathrm{~m}^{2} \mathrm{ha}^{-1}$ & Total stand basal area \\
$C$ & $\mathrm{~m}^{3} \mathrm{ha}^{-1} \mathrm{yr}^{-1}$ & Site productivity \\
$D$ & $\mathrm{~cm}$ & Diameter at breast height \\
$g$ & $\mathrm{~cm} \mathrm{yr}{ }^{-1}$ & Annual diameter growth \\
$E$ & $\mathrm{~km}$ & Plot elevation \\
$S$ & degrees & Plot slope \\
$H_{d}$ & & Tree size diversity in Shannon's index \\
$H_{S}$ & & Tree species diversity in Shannon's index \\
$T$ & \multicolumn{1}{c}{$\mathrm{C}$} & Mean annual temperature \\
$P$ & \multicolumn{1}{c}{$100 \mathrm{~mm} \mathrm{month}^{-1}$} & Annual average of monthly mean precipitation \\
$m$ & $\mathrm{yr}^{-1}$ & Annual tree mortality \\
$N$ & trees ha- $_{R}^{-1}$ & Number of trees per hectare \\
& trees ha $^{-1} \mathrm{yr}^{-1}$ & Recruitment, the number of trees per hectare growing \\
& & into the smallest diameter class $(2.54-7 \mathrm{~cm})$ in a year \\
\hline
\end{tabular}


Table B2. Estimated parameters of stem volume equations of the Central Hardwood forests.

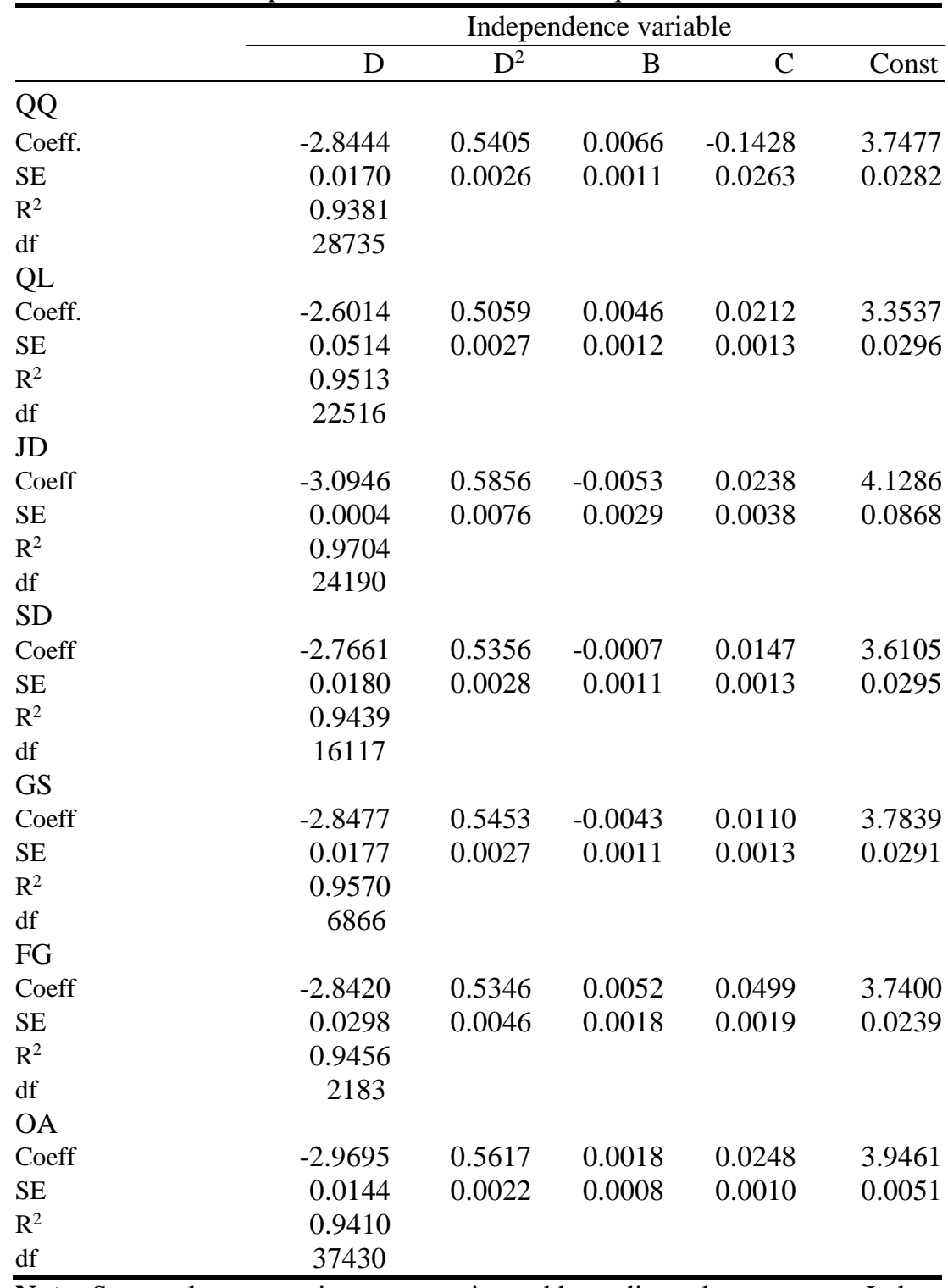

Note: Stem volume equations were estimated by ordinary least squares. Independent and response variables are $1 n+1$ transformed. The dependent variable, volume, is measured in units of trees. Coeff, coefficient; SE, standard error; $\mathrm{R}^{2}$, coefficient of determination; df, degrees of freedom. 
Table B3. Chemical composition of litter and relative proportion to Yasso07 compartments.

\begin{tabular}{llllll}
\hline Litter type & \multicolumn{5}{c}{ Yasso07 compartments } \\
\cline { 2 - 6 } & $\mathrm{A}$ & $\mathrm{W}$ & $\mathrm{E}$ & $\mathrm{N}$ & $\mathrm{H}$ \\
Fine root & 0.510 & 0.130 & 0.130 & 0.230 & 0.000 \\
Foliage & 0.560 & 0.150 & 0.150 & 0.140 & 0.000 \\
Branch, coarse root & 0.660 & 0.015 & 0.015 & 0.310 & 0.000 \\
Stem, stump & 0.690 & 0.005 & 0.005 & 0.300 & 0.000 \\
\hline Liski et al. (2009) & & & & &
\end{tabular}

Liski et al. (2009) 
Table B4. Litter size classification.

\begin{tabular}{lccc}
\hline Species & \multicolumn{3}{c}{ Litter size classes } \\
group* & $\begin{array}{c}\text { Class 1 } \\
\text { Non woody } \\
\text { (needle \& fine roots) } \\
(\mathrm{cm})\end{array}$ & $\begin{array}{c}\text { Class 2 } \\
\text { Fine woody }\end{array}$ & $\begin{array}{c}\text { Class 3 } \\
\text { Coarse woody } \\
\text { (stem \& stumps) } \\
\text { (branches and coarse roots) }\end{array}$ \\
QQ & 0 & $(\mathrm{~cm})$ & 12 \\
QL & 0 & 2.5 & 12 \\
JD & 0 & 2.5 & 12 \\
SD & 0 & 2.5 & 10 \\
GS & 0 & 2.0 & 10 \\
FG & 0 & 2.0 & 08 \\
OA & 0 & 1.5 & 08 \\
\hline
\end{tabular}

${ }^{*}$ QQ: Quercus-Quercus (white oak species), QL: Quercus-Lobatae (red oak species), JD: Juglandaceae (Hickory), SD: Sapindaceae (maple family), GS: Gymnosperms (Softwoods), FG: Fagus (American beech), OA: Other Angiosperms (other species). 